\title{
Antenatal corticosteroids and brain development : the use of S100B as an early predictor of brain impairment
}

Citation for published version (APA):

Bruschettini, M. (2007). Antenatal corticosteroids and brain development : the use of S100B as an early predictor of brain impairment. [Doctoral Thesis, Maastricht University]. Universiteit Maastricht. https://doi.org/10.26481/dis.20071114mb

Document status and date:

Published: 01/01/2007

DOI:

10.26481/dis.20071114mb

Document Version:

Publisher's PDF, also known as Version of record

\section{Please check the document version of this publication:}

- A submitted manuscript is the version of the article upon submission and before peer-review. There can be important differences between the submitted version and the official published version of record.

People interested in the research are advised to contact the author for the final version of the publication, or visit the DOI to the publisher's website.

- The final author version and the galley proof are versions of the publication after peer review.

- The final published version features the final layout of the paper including the volume, issue and page numbers.

Link to publication

\footnotetext{
General rights rights.

- You may freely distribute the URL identifying the publication in the public portal. please follow below link for the End User Agreement:

www.umlib.nl/taverne-license

Take down policy

If you believe that this document breaches copyright please contact us at:

repository@maastrichtuniversity.nl

providing details and we will investigate your claim.
}

Copyright and moral rights for the publications made accessible in the public portal are retained by the authors and/or other copyright owners and it is a condition of accessing publications that users recognise and abide by the legal requirements associated with these

- Users may download and print one copy of any publication from the public portal for the purpose of private study or research.

- You may not further distribute the material or use it for any profit-making activity or commercial gain

If the publication is distributed under the terms of Article $25 \mathrm{fa}$ of the Dutch Copyright Act, indicated by the "Taverne" license above, 


\section{Antenatal Corticosteroids and Brain Development:}

\section{The use of S100B as an Early Predictor of Brain Impairment}

Matteo Bruschettini 
(C) Matteo Bruschettini, Maastricht, 2007

Cover: The Three Ages of Woman (Die drei Lebensalter), by Gustav Klimt 1905

Printed in Estonia 


\title{
Antenatal Corticosteroids and Brain Development:
}

\section{The use of S100B as an Early Predictor of Brain Impairment}

\author{
Proefschrift \\ ter verkrijging van de graad van doctor \\ aan de Universiteit Maastricht \\ op gezag van de Rector Magnificus, Prof. Mr. G.P.M.F. Mols \\ volgens het besluit van het College van Decanen \\ in het openbaar te verdedigen \\ op woensdag 14 november om 14:00 uur \\ door
}

Matteo Bruschettini 
Promotores:

Prof. Dr. H.W.M. Steinbusch

Prof. Dr. C.E. Blanco

Co-promotores:

Dr. D. Gazzolo (University of Genoa, Italy)

Dr. D.L.A. van den Hove

Beoordelingscommissie:

Prof. Dr. L. J. I. Zimmerman (voorzitter)

Prof. J.G. Nijhuis

Prof M. De Baets

Dr. D. Gavilanes 


\section{Contents}

Chapter 1 General introduction. Antenatal betamethasone and brain $\quad 9$ development: benefits and potential risks

Chapter 2 Maternal glucocorticoid supplementation and S100B protein concentrations in cord blood and urine of preterm infants

Chapter 3 A single course of antenatal betamethasone reduces neurotrophic factor S100B concentration in the hippocampus and serum in the neonatal rat

Chapter 4 Lowering the dose of antenatal steroids: the effects of a single course of betamethasone on somatic growth and brain cell proliferation in the rat

Chapter 5 Cognition- and anxiety-related behavior, synaptophysinand MAP2- immunoreactivity in the adult rat treated with a single course of antenatal betamethasone

Chapter 6 General discussion. Antenatal betamethasone and brain development: future perspectives

Summary

Curriculum Vitae

Acknowledgements

Publications 



\title{
Abbreviations
}

\author{
AB antenatal betamethasone \\ ANOVA analysis of variance \\ BBB brain-blood barrier \\ BDNF brain-derived growth factor \\ CD clinically-equivalent dose (corresponding to $12 \mathrm{mg}$ in the \\ woman) \\ DG dentate gyrus \\ DOHaD developmental origins of adult health and disease \\ E embryonic day, e.g. embryonic day 20 - E20 \\ GC glucocorticoid \\ HD half of CD (corresponding to $6 \mathrm{mg}$ in the woman) \\ HPA hypothalamic-pituitary-adrenal \\ IR immunoreactivity \\ IVH intraventricular hemorrhage \\ MAP2 microtubule-associated protein 2 \\ MWM Morris water maze \\ OB olfactory bulbs \\ OF open field test \\ ORT object recognition task \\ P postnatal day, e.g. postnatal day $2-\mathrm{P} 2$ \\ RDS respiratory distress syndrome \\ SVZ subventricular zone \\ ${ }^{3} \mathrm{H}$-Thy $\quad{ }^{3} \mathrm{H}$-thymidine
}





\section{Chapter 1}

General Introduction

\section{Antenatal betamethasone and brain development: benefits and potential risks}

Bruschettini Matteo 


\section{Antenatal glucocorticoids: achievements and problems}

Infant respiratory distress syndrome (RDS), also known as hyaline membrane disease, is a life-threatening disorder associated with preterm delivery and is caused by developmental insufficiency of surfactant production and structural immaturity in the lungs (Crowley 2003). Among different therapeutic strategies aimed to improve the quality of life of preterm infants, antenatal maternal supplementation with glucocorticoids (GCs) constitutes a gold standard (Pine and Charney 2002; Fraser, Walls et al. 2004). GCs are currently used in about 10 percent of all pregnancies, thus encompassing hundreds of thousands of infants born each year (Matthews, Owen et al. 2002). In the last decades antenatal GC treatment improved pulmonary outcome in high-risk newborns causing a significant decrease in the mortality rate (Roberts and Dalziel 2006).

Though beneficial for lung maturation, this treatment may cause a wide range of side effects in humans, including a reduction in weight and head circumference at birth (Thorp, Jones et al. 2002; Rodriguez-Pinilla, PrietoMerino et al. 2006), higher total thyroxine levels (Martin, Van Marter et al. 2005), higher GC bioactivity in the cord vein (Kajantie, Raivio et al. 2004) and a suppressed cortisol response to stressors (Davis, Townsend et al. 2004). The hypothalamic-pituitary-adrenal (HPA) axis controls the synthesis and secretion of cortisol. Cortisol in turn inhibits the HPA at different levels, i.e., at the level of the hippocampus, the hypothalamus and the pituitary (Jacobson and Sapolsky 1991). Of note, an impairment in HPA function has been linked to the development of mood disorders like anxiety and depression (Pine and Charney 2002). The effects of antenatal GCs on HPA axis function have been reported in both fetal (Jellyman, Gardner et al. 2004), neonatal (Burlet, Fernette et al. 2005) and adult (Theogaraj, John et al. 2005; Sloboda, Moss et al. 2007) animals. Within the hippocampus, antenatal GCs have been associated with impaired lipid peroxidation (Miller, Chai et al. 2006), increased oxidative damage (Miller, Chai et al. 2006) and neuropeptide $Y$ expression (Velisek 2006), reduced cell proliferation rate (Scheepens, van de Waarenburg et al. 2003) and decreased synaptic density and levels of cytoskeletal proteins (Antonow-Schlorke, Schwab et al. 2003; Colberg, 
Antonow-Schlorke et al. 2004). Further, reductions in hippocampal levels of neurotrophic factors like BDNF (Schaaf, Hoetelmans et al. 1997) and S100B (Niu, Hinkle et al. 1997) have been reported.

Little is known about the consequences of antenatal GCs for later life. Antenatal GCs may affect cholinergic neurons and cognitive functions in adulthood (Emgard, Paradisi et al. 2007). However, the effects on cognitionand anxiety- related behavior are controversial (Rayburn, Christensen et al. 1998; Burlet, Fernette et al. 2005; Sloboda, Challis et al. 2005; Velisek 2006).

\section{Antenatal betamethasone $(A B)$ versus dexamethasone}

The use of antenatal GCs in the prevention of RDS was first reported in 1968 (Liggins 1968). A randomized controlled trial in 1972 demonstrated that they improved clinical outcome in preterm neonates (Liggins and Howie 1972). In the following decades this treatment became widely used and different dose regimens of synthetic GCs have been adopted. The most widely used compounds are 1) betamethasone which is normally administered at a dose of $12 \mathrm{mg}$; twice, 24 hours apart and 2) dexamethasone, which is normally administered 4 times at a dose of $6 \mathrm{mg}$, using 12-hour intervals. In recent years, betamethasone is preferred, because dexamethasone seems to be less effective in promoting lung maturation whilst inducing more serious side effects like intraventricular hemorrhage and retinopathy (Lee, Stoll et al. 2006; Benzon, Chew et al. 2007). Betamethasone is first detectable in the fetal circulation 1 hour after maternal injection, peaking at 3 hours, and decreasing below the limit of detection at 8 hours (Schwab, Coksaygan et al. 2006).

In case delivery does not occur, the use of multiple courses has become more and more common, though the efficacy of this strategy is controversial (Wijnberger, Nikkels et al. 2002; Ogunyemi 2005; Crowther, Haslam et al. 2006). Repeated antenatal GC administration may reduce the need for mechanical ventilation and treatment with surfactant in neonates, but it does not improve composite primary morbidity outcome (Wapner, Sorokin et al. 2006). Actually, more side effects have been described using repeated courses, including an increased risk of RDS (Peltoniemi, Kari et al. 2007). 
Thus, it has been proposed to administer the second course of GCs only after a longer period of time, e.g. two weeks after the first course instead of one (Parer 2004). This approach is thought to reduce the detrimental side-effects described following multiple courses of GCs. Yet, other authors have suggested reducing the injection interval from 24 to 12 hours (Haas, McCullough et al. 2005; Haas, McCullough et al. 2006) or decreasing the dose from 12 to $6 \mathrm{mg}$ (Jobe and Soll 2004). Clinical trials need to show whether these new strategies are effective in inducing lung maturation.

\section{A rat model for assessing the neurodevelopmental effect of}

\section{$A B$}

It is not possible to fully analyze the effects of $A B$ on brain development and functioning in humans. For this purpose, the rat constitutes a suitable model to assess the effects of $A B$.

In our study dams were injected with either 170 or $85 \mu \mathrm{g} \mathrm{kg}{ }^{-1}$ betamethasone or vehicle-only on day 20 of gestation. With an approximate weight in the pregnant woman of $80 \mathrm{~kg}$, the $170 \mu \mathrm{g} \mathrm{kg}^{-1}$ dose corresponds to a single course of $12 \mathrm{mg}$ betamethasone twice, 24 hours apart. Moreover, we used half of this dose $\left(85 \mathrm{\mu g} \mathrm{kg}^{-1}\right)$ to investigate whether a lower dose would induce fewer and/or less severe side effects on brain development. As betamethasone plasma half-life is threefold shorter in the rat as compared to the human (Tamvakopoulos, Neugebauer et al. 2002), the second injection occurred at an interval of 8 hours. For more details, see Chapters 3 and 4.

The comparison of the stage of brain development is a major concern with regard to the interpretation of animal studies examining the effects of GCs. A 10- to 14-day-old rat is equivalent to a term human in respect of neural development (Clancy, Darlington et al. 2001). Term rats are therefore equivalent to very preterm human infants, i.e., those who would receive antenatal GCs in utero.

A further concern is the comparison of neural cell cycle times. Ideally, one would like to expose the rat brain to betamethasone for the same number of cell cycles as in the human. Fortuitously, the cell cycle time of the 
developing primate brain is 3 to 5 times longer than that of a rodent fetus in the third trimester of pregnancy, which is similar to the difference in betamethasone half-life between primates and rodents (Kornack and Rakic 1998).

The responsivity to corticosteroids differs considerably amongst rat strains. For the purpose of our studies, Fischer 344 rats were used, because these represent a pure breeding inbred strain with low heterogeneity and are known to be reasonably stress responsive (Sternberg, Glowa et al. 1992; Dhabhar, McEwen et al. 1997; Izumi, Washizuka et al. 1997).

\section{Mechanisms}

Primary effects of $A B$ involve the activation of corticosteroid receptors. Due to its high numbers of both glucocorticoid (GR) and mineralocorticoid (MR) receptors, the hippocampus, which plays an important role in emotional processing and is involved in the pathophysiology of mood disorders and cognitive problems (Pine and Charney 2002; Martin and Clark 2007), is very sensitive to stress and glucocorticoids (De Kloet, Vreugdenhil et al. 1998). Similarly AB treatment may affect hippocampus development and function.

Possible (permanent) alterations in hippocampal structure and function may be related to altered levels of neurotrophic factors such as $\mathrm{S} 100 \mathrm{~B}$, or to an impairment in developmental hippocampal cell proliferation. Below, these and other possible mechanisms that may be involved in inducing the effects of $A B$ are discussed in more detail.

\section{DOHaD (Developmental origins of adult health and disease)}

According to the $\mathrm{DOHaD}$ (Developmental origins of adult health and disease) concept, the risk of disease in adulthood partly depends upon variations in the prenatal environment, which are often reflected in body weight at birth (Gillman 2005). Low birth weight has been associated with higher risk for disease (Barker 1995). For example, low birth weight has been associated with an increased susceptibility to stress (Nilsson, Nyberg et al. 2001) and depression (Thompson, Syddall et al. 2001; Gale and Martyn 2004) of note, 
the relationship between fetal growth and disease risk in later life reflects the sensitivity of growth to adverse antenatal influences, i.e., birth weight is a rough integrated measure of in utero events (Gluckman and Hanson 2004).

\section{S100B protein}

S100B protein belongs to a multigenic family of calcium-binding proteins (S100 proteins) and has a neurotrophic effect during brain development (Donato 2001). S100B - mainly produced by astrocytes (Pinto, Gottfried et al. 2000) - can be reduced by antenatal insults, e.g. exposure to ethanol (Eriksen, Gillespie et al. 2000), cocaine (Akbari, Whitaker-Azmitia et al. 1994) or maternal stress during gestation (Van den Hove, Steinbusch et al. 2006), thus leading to impaired development of serotonergic neurons (Tajuddin and Druse 1999). Since the half-life of $\mathrm{S} 100 \mathrm{~B}$ is about $1 \mathrm{hr}$ and it is excreted mainly in urine, S100B concentrations in biological fluids have been shown to be a useful tool to evaluate brain development and damage (Michetti and Gazzolo 2002).

\section{Cell proliferation in the brain}

Antenatal GC administration has been shown to be able to suppress the proliferation of hippocampal cells in the rat both in vitro (Yu, Lee et al. 2004) and in vivo (Scheepens, van de Waarenburg et al. 2003). Though this effect was followed by a catch-up in cell proliferation, it might permanently alter brain structure (Matthews 2000). In our study the ${ }^{3} \mathrm{H}$-thymidine incorporation method was used to calculate mitotic activity in specific brain regions by measuring the DNA synthetic rate, which is proportional to the rate of cell proliferation (Scheepens, Wassink et al. 2003).

\section{MAP2, Synaptophysin and behavioral tests}

Microtubule-associated protein 2 (MAP2) determines stability and arrangement of neuronal microtubules. Loss of MAP2-immunoreactivity (IR) after brain injury correlates with neuronal degeneration (Matesic and Lin 1994) and is associated with age-related impairment of synaptic plasticity, cognition and memory functions. Synaptophysin is a presynaptic marker protein involved in the generation and maintenance of small vesicle 
membranes and their interaction with cytoskeletal elements. Decrease in synaptophysin-IR is associated with brain injury and aging, possibly reflecting functional disturbances of synaptic transmission (Martinez, Di Giacomo et al. 1997).

Studies in the sheep and in the baboon have shown that the injection of $A B$ may alter MAP2 and synaptophysin in the fetus and in the neonate (Antonow-Schlorke, Kuhn et al. 2001; Schwab, Antonow-Schlorke et al. 2001; Antonow-Schlorke, Schwab et al. 2003; Colberg, Antonow-Schlorke et al. 2004). However, the long term effects of GCs on MAP2-IR and synaptophysin-IR have not been investigated. Moreover, these morphological changes might underlie the behavioral and learning impairment following GC exposure (Burlet, Fernette et al. 2005; Sloboda, Challis et al. 2005; Velisek 2006). 


\section{Aim and outline of the thesis}

The focus of this thesis is on the effects of a single course of $A B$ on brain development in human and animal studies. In addition, we investigated the effects of a lower dose regimen.

The aims of this thesis are to investigate the effects of antenatal GCs on:

- fetal growth, brain cell proliferation and S100B levels in the brain, blood and urine;

- cognition- and anxiety- related behavior in the adult offspring;

- MAP2- and synaptophysin-IR in the adult offspring.

Further, we aim to investigate whether lowering the dose of $A B$ might induce less effect on the parameters stated above.

We first focused on the levels of the neurotrophic factor S100B in the urine of infants antenatally treated with betamethasone (Chapter 2). The effects in the rat are presented in the following chapters: on somatic growth and brain cell proliferation (Chapter 3); on S100B concentration in the hippocampus and serum (Chapter 4); on adult cognition- and anxiety-related behavior, and synaptophysin- and MAP2- immunoreactivity (Chapter 5). In Chapter 6, the findings and implications of this thesis are discussed in more detail. 


\section{References}

Akbari, H. M., P. M. Whitaker-Azmitia, et al. (1994). "Prenatal cocaine decreases the trophic factor S-100 beta and induced microcephaly: reversal by postnatal 5-HT1A receptor agonist." Neurosci Lett 170(1): 141-4.

Antonow-Schlorke, I., B. Kuhn, et al. (2001). "Antenatal betamethasone treatment reduces synaptophysin immunoreactivity in presynaptic terminals in the fetal sheep brain." Neurosci Lett 297(3): 147-50.

Antonow-Schlorke, I., M. Schwab, et al. (2003). "Glucocorticoid exposure at the dose used clinically alters cytoskeletal proteins and presynaptic terminals in the fetal baboon brain." J Physiol 547(Pt 1): 117-23.

Barker, D. J. (1995). "The fetal origins of adult disease." Proc R Soc Lond B Biol Sci 262: 3743.

Benzon, H. T., T. L. Chew, et al. (2007). "Comparison of the Particle Sizes of Different Steroids and the Effect of Dilution: A Review of the Relative Neurotoxicities of the Steroids." Anesthesiology 106(2): 331-338.

Burlet, G., B. Fernette, et al. (2005). "Antenatal glucocorticoids blunt the functioning of the hypothalamic-pituitary-adrenal axis of neonates and disturb some behaviors in juveniles." Neuroscience 133(1): 221-30.

Clancy, B., R. B. Darlington, et al. (2001). "Translating developmental time across mammalian species." Neuroscience 105(1): 7-17.

Colberg, C., I. Antonow-Schlorke, et al. (2004). "Recovery of glucocorticoid-related loss of synaptic density in the fetal sheep brain at 0.75 of gestation." Neurosci Lett $364(2)$ : 130-4.

Crowley, P. (2003). "Antenatal corticosteroids--current thinking." Bjog 110 Suppl 20: 77-8.

Crowther, C. A., R. R. Haslam, et al. (2006). "Neonatal respiratory distress syndrome after repeat exposure to antenatal corticosteroids: a randomised controlled trial." Lancet 367(9526): 1913-9.

Davis, E. P., E. L. Townsend, et al. (2004). "Effects of prenatal betamethasone exposure on regulation of stress physiology in healthy premature infants." Psychoneuroendocrinology 29(8): 1028-36.

De Kloet, E. R., E. Vreugdenhil, et al. (1998). "Brain corticosteroid receptor balance in health and disease." Endocr Rev 19(3): 269-301.

Dhabhar, F. S., B. S. McEwen, et al. (1997). "Adaptation to prolonged or repeated stress-comparison between rat strains showing intrinsic differences in reactivity to acute stress." Neuroendocrinology 65(5): 360-8.

Donato, R. (2001). "S100: a multigenic family of calcium-modulated proteins of the EF-hand type with intracellular and extracellular functional roles." Int J Biochem Cell Biol 33(7): 637-68.

Emgard, M., M. Paradisi, et al. (2007). "Prenatal glucocorticoid exposure affects learning and vulnerability of cholinergic neurons." Neurobiol Aging 28(1): 112-21.

Eriksen, J. L., R. A. Gillespie, et al. (2000). "Effects of in utero ethanol exposure and maternal treatment with a $5-\mathrm{HT}(1 \mathrm{~A})$ agonist on S100B-containing glial cells." Brain Res Dev Brain Res 121(2): 133-43.

Fraser, J., M. Walls, et al. (2004). "Respiratory complications of preterm birth." Bmj 329(7472): 962-5.

Gale, C. R. and C. N. Martyn (2004). "Birth weight and later risk of depression in a national birth cohort." Br J Psychiatry 184: 28-33.

Gillman, M. W. (2005). "Developmental origins of health and disease." N Engl J Med 353(17): 1848-50.

Gluckman, P. D. and M. A. Hanson (2004). "Living with the past: evolution, development, and patterns of disease." Science 305(5691): 1733-6.

Haas, D. M., W. McCullough, et al. (2006). "The first 48 hours: Comparing 12-hour and 24hour betamethasone dosing when preterm deliveries occur rapidly." J Matern Fetal Neonatal Med 19(6): 365-9.

Haas, D. M., W. McCullough, et al. (2005). "Neonatal outcomes with different betamethasone dosing regimens: a comparison." J Reprod Med 50(12): 915-22. 
Izumi, J., M. Washizuka, et al. (1997). "Evidence for a depressive-like state induced by repeated saline injections in Fischer 344 rats." Pharmacol Biochem Behav 57(4): 8838.

Jacobson, L. and R. Sapolsky (1991). "The role of the hippocampus in feedback regulation of the hypothalamic-pituitary-adrenocortical axis." Endocr Rev 12(2): 118-34.

Jellyman, J. K., D. S. Gardner, et al. (2004). "Pituitary-adrenal responses to acute hypoxemia during and after maternal dexamethasone treatment in sheep." Pediatr Res 56(6): 864-72.

Jobe, A. H. and R. F. Soll (2004). "Choice and dose of corticosteroid for antenatal treatments." Am J Obstet Gynecol 190(4): 878-81.

Kajantie, E., T. Raivio, et al. (2004). "Circulating glucocorticoid bioactivity in the preterm newborn after antenatal betamethasone treatment." $\mathrm{J}$ Clin Endocrinol Metab 89(8): 3999-4003.

Kornack, D. R. and P. Rakic (1998). "Changes in cell-cycle kinetics during the development and evolution of primate neocortex." Proc Natl Acad Sci U S A 95(3): 1242-6.

Lee, B. H., B. J. Stoll, et al. (2006). "Adverse neonatal outcomes associated with antenatal dexamethasone versus antenatal betamethasone." Pediatrics 117(5): 1503-10.

Liggins, G. C. (1968). "Premature parturition after infusion of corticotrophin or cortisol into foetal lambs." J Endocrinol 42(2): 323-9.

Liggins, G. C. and R. N. Howie (1972). "A controlled trial of antepartum glucocorticoid treatment for prevention of the respiratory distress syndrome in premature infants." Pediatrics 50(4): 515-25.

Martin, C. R., L. J. Van Marter, et al. (2005). "Antenatal Glucocorticoids Increase Early Total Thyroxine Levels in Premature Infants." Biol Neonate 87(4): 273-280.

Martin, S. J. and R. E. Clark (2007). "The rodent hippocampus and spatial memory: from synapses to systems." Cell Mol Life Sci 64(4): 401-31.

Martinez, G., C. Di Giacomo, et al. (1997). "MAP2, synaptophysin immunostaining in rat brain and behavioral modifications after cerebral postischemic reperfusion." Dev Neurosci 19(6): 457-64.

Matesic, D. F. and R. C. Lin (1994). "Microtubule-associated protein 2 as an early indicator of ischemia-induced neurodegeneration in the gerbil forebrain." $\mathrm{J}$ Neurochem 63(3): 1012-20.

Matthews, S. G. (2000). "Antenatal glucocorticoids and programming of the developing CNS." Pediatr Res 47(3): 291-300.

Matthews, S. G., D. Owen, et al. (2002). "Glucocorticoids, hypothalamo-pituitary-adrenal (HPA) development, and life after birth." Endocr Res 28(4): 709-18.

Michetti, F. and D. Gazzolo (2002). "S100B protein in biological fluids: a tool for perinatal medicine." Clin Chem 48(12): 2097-104.

Miller, S. L., M. Chai, et al. (2006). "The effects of maternal betamethasone administration on the intrauterine growth restricted fetus." Endocrinology.

Nilsson, P. M., P. Nyberg, et al. (2001). "Increased susceptibility to stress at a psychological assessment of stress tolerance is associated with impaired fetal growth." Int J Epidemiol 30(1): 75-80.

Niu, H., D. A. Hinkle, et al. (1997). "Dexamethasone regulates basic fibroblast growth factor, nerve growth factor and S100beta expression in cultured hippocampal astrocytes." Brain Res Mol Brain Res 51(1-2): 97-105.

Ogunyemi, D. (2005). "A comparison of the effectiveness of single-dose vs multi-dose antenatal corticosteroids in pre-term neonates." J Obstet Gynaecol 25(8): 756-60.

Parer, J. (2004). "Repeat courses of antenatal corticosteroids: what does the evidence show?" J Matern Fetal Neonatal Med 15(6): 349-50.

Peltoniemi, O. M., M. A. Kari, et al. (2007). "Randomized trial of a single repeat dose of prenatal betamethasone treatment in imminent preterm birth." Pediatrics 119(2): 2908.

Pine, D. and D. Charney (2002). "Children, stress, and sensitization: an integration of basic and clinical research on emotion?" Biol Psychiatry 52(8): 773.

Pinto, S. S., C. Gottfried, et al. (2000). "Immunocontent and secretion of S100B in astrocyte cultures from different brain regions in relation to morphology." FEBS Lett 486(3): 203-7. 
Rayburn, W. F., H. D. Christensen, et al. (1998). "Effect of in utero exposure to betamethasone on motivation/anxiety testing in mice offspring." Neurotoxicol Teratol 20(4): 475-81.

Roberts, D. and S. Dalziel (2006). "Antenatal corticosteroids for accelerating fetal lung maturation for women at risk of preterm birth." Cochrane Database Syst Rev 3: CD004454.

Rodriguez-Pinilla, E., D. Prieto-Merino, et al. (2006). "[Antenatal exposure to corticosteroids for fetal lung maturation and its repercussion on weight, length and head circumference in the newborn infant]." Med Clin (Barc) 127(10): 361-7.

Schaaf, M. J., R. W. Hoetelmans, et al. (1997). "Corticosterone regulates expression of BDNF and trkB but not NT-3 and trkC mRNA in the rat hippocampus." J Neurosci Res 48(4): 334-41.

Scheepens, A., D. van den Hove, et al. (2003). "A single course of prenatal betamethasone in the rat alters postnatal brain cell proliferation but not apoptosis." J Physiol 552(Pt 1): 163-75.

Scheepens, A., G. Wassink, et al. (2003). "A delayed increase in hippocampal proliferation following global asphyxia in the neonatal rat." Brain Res Dev Brain Res 142(1): 67-76.

Schwab, M., I. Antonow-Schlorke, et al. (2001). "Effect of antenatal betamethasone treatment on microtubule-associated proteins MAP1B and MAP2 in fetal sheep." J Physiol 530(Pt 3): 497-506.

Schwab, M., T. Coksaygan, et al. (2006). "Kinetics of betamethasone and fetal cardiovascular adverse effects in pregnant sheep after different doses." Obstet Gynecol 108(3 Pt 1): $617-25$.

Sloboda, D. M., J. R. Challis, et al. (2005). "Synthetic glucocorticoids: antenatal administration and long-term implications." Curr Pharm Des 11(11): 1459-72.

Sloboda, D. M., T. J. Moss, et al. (2007). "Prenatal betamethasone exposure results in pituitary-adrenal hyporesponsiveness in adult sheep." Am J Physiol Endocrinol Metab 292(1): E61-70.

Sternberg, E. M., J. R. Glowa, et al. (1992). "Corticotropin releasing hormone related behavioral and neuroendocrine responses to stress in Lewis and Fischer rats." Brain Res 570(1-2): 54-60.

Tajuddin, N. F. and M. J. Druse (1999). "In utero ethanol exposure decreased the density of serotonin neurons. Maternal ipsapirone treatment exerted a protective effect." Brain Res Dev Brain Res 117(1): 91-7.

Tamvakopoulos, C. S., J. M. Neugebauer, et al. (2002). "Analysis of betamethasone in rat plasma using automated solid-phase extraction coupled with liquid chromatographytandem mass spectrometry. Determination of plasma concentrations in rat following oral and intravenous administration." $\underline{\mathrm{J} \text { Chromatogr B Analyt Technol Biomed Life Sci }}$ 776(2): 161-8.

Theogaraj, E., C. D. John, et al. (2005). "Perinatal Glucocorticoid Treatment Produces Molecular, Functional and Morphological Changes in the Anterior Pituitary Gland of the Adult Male Rat." Endocrinology.

Thompson, C., H. Syddall, et al. (2001). "Birth weight and the risk of depressive disorder in late life." Br J Psychiatry 179: 450-5.

Thorp, J. A., P. G. Jones, et al. (2002). "Does antenatal corticosteroid therapy affect birth weight and head circumference?" Obstet Gynecol 99(1): 101-8.

Van den Hove, D. L., H. W. Steinbusch, et al. (2006). "Prenatal stress reduces S100B in the neonatal rat hippocampus." Neuroreport 17(10): 1077-80.

Velisek, L. (2006). "Prenatal exposure to betamethasone decreases anxiety in developing rats: hippocampal neuropeptide y as a target molecule." Neuropsychopharmacology 31(10): 2140-9.

Wapner, R. J., Y. Sorokin, et al. (2006). "Single versus weekly courses of antenatal corticosteroids: evaluation of safety and efficacy." Am J Obstet Gynecol 195(3): 63342.

Wijnberger, L. D., J. M. Mostert, et al. (2002). "Comparison of single and repeated antenatal corticosteroid therapy to prevent neonatal death and morbidity in the preterm infant." Early Hum Dev 67(1-2): 29-36.

Yu, I. T., S. H. Lee, et al. (2004). "Differential effects of corticosterone and dexamethasone on hippocampal neurogenesis in vitro." Biochem Biophys Res Commun 317(2): 484-90. 



\title{
Chapter 2
}

\section{Maternal glucocorticoid supplementation and S100B protein concentrations in cord blood and urine of preterm infants}

\author{
Gazzolo $D^{1}$, Kornacka $\mathbf{M}^{2}$, Bruschettini $\mathbf{M}^{1}$, Lituania $\mathbf{M}^{1}$, \\ Giovannini $L^{1}$, Serra $\mathrm{G}^{1}$, Majewska $\mathrm{U}^{2}$, Michetti $\mathrm{F}^{3}$ \\ ${ }^{1}$ Department of Pediatrics and Obstetrics, G Gaslini Children's Hospital, Genoa, Italy, \\ ${ }^{2}$ Department of Neonatology, Warsaw Medical University Hospital, Warsaw, Poland, \\ ${ }^{3}$ Institute of Anatomy and Cell Biology, Catholic University, Rome, Italy
}


Chapter 2

\section{INTRODUCTION}

Maternal glucocorticoid (GC) supplementation is widely used for the prevention of lung immaturity (Crowley 1995; O'Shea, Kothadia et al. 1999), but its possible harmful effects on other organs, including the central nervous system (CNS), are still a matter of debate (Uno, Lohmiller et al. 1990; 1995; Mulder, Derks et al. 1997; Sousa, Madeira et al. 1998; Huang, Beazley et al. 1999; Whitelaw and Thoresen 2000; Vidaeff and Mastrobattista 2001).

$\mathrm{S} 100 \mathrm{~B}$, which is present mainly in the nervous system (Heizmann 1999) and has a short half-life (Jonsson, Johnsson et al. 2000), is regarded as a useful marker of brain injury, although at physiologic concentrations it may act as a cytokine with a neurotrophic effect (Michetti, Massaro et al. 1979; Michetti, Massaro et al. 1980; Gazzolo, Vinesi et al. 1998; Gazzolo, Vinesi et al. 1999; Heizmann 1999; Gazzolo, Vinesi et al. 2000; Gazzolo, Bruschettini et al. 2001; Gazzolo, Marinoni et al. 2002; Michetti and Gazzolo 2002). S100B concentrations in cord blood or urine have already been used to monitor brain distress on the fetal/newborn CNS (Gazzolo, Vinesi et al. 2000; Gazzolo, Bruschettini et al. 2001; Gazzolo, Bruschettini et al. 2001; Gazzolo, Bruschettini et al. 2002; Gazzolo, Marinoni et al. 2002; Michetti and Gazzolo 2002).

\section{METHODS}

We investigated the possible effects of maternal GC administration on the CNS of newborns by measuring S100B in cord blood and longitudinally in urine. Between April 2000 and June 2002, we measured S100B in the umbilical cord blood and urine of infants, born at our tertiary referral centers for obstetric care, who were admitted to the neonatal intensive care units (NICUs) of our hospitals. From our database we retrieved the 39 infants whose mothers had been treated antenatally with corticosteroids and matched them for gestational age at recording with 39 infants whose mothers had not been treated with steroids (1 control for each patient in the GC group). 
Exclusion criteria included multiple pregnancies, fetal/neonatal cardiac or hemolytic diseases, fetal malformations, and chromosomal abnormalities.

The mothers in the GC group had received betamethasone $(12 \mathrm{mg}$ intravenously for 2 days) when spontaneous or planned preterm delivery was expected to occur. The main complications in the cases admitted to the study were intrauterine growth retardation (14 of 39 in the GC group; 15 of 39 in the control group), pregnancy-induced hypertension (13 of 39 in the GC group; 14 of 39 in the control group), and preterm delivery not complicated by intrauterine growth retardation, maternal hypertension, or diabetes (12 of 39 in the GC group; 10 of 39 in the control group).

S100B protein was measured at delivery in the umbilical cord blood and subsequently in urine at five predetermined points: at first urination (time 0 ) and at $24 \mathrm{~h}$ (time 1), $48 \mathrm{~h}$ (time 2), $72 \mathrm{~h} \mathrm{(time} \mathrm{3),} \mathrm{and} 120 \mathrm{~h}$ of age (time 4).

On admission to the NICU, all newborns routinely had measurements of red blood cell count, venous blood pH, ion concentrations, plasma glucose, urea, creatinine clearance, osmolality, urinary specific gravity, and arterial blood pressure; all underwent cerebral ultrasound and neurologic examinations. For cases in which GC had been administered, clinical and laboratory tests and cerebral ultrasound scans recorded the predetermined monitoring time points were reevaluated and compared with those obtained from a control group.

The local Ethics Committees approved the study, and the parents of the infants/patients gave informed and signed consent.

Standard cerebral ultrasound was performed by real-time ultrasound at the same time points as urine sampling, and the grade of intraventricular hemorrhage (IVH) was classified (Papile, Burstein et al. 1978). The neurologic condition of each neonate was classified qualitatively (Prechtl 1974) as normal, suspect, or abnormal. An infant was considered as having an abnormal neurologic condition when hyper- or hypokinesia, hyper- or hypotonia, hemi syndrome, apathy syndrome, or hyperexcitability syndrome 
was present. An infant was classified as suspect if isolated symptoms, but no defined syndromes, were present. The same examiner tested all of the infants.

At delivery, the umbilical cord was clamped before any signs of breathing were seen, and blood was drawn from the umbilical vein for S100B measurements. None of the patients who underwent cesarean section experienced uterine contractility before the surgical procedure (Table 1).

\section{Table 1}

\begin{tabular}{lcc}
\hline \multicolumn{1}{|c}{ Characteristics of infants studied. } & Controls $(\mathrm{n}=39)$ & $\mathrm{GC}(\mathrm{n}=39)$ \\
\hline Maternal age, ${ }^{1}$ years & $27(2)$ & $26(3)$ \\
Cesarean section, $\mathrm{n}$ & 15 & 13 \\
Gestational age at birth, ${ }^{1}$ weeks & $34(2)$ & $34(1)$ \\
Birth weight, ${ }^{1}$ kg & $1.69(0.56)$ & $1.72(0.43)$ \\
M/F, $\mathrm{n}$ & $16 / 13$ & $17 / 12$ \\
Apgar, yes/total & & \\
1st min $<7$ & $5 / 39$ & $4 / 39$ \\
5th min $<7$ & $0 / 39$ & $0 / 39$ \\
RDS, yes/total & $16 / 39$ & $7 / 39^{2}$ \\
Neurologic abnormalities, & $8 / 14 / 17$ & $20 / 19 / 0^{2}$ \\
normal/suspect/abnormal & & \\
Cerebral ultrasound, normal/IVH & $15 / 24^{2}$ & $39 / 0^{2}$ \\
Mechanical ventilation support, yes/total & $22 / 39$ & $9 / 39^{2}$ \\
Mean NICU stay, days & 31 & $22^{2}$ \\
Sepsis (within 7 days from birth), & $7 / 39$ & $5 / 39$ \\
yes/total & & \\
\hline
\end{tabular}

${ }^{1}$ Mean (SD).

${ }^{2} P<0.05$.

Blood and urine samples were centrifuged at $900 \mathrm{~g}$ for $10 \mathrm{~min}$, and the supernatants were stored at $-70^{\circ} \mathrm{C}$ before measurement. $\mathrm{S100B}$ was 
measured by an immunoluminometric assay (Lia-mat Sangtec 100; $A B$ Sangtec Medical) that specifically measures the B-subunit, which is known to be predominant in the human brain (Baudier, Glasser et al. 1984; Gazzolo, Bruschettini et al. 2001; Michetti and Gazzolo 2002). The results reported are the means of duplicate measurements. The limit of detection of the assay $\left(B_{0}\right.$ + $3 \mathrm{SD}$ ) was $0.02 \mu \mathrm{g} / \mathrm{L}$, and the intra- and interassay imprecisions (as CVs) were $\leq 5.5 \%$ and $\leq 10 \%$, respectively, at $0.28-4.2 \mu \mathrm{g} / \mathrm{L}$.

The data are reported as the mean (SD). Groups were compared by the Kruskal-Wallis one-way ANOVA or by Mann-Whitney U-test for nongaussian-distributed data. The Fisher exact test was used for comparisons of the incidences of neonatal neurologic outcome in patient groups and of acute respiratory distress syndrome (RDS) in patients vs controls.

\section{RESULTS}

Fetal and neonatal characteristics are summarized in Table 1. The incidence of RDS, IVH, and neurologic abnormalities, the need for mechanical ventilation support, and NICU hospitalization duration were higher in the infants whose mothers had not received antenatal GC treatment $(P<0.05)$ : 20 preterm control infants developed IVH grade I and 4 developed IVH grade II, whereas there were no cases of IVH in the GC group.

S100B measurements in cord blood showed no significant differences between the two groups $(P>0.05)$. In infants born to untreated women, mean blood S100B was significantly higher in group B [brain damage; 3.67 (1.20) $\mu \mathrm{g} / \mathrm{L}$ ] than in group $A$ [no brain damage; $1.21(0.24) \mu \mathrm{g} / \mathrm{L}$ ] or in infants in the GC group [1.11 (0.24) $\mu \mathrm{g} / \mathrm{L} ; P<0.001]$. S100B concentrations in group $A$ and the GC group were not significantly different $(P>0.05)$.

Urine $\mathrm{S} 100 \mathrm{~B}$ in the $\mathrm{GC}$ group showed no temporal trend and ranged from $0.11(0.08) \mu \mathrm{g} / \mathrm{L}$ at first urination to $0.27(0.11) \mu \mathrm{g} / \mathrm{L}$ at $120 \mathrm{~h}$. In the untreated group, S100B ranged from $0.59(0.23) \mu \mathrm{g} / \mathrm{L}$ at first urination to 0.28 
(0.19) $\mu \mathrm{g} / \mathrm{L}$ at $120 \mathrm{~h}$. S100B concentrations in urine were consistently lower in the $\mathrm{GC}$ group $(P<0.05)$. Urinary $\mathrm{S100 \textrm {B }}$ was significantly lower at all predetermined monitoring time points in the GC group than in group $\mathrm{B}(P$ $<0.01)$ and, notably, group $A$ infants $(P<0.001$; Fig. 1).

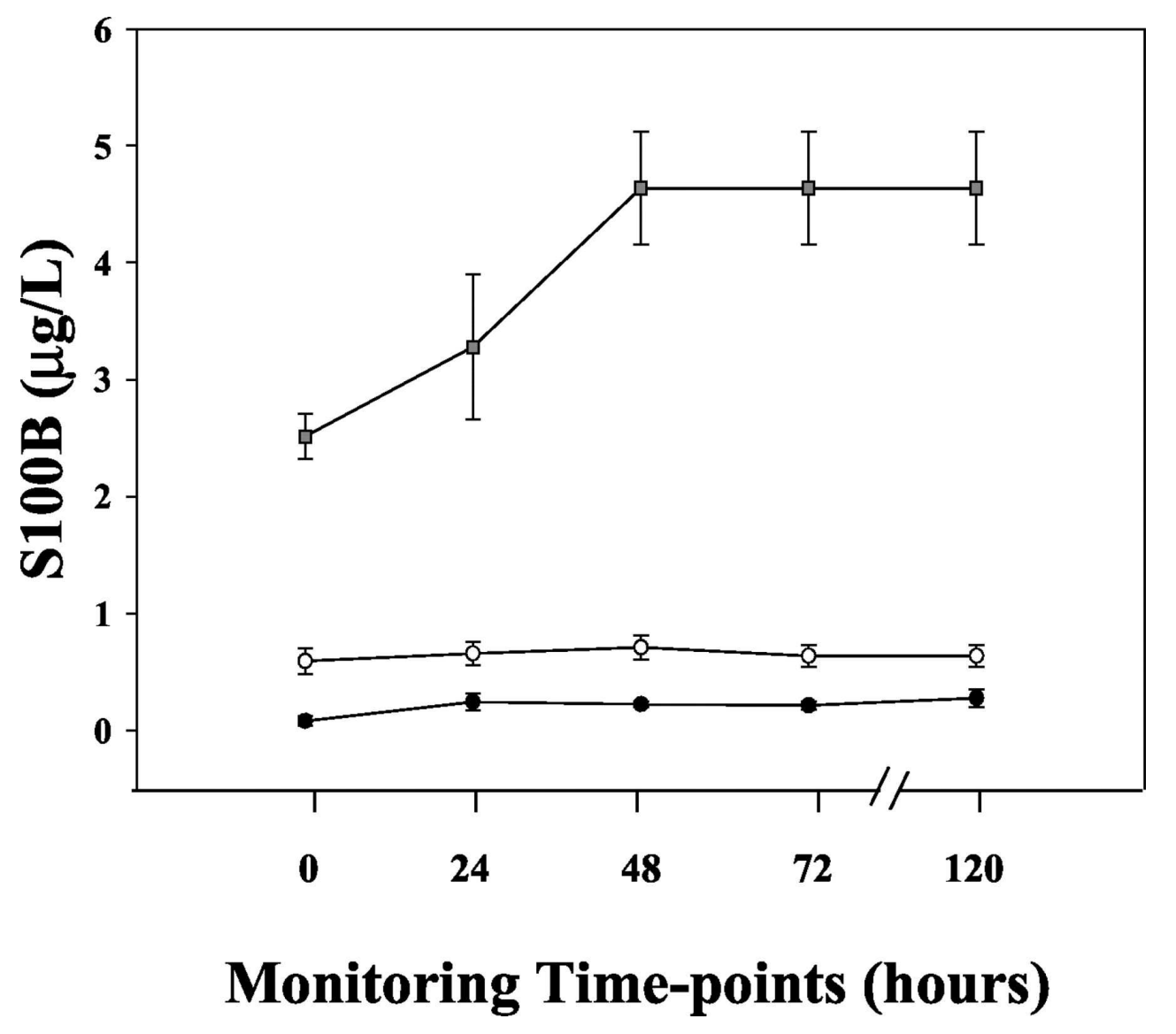

Figure 1. Mean (SD; error bars) urinary $\mathrm{S} 100 \mathrm{~B}$ concentrations $(\mu \mathrm{g} / \mathrm{L})$ at first urination (time 0 ) and at $24 \mathrm{~h}$ (time 1), $48 \mathrm{~h}$ (time 2), $72 \mathrm{~h}$ (time 3), and $120 \mathrm{~h} \mathrm{(time} \mathrm{4)} \mathrm{in} \mathrm{preterm} \mathrm{infants} \mathrm{whose}$ mothers were treated antenatally with GC (F) and in controls without (group A) and with (group B) brain damage.

S100B was significantly lower at all monitoring time points in the GC group than in control groups $A(P<0.01)$ and $B(P<0.001)$.

\section{DISCUSSION}


The present research shows that a well-established biochemical marker of brain distress, S100B protein, is present in significantly lower concentrations in the urine of newborns whose mothers were treated antenatally with GC than in newborns whose mothers were not treated. Urinary S100B concentrations in infants born to GC-treated mothers were also lower than those in infants without brain damage born to untreated mothers when these were subgrouped according to the occurrence of postnatal brain damage. The results for healthy preterm newborns whose mothers were not treated with GC are in agreement with previous observations of S100B in the urine of healthy preterm infants (Gazzolo, Bruschettini et al. 2001). The high concentrations of urinary S100B observed in brain-damaged newborns whose mothers were not treated with GC offer laboratory support for a previous observation (Gazzolo, Bruschettini et al. 2001).

The presence of $\mathrm{S} 100 \mathrm{~B}$ in urine has already been demonstrated in healthy newborns, and increased urinary S100B has been shown to be an early indicator of risk for cerebral bleeding (Gazzolo, Bruschettini et al. 2001). Because we found no significant differences in renal function among the three groups studied, the lower S100B in the infants in the GC group is not likely to be attributable to different concentrations of the protein in urine. Furthermore, because $\mathrm{S100B}$ is absent from kidney tissue, it is reasonable to suppose that its source in the urine is the CNS (Heizmann 1999; Michetti and Gazzolo 2002). On the other hand, it is possible that at least some S100B may be released from other sites in which it is concentrated, such as adipose tissue (Michetti, Dell'Anna et al. 1983), although data in this setting are lacking.

The longitudinal low S100B concentrations in infants from GC-treated mothers are intriguing. One explanation lies in the lower incidence of neurologic abnormalities in the GC group; these abnormalities almost certainly have a relevant role in the release of the protein into the systemic circulation and the urine. Another explanation may reside in the fact that infants born of GC-treated mothers require fewer intensive care interventions that affect blood-brain barrier permeability (O'Shea, Kothadia et al. 1999) and would thus likely increase the release of $5100 B$ into the systemic circulation 
(Kapural, Krizanac-Bengez et al. 2002) and finally into the urine. In addition, it should be noted that data on experimental models and in humans support the hypothesis that antenatal GC administration decreases blood-brain barrier permeability, protecting the brain (Ment, Oh et al. 1995; Stonestreet, Petersson et al. 1999).

S100B is regarded as a cytokine with a neurotrophic role at low concentrations and a neurotoxic effect at high concentrations (Haglid, Yang et al. 1997; Heizmann 1999; Jonsson, Johnsson et al. 2000). Our findings of lower S100B concentrations after GC administration open new possibilities for studies aimed at investigating the possible effects of GC on the activity of $\mathrm{S} 100 \mathrm{~B}$ as a cytokine. Because GCs are known to affect cytokine production in some conditions and GC receptors have been shown to be present in S100Bproducing cell types, the possibility that GC action on the CNS is accompanied by a modulation of $\mathrm{S100B}$ production and/or release should be taken into consideration (Bohn, O'Banion et al. 1994; Jung-Testas and Baulieu 1998; Elenkov and Chrousos 2002). The present finding of low S100B concentrations after maternal GC treatment appears to be relevant, especially for other perinatal conditions in which GC treatment is used, such as the prevention of bronchopulmonary dysplasia in preterm infants.

Data on S100B measurements in cord blood indicate that GC administration is associated with lower concentrations of the protein in infants not affected by brain injury, consistent with the data regarding urine. Another difference between urinary and cord blood S100B could be related to the possibility that at least a part of the protein present in cord blood has a placental origin, as supported by recent observations (Marinoni, Di lorio et al. 2002; Wijnberger, Nikkels et al. 2002).

In conclusion, the present findings offer additional data in the debate concerning the effects of antenatal GC administration on the fetal/newborn brain, suggest the use of $\mathrm{S100B}$ as a tool to assess the effects of antenatal drug treatment, and offer a clue for future studies on a possible GC-derived modulation of S100B. 


\section{Acknowledgments}

This work was partially supported by grants from Università Cattolica del S. Cuore, from Ministero della Salute, and from Ministero dell'Università e Ricerca Scientifica e Tecnologica (to F.M.), and from the "Let's Improve Prenatal Life" Foundation (to D.G.). We are especially grateful to the Nursery Teams of the Department of Neonatology of the Giannina Gaslini Children's University Hospital (Genoa, Italy) and the Department of Neonatology, Warsaw Medical University Hospital, for their constant enthusiasm and participation during the performance of this research project.

\section{References}

Effect of corticosteroids for fetal maturation on perinatal outcomes. NIH Consensus Development Panel on the Effect of Corticosteroids for Fetal Maturation on Perinatal Outcomes, Jama, 273 (1995) 413-8.

Baudier, J., Glasser, N., Haglid, K. and Gerard, D., Purification, characterization and ion binding properties of human brain S100b protein, Biochim Biophys Acta, 790 (1984) 164-73.

Bohn, M.C., O'Banion, M.K., Young, D.A., Giuliano, R., Hussain, S., Dean, D.O. and Cunningham, L.A., In vitro studies of glucocorticoid effects on neurons and astrocytes, Ann N Y Acad Sci, 746 (1994) 243-58; discussion 258-9, 289-93.

Crowley, P.A., Antenatal corticosteroid therapy: a meta-analysis of the randomized trials, 1972 to 1994, Am J Obstet Gynecol, 173 (1995) 322-35.

Elenkov, I.J. and Chrousos, G.P., Stress hormones, proinflammatory and antiinflammatory cytokines, and autoimmunity, Ann N Y Acad Sci, 966 (2002) 290-303.

Gazzolo, D., Bruschettini, M., Di lorio, R., Marinoni, E., Lituania, M., Marras, M., Sarli, R., Bruschettini, P.L. and Michetti, F., Maternal nitric oxide supplementation decreases cord blood S100B in intrauterine growth-retarded fetuses, Clin Chem, 48 (2002) $647-$ 50.

Gazzolo, D., Bruschettini, M., Lituania, M., Serra, G., Bonacci, W. and Michetti, F., Increased urinary $\mathrm{S} 100 \mathrm{~B}$ protein as an early indicator of intraventricular hemorrhage in preterm infants: correlation with the grade of hemorrhage, Clin Chem, 47 (2001) 1836-8.

Gazzolo, D., Bruschettini, M., Lituania, M., Serra, G., Gandullia, E. and Michetti, F., S100b protein concentrations in urine are correlated with gestational age in healthy preterm and term newborns, Clin Chem, 47 (2001) 1132-3. 
Gazzolo, D., Marinoni, E., di lorio, R., Lituania, M., Bruschettini, P.L. and Michetti, F., Circulating S100beta protein is increased in intrauterine growth-retarded fetuses, Pediatr Res, 51 (2002) 215-9.

Gazzolo, D., Vinesi, P., Bartocci, M., Geloso, M.C., Bonacci, W., Serra, G., Haglid, K.G. and Michetti, F., Elevated S100 blood level as an early indicator of intraventricular hemorrhage in preterm infants. Correlation with cerebral Doppler velocimetry, $J$ Neurol Sci, 170 (1999) 32-5.

Gazzolo, D., Vinesi, P., Geloso, M.C., Marcelletti, C., Iorio, F.S., Cipriani, A., Marianeschi, S.M. and Michetti, F., S100 blood concentrations in children subjected to cardiopulmonary by-pass, Clin Chem, 44 (1998) 1058-60.

Gazzolo, D., Vinesi, P., Marinoni, E., Di lorio, R., Marras, M., Lituania, M., Bruschettini, P. and Michetti, F., S100B protein concentrations in cord blood: correlations with gestational age in term and preterm deliveries, Clin Chem, 46 (2000) 998-1000.

Haglid, K.G., Yang, Q., Hamberger, A., Bergman, S., Widerberg, A. and Danielsen, N., S100beta stimulates neurite outgrowth in the rat sciatic nerve grafted with acellular muscle transplants, Brain Res, 753 (1997) 196-201.

Heizmann, C.W., Ca2+-binding S100 proteins in the central nervous system, Neurochem Res, 24 (1999) 1097-100.

Huang, W.L., Beazley, L.D., Quinlivan, J.A., Evans, S.F., Newnham, J.P. and Dunlop, S.A., Effect of corticosteroids on brain growth in fetal sheep, Obstet Gynecol, 94 (1999) 213-8.

Jonsson, H., Johnsson, P., Hoglund, P., Alling, C. and Blomquist, S., Elimination of S100B and renal function after cardiac surgery, J Cardiothorac Vasc Anesth, 14 (2000) 698701.

Jung-Testas, I. and Baulieu, E.E., Steroid hormone receptors and steroid action in rat glial cells of the central and peripheral nervous system, J Steroid Biochem Mol Biol, 65 (1998) 243-51.

Kapural, M., Krizanac-Bengez, L., Barnett, G., Perl, J., Masaryk, T., Apollo, D., Rasmussen, P., Mayberg, M.R. and Janigro, D., Serum S-100beta as a possible marker of bloodbrain barrier disruption, Brain Res, 940 (2002) 102-4.

Marinoni, E., Di lorio, R., Gazzolo, D., Lucchini, C., Michetti, F., Corvino, V. and Cosmi, E.V., Ontogenetic localization and distribution of S-100beta protein in human placental tissues, Obstet Gynecol, 99 (2002) 1093-9.

Ment, L.R., Oh, W., Ehrenkranz, R.A., Philip, A.G., Duncan, C.C. and Makuch, R.W., Antenatal steroids, delivery mode, and intraventricular hemorrhage in preterm infants, Am J Obstet Gynecol, 172 (1995) 795-800.

Michetti, F., Dell'Anna, E., Tiberio, G. and Cocchia, D., Immunochemical and immunocytochemical study of S-100 protein in rat adipocytes, Brain Res, 262 (1983) 352-6. 
Michetti, F. and Gazzolo, D., S100B protein in biological fluids: a tool for perinatal medicine, Clin Chem, 48 (2002) 2097-104.

Michetti, F., Massaro, A. and Murazio, M., The nervous system-specific S-100 antigen in cerebrospinal fluid of multiple sclerosis patients, Neurosci Lett, 11 (1979) 171-5.

Michetti, F., Massaro, A., Russo, G. and Rigon, G., The S-100 antigen in cerebrospinal fluid as a possible index of cell injury in the nervous system, J Neurol Sci, 44 (1980) 25963.

Mulder, E.J., Derks, J.B. and Visser, G.H., Antenatal corticosteroid therapy and fetal behaviour: a randomised study of the effects of betamethasone and dexamethasone, Br J Obstet Gynaecol, 104 (1997) 1239-47.

O'Shea, T.M., Kothadia, J.M., Klinepeter, K.L., Goldstein, D.J., Jackson, B.G., Weaver, R.G., 3rd and Dillard, R.G., Randomized placebo-controlled trial of a 42-day tapering course of dexamethasone to reduce the duration of ventilator dependency in very low birth weight infants: outcome of study participants at 1-year adjusted age, Pediatrics, 104 (1999) 15-21.

Papile, L.A., Burstein, J., Burstein, R. and Koffler, H., Incidence and evolution of subependymal and intraventricular hemorrhage: a study of infants with birth weights less than 1,500 gm, J Pediatr, 92 (1978) 529-34.

Prechtl, H.F., The behavioural states of the newborn infant (a review), Brain Res, 76 (1974) 185-212.

Sousa, N., Madeira, M.D. and Paula-Barbosa, M.M., Effects of corticosterone treatment and rehabilitation on the hippocampal formation of neonatal and adult rats. An unbiased stereological study, Brain Res, 794 (1998) 199-210.

Stonestreet, B.S., Petersson, K.H., Sadowska, G.B., Pettigrew, K.D. and Patlak, C.S., Antenatal steroids decrease blood-brain barrier permeability in the ovine fetus, $A m \mathrm{~J}$ Physiol, 276 (1999) R283-9.

Uno, H., Lohmiller, L., Thieme, C., Kemnitz, J.W., Engle, M.J., Roecker, E.B. and Farrell, P.M., Brain damage induced by prenatal exposure to dexamethasone in fetal rhesus macaques. I. Hippocampus, Brain Res Dev Brain Res, 53 (1990) 157-67.

Vidaeff, A.C. and Mastrobattista, J.M., Controversies in the use of antenatal steroids for fetal maturation, Semin Perinatol, 25 (2001) 385-96.

Whitelaw, A. and Thoresen, M., Antenatal steroids and the developing brain, Arch Dis Child Fetal Neonatal Ed, 83 (2000) F154-7.

Wijnberger, L.D., Nikkels, P.G., van Dongen, A.J., Noorlander, C.W., Mulder, E.J., Schrama, L.H. and Visser, G.H., Expression in the placenta of neuronal markers for perinatal brain damage, Pediatr Res, 51 (2002) 492-6. 



\section{Chapter 3}

\section{A single course of antenatal \\ betamethasone reduces neurotrophic \\ factor S100B concentration in the \\ hippocampus and serum in the neonatal rat}

Bruschettini $\mathbf{M}^{1 / 2 / 4 / 5}$ van den Hove DLA ${ }^{1 / 2 / 5}$, Gazzolo $D^{3 / 4}$,

Bruschettini $\mathrm{P}^{4}$, Blanco $\mathrm{CE}^{2 / 5}$, Steinbusch $\mathrm{HWM}^{1 / 5}$

\footnotetext{
Department of Psychiatry and Neuropsychology, Division of Cellular Neuroscience \&

${ }^{2}$ Department of Pediatrics, Research Institute Growth and Development (GROW),

Faculty of Medicine, University of Maastricht, Maastricht, The Netherlands

${ }^{3}$ Maternal Fetal and Neonatal Health, G. Garibaldi Hospital, Catania, Italy

${ }^{4}$ G. Gaslini Children's Hospital, University of Genoa, Genoa, Italy

${ }^{5}$ European Graduate School of Neuroscience (EURON)
}

Brain Research Developmental Brain Research 159(2):113-8 (2005) 


\section{Abstract}

The effects of a single course of antenatal betamethasone on S100B protein concentration were investigated in Fisher 344 rats. On day 20 of gestation pregnant rats were injected twice 8 hours apart with either 1) $170 \mu \mathrm{g} \mathrm{kg}^{-1}$ body weight betamethasone ("clinically-equivalent dose", equivalent to $12 \mathrm{mg}$ twice, 24 hours apart in humans), 2) half of this dose (equivalent to $6 \mathrm{mg}$ ) or 3) vehicle. We report reference values for S100B protein in the serum and different brain regions in both genders at 1,2 and 21 days after birth. Interestingly, S100B concentration showed a time-dependent and brain region-specific pattern of expression. At P1, S100B was higher in the serum of males compared to females. In addition, we show that both doses of betamethasone decreased $\mathrm{S} 100 \mathrm{~B}$ concentration in the serum of males at $\mathrm{P} 1$, whereas in the hippocampus it was reduced by the clinically-equivalent dose only. This suggests that lowering the dose of antenatal betamethasone may be less detrimental for brain maturation and therefore we reiterate the need for clinical trials with a low dose regimen.

\section{INTRODUCTION}

Antenatal glucocorticoids are widely used in premature infants where they reduce neonatal morbidity and mortality (2000; Pine and Charney 2002; Crowley 2003; Fraser, Walls et al. 2004). However, maternal administration of betamethasone has also been shown to cause a wide range of side effects, including higher thyroxine levels in the first postnatal week (Martin, Van Marter et al. 2005) and neurodevelopmental abnormalities at 2 years of age (Spinillo, Viazzo et al. 2004). In animal models, antenatal glucocorticoids cause a reduction of DNA content (Velazquez and Romano 1987) and cell proliferation rate within the brain (Scheepens, van de Waarenburg et al. 2003), reduced brain growth (Huang, Beazley et al. 1999), loss of synaptic density (Antonow-Schlorke, Schwab et al. 2003), optic nerve hypomyelination (Dunlop, Archer et al. 1997) and an increased susceptibility of cerebellar neurons to oxidative cell death (Fuentes-Pardo, Hernandez-Falcon et al. 1990). 
Little is known about the mechanisms responsible for these effects. Glucocorticoids have been shown to be able to reduce neurotrophins levels, e.g. BDNF (Schaaf, Hoetelmans et al. 1997) and S100B. The latter neurotrophic factor is decreased both in the hippocampus, as shown by an in vitro study by Niu and colleagues (1997) and in the urine of infants antenatally treated with a single course of betamethasone (Gazzolo, Kornacka et al. 2003). A lower concentration of the neurotrophic factor S100B might partly explain the detrimental effects of antenatal steroids on brain development. Moreover, S100B levels in biological fluids have been suggested to be a useful and non-invasive tool to monitor brain development and damage (Michetti and Gazzolo 2002). At nanomolar concentrations S100B exerts neurotrophic effects, whereas it is known to be toxic at micromolar concentrations (Donato 2001).

The aims of this investigation were (i) to measure the physiological expression of $\mathrm{S100B}$ during development in different brain regions and the serum of the rat; (ii) to investigate the effects of a single course of antenatal betamethasone on S100B concentration by using a clinically-equivalent dose and half of this dose.

\section{METHODS}

The animal study was approved by the Animal Ethics Board of the University of Maastricht, The Netherlands.

\section{Animals}

Pregnant Fisher 344 dams (Charles River, The Netherlands; pregnancy confirmed by vaginal plug) were delivered to our animal facility on day 14 of gestation (Embryonic day 14, E14). The animals were kept under standard laboratory conditions with 12 hours light/12 hours dark and standard rat chow and water ad libitum. The rats were randomly assigned to an experimental group treated either with a clinically-equivalent dose (CD) of antenatal betamethasone, half of this dose (HD), or vehicle (as specified in the next paragraph). 
All the dams delivered on E22, that corresponds to pup age P0 (Postnatal day 0). Pups were analyzed at P1, P2 and P21. For the age between P2 and P21 the pups were all cross-fostered to dams that had given birth on the same day and had received vehicle-only treatment (to prevent a possible betamethasone effect on maternal behavior influencing the results) (Brabham, Phelka et al. 2000). All the litters were kept at 8 pups per dam.

\section{Betamethasone treatment}

Dams were injected in the nape of the neck with either 170 or $85 \mu \mathrm{g} \mathrm{kg}^{-1}$ betamethasone (Celestone Chronodose, Schering-Plough, The Netherlands, diluted in its own buffer to a concentration of $230 \mu \mathrm{g} \mathrm{ml}^{-1}$ ) or vehicle-only on E20. With an approximate weight in the pregnant woman of $80 \mathrm{~kg}$, the $170 \mu \mathrm{g}$ $\mathrm{kg}^{-1}$ dose represents a clinically-equivalent dose (CD), corresponding to a single course of $12 \mathrm{mg}$ betamethasone twice, 24 hours apart in the woman. Moreover, we used half of this dose ( $\left.\mathrm{HD}, 85 \mathrm{\mu g} \mathrm{kg}^{-1}\right)$ to investigate whether a lower dose would induce fewer and/or less severe side effects on brain development.

As betamethasone plasma half-life is threefold shorter in the rat compared to the human (Tamvakopoulos, Neugebauer et al. 2002), the second injection occurred at an interval of 8 hours, namely at 9 AM and 5 PM, equivalent to an interval of four half-lives.

An additional crucial difference between humans and rats consists of the timing of brain development. With respect to this issue, a term human infant is equivalent to a 10- to 14-day-old rat (Romijn, Hofman et al. 1991; Clancy, Darlington et al. 2001), therefore betamethasone injection at E20 in the rat occurs when neural development is comparable to very preterm human infants.

\section{S100B measurements}

To study the effects of betamethasone on cell proliferation rate within the brain (Bruschettini, Steinbusch et al. 2005) the pups were injected (s.c.) with 5 $\mu \mathrm{Ci}$ (g body weight) ${ }^{-1}{ }^{3} \mathrm{H}$-thymidine $\left({ }^{3} \mathrm{H}\right.$-Thy) on their assigned day (either $\mathrm{P} 1$, $\mathrm{P} 2$, or $\mathrm{P} 21)$. Following ${ }^{3} \mathrm{H}$-Thy infusion the pups were kept in a pediatric 
incubator at $34^{\circ} \mathrm{C}$ and $75 \%$ humidity. The pups were sacrificed $1 \mathrm{~h}$ later by decapitation and subsequently blood samples were collected from the trunk.

The brains were dissected using the method of Wagner et al. (Wagner, Black et al. 1999) by the same investigator (M.B.) to preserve consistency. The following brain regions were isolated: the olfactory bulbs, the cerebellum, the hippocampus, the sub ventricular zone. The rest of the brain was also taken for analysis. The 5 regions were snap frozen in liquid nitrogen and subsequently stored at $-70^{\circ} \mathrm{C}$. The dissected brain regions were then placed in $350 \mu \mathrm{l}$ (olfactory bulbs and hippocampus) or $1 \mathrm{ml}$ (cerebellum, sub ventricular zone, and rest) pre-cooled lysis buffer containing: $137 \mathrm{mM} \mathrm{NaCl}$, $20 \mathrm{mM}$ Tris- $\mathrm{HCl}$ (pH 8.0), 1 \% NP-40, $10 \%$ glycerol and a protease inhibitor tablet (Roche, The Netherlands). The samples were then homogenized using a Bead Beater (Biospec products, USA) for $3 \times 30 \mathrm{sec}$, cooling the samples on ice between runs to avoid overheating brain damage.

The S100B protein concentration was measured by use of a commercially available S100B immunoluminometric assay (Liaison, BykSangtec Diagnostica, Germany). This is a two-step sandwich assay based on paramagnetic particles as solid phase and a tracer antibody labelled with an isoluminol derivative. Data reduction is done with a master curve after recalibration with two calibrators.

Since extracellular S100B corresponds to less than $1 \%$ of the intracellular content (Tramontina, Conte et al. 2002), our data on S100B content in the brain homogenates reflect essentially the intracellular concentration of the protein. Values are expressed as $\mu \mathrm{g} \mathrm{S100B/mg}$ brain weight (brain regions) or $\mu \mathrm{g} \mathrm{S} 100 \mathrm{~B} / \mathrm{L}$ (serum).

\section{Statistics}

We used a standardized and randomized block design for these studies whereby each dam had one pup of each sex used at each time point to remove any litter effects (Chapman and Stern 1978). Each experimental group consisted of approximately 8 pups per gender per time point. Data were evaluated with a three-way ANOVA (experimental group $x$ gender $x$ age). Effects were analyzed in more detail with least significant difference (LSD) 
post hoc tests $(P<0.05)$. All statistics were carried out using SPSS software version 11.5 (SPSS Inc, USA). Data are presented as means \pm S.E.M.

\section{RESULTS}

\section{Developmental expression of S100B}

Brain region and serum $\mathrm{S100B}$ concentrations over time are displayed in Table 1 (vehicle-treated only). An overall effect of age was observed in all the brain regions $(P<0.001)$ except for the olfactory bulbs (Fig. 1). Serum S100B levels in vehicle-treated animals were higher at P21 $(1.03 \mathrm{ng} / \mathrm{ml})$ than at P1 $(0.83 \mathrm{ng} / \mathrm{ml})$ and $\mathrm{P} 2(0.69 \mathrm{ng} / \mathrm{ml})(\mathrm{P}<0.01)$. Post-hoc analysis revealed that this age effect was present in female pups only $(P<0.01)$. In addition, serum S100B levels were lower in female compared to male pups at P1 $(-45.5 \%$, $\mathrm{P}=0.022)$.

Table 1. Developmental expression of $\mathrm{S} 100 \mathrm{~B}$ concentrations in the brain and serum in vehicle-treated animals only. An overall effect of age was observed in both genders in the serum $(P<0.01)$ and in all the brain regions $(P<0.001)$ except for the olfactory bulbs. At $P 1$, serum $\mathrm{S} 100 \mathrm{~B}$ levels were lower in females as compared to males $(\mathrm{P}=0.022)$.

Values, expressed as $\mu \mathrm{g} \mathrm{S} 100 \mathrm{~B} / \mathrm{mg}$ brain weight (brain regions) or $\mu \mathrm{g} \mathrm{S} 100 \mathrm{~B} / \mathrm{L}$ (serum), represent means $\pm \mathrm{SEM} ;{ }^{\#}=$ female $<$ male.

\begin{tabular}{|c|c|c|c|c|}
\hline Region & Gender & P1 & P2 & P21 \\
\hline \multirow{2}{*}{ Hippocampus } & Male & $5.07 \pm 0.49$ & $9.12 \pm 1.65$ & $12.33 \pm 0.46$ \\
\cline { 2 - 5 } & Female & $5.25 \pm 0.83$ & $8.17 \pm 1.49$ & $12.86 \pm 0.94$ \\
\hline \multirow{2}{*}{ Cerebellum } & Male & $6.02 \pm 0.28$ & $6.50 \pm 0.66$ & $1.43 \pm 0.10$ \\
\cline { 2 - 5 } & Female & $5.19 \pm 0.62$ & $6.23 \pm 0.33$ & $1.53 \pm 0.10$ \\
\hline \multirow{2}{*}{ Olfactory bulbs } & Male & $7.00 \pm 3.27$ & $12.93 \pm 4.45$ & $8.73 \pm 1.75$ \\
\cline { 2 - 5 } & Female & $8.37 \pm 3.77$ & $12.11 \pm 3.75$ & $11.62 \pm 1.48$ \\
\hline \multirow{2}{*}{ Subventricular zone } & Male & $0.36 \pm 0.04$ & $0.63 \pm 0.02$ & $0.46 \pm 0.03$ \\
\cline { 2 - 5 } & Female & $0.34 \pm 0.06$ & $0.48 \pm 0.07$ & $0.49 \pm 0.05$ \\
\hline \multirow{2}{*}{ Rest of the brain } & Male & $1.84 \pm 0.21$ & $1.43 \pm 0.27$ & $0.42 \pm 0.03$ \\
\cline { 2 - 5 } & Female & $1.76 \pm 0.28$ & $2.14 \pm 0.14$ & $0.43 \pm 0.03$ \\
\hline \multirow{2}{*}{ Whole brain } & Male & $1.62 \pm 0.16$ & $1.98 \pm 0.34$ & $1.36 \pm 0.10$ \\
\cline { 2 - 5 } & Female & $1.46 \pm 0.28$ & $2.13 \pm 0.18$ & $1.59 \pm 0.12$ \\
\hline \multirow{2}{*}{ Serum } & Male & $1.14 \pm 0.33 \#$ & $0.63 \pm 0.17$ & $1.15 \pm 0.07$ \\
\cline { 2 - 5 } & Female & $0.52 \pm 0.14$ & $0.75 \pm 0.19$ & $0.91 \pm 0.27$ \\
\hline
\end{tabular}




\section{Developmental expression}

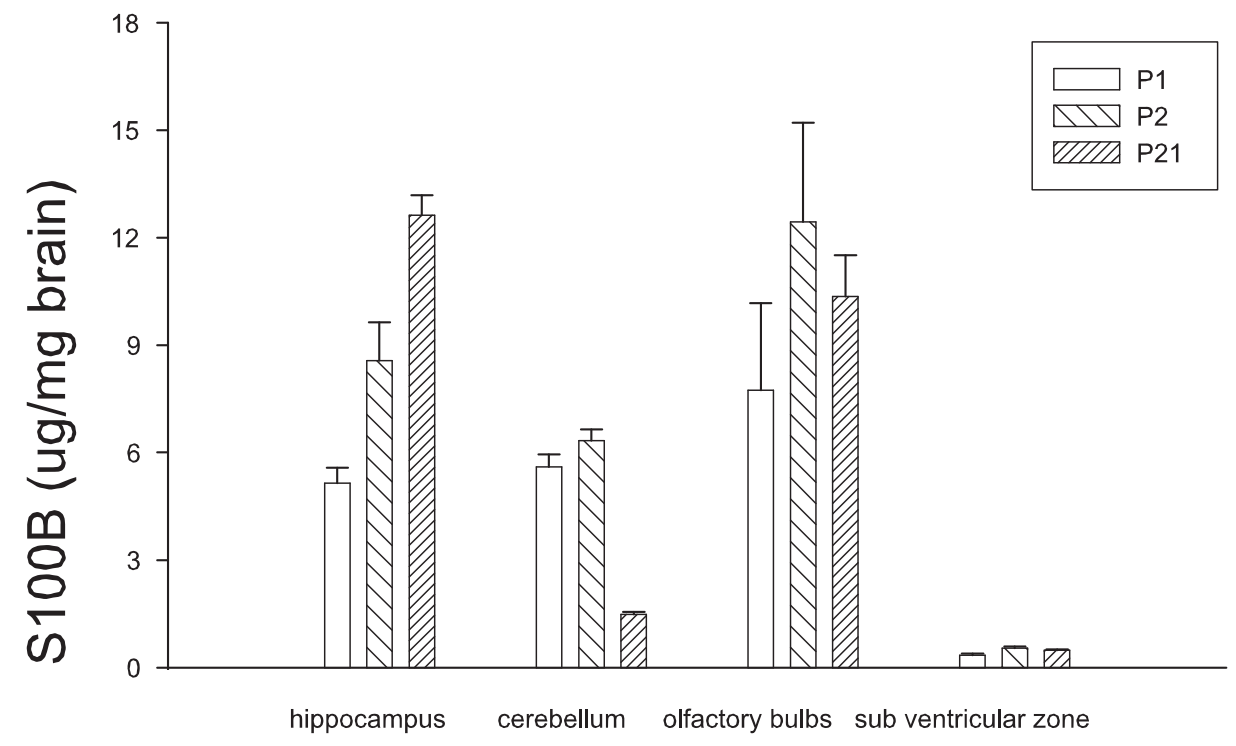

Figure 1. Developmental expression of $\mathrm{S} 100 \mathrm{~B}$ concentrations within different brain regions, males and females combined. There was an overall effect of age in all the brain regions $(\mathrm{P}<0.001)$ except for the olfactory bulbs.

Bars, expressed as $\mu \mathrm{g} \mathrm{S100B/mg} \mathrm{brain} \mathrm{weight,} \mathrm{represent} \mathrm{means} \pm \mathrm{SEM} ; \dagger=$ overtime trend $(\mathrm{P}<0.05)$.

\section{Effects of antenatal betamethasone on S100B concentration}

Fig. 2 shows that $C D$ reduced $\mathrm{S} 100 \mathrm{~B}$ at $\mathrm{P} 1$ in the hippocampus in males ($40.9 \%, P=0.042$ ), but not in females. In all the other brain regions, $S 100 \mathrm{~B}$ was not affected (data not shown). In the serum, S100B was reduced by both $C D$ (-60.0\%, $\mathrm{P}=0.016)$ and $\mathrm{HD}(-53.5, \mathrm{P}=0.030)$ in males at $\mathrm{P} 1$ (Fig. 3). 


\section{Hippocampus - P1}

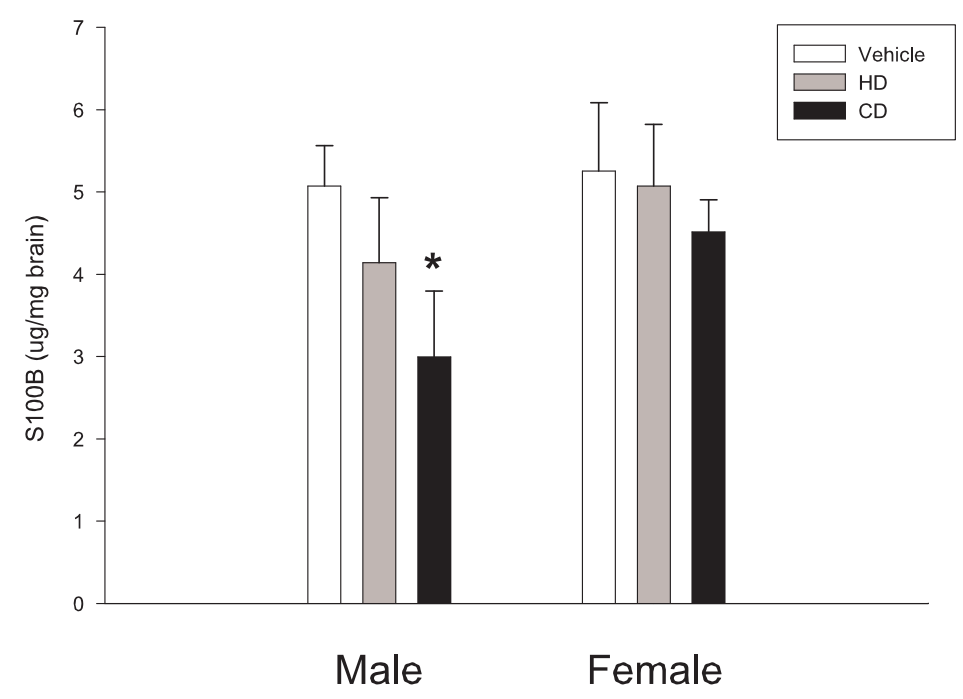

Figure 2. Effects of antenatal betamethasone on hippocampal S100B concentrations at P1. In males, $\mathrm{S} 100 \mathrm{~B}$ was reduced by $\mathrm{CD}$ only $(\mathrm{P}=0.042)$. Bars, expressed as $\mu \mathrm{g} \mathrm{S} 100 \mathrm{~B} / \mathrm{mg}$ brain weight, represent means $\pm \mathrm{SEM} ;{ }^{*}=\mathrm{P}<0.05$ compared to Vehicle.

\section{Serum - P1}

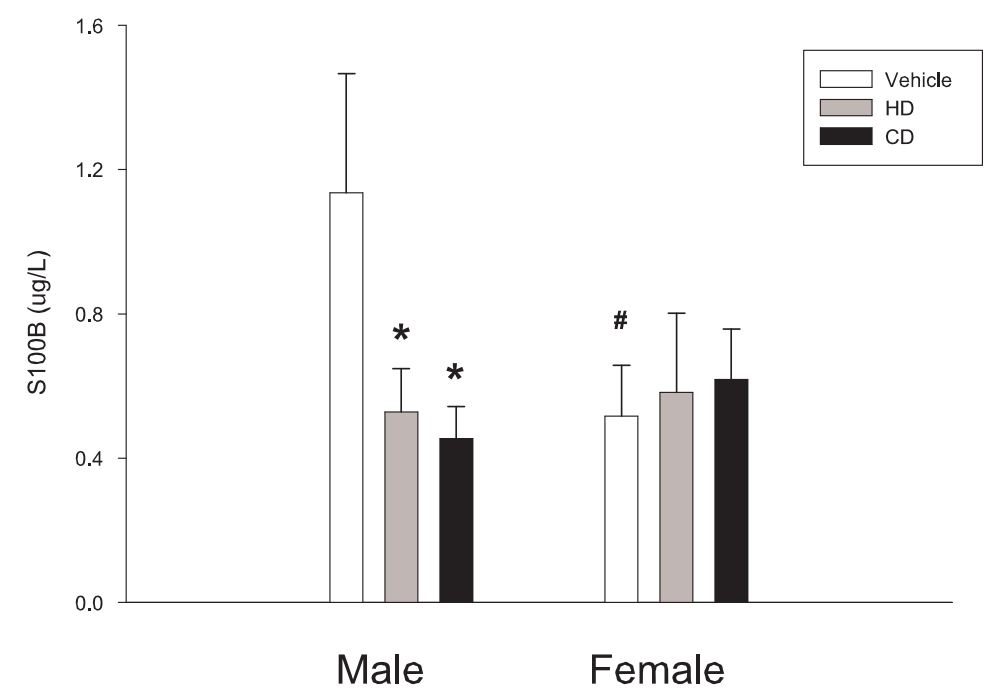

Figure 3. Effects of antenatal betamethasone on serum $\mathrm{S} 100 \mathrm{~B}$ concentrations at $\mathrm{P} 1$. In vehicle-treated pups, $\mathrm{S} 100 \mathrm{~B}$ levels were lower in females as compared to males $(\mathrm{P}=0.022)$. In males, $\mathrm{S} 100 \mathrm{~B}$ was reduced by both $\mathrm{CD}(\mathrm{P}=0.016)$ and $\mathrm{HD}(\mathrm{P}=0.030)$. Bars, expressed as $\mu \mathrm{g} \mathrm{S100B/L}$, represent means $\pm \mathrm{SEM} ;{ }^{*}=\mathrm{P}<0.05$ compared to Vehicle, ${ }^{\#}=$ female $<$ male. 


\section{DISCUSSION}

We report for the first time that a single course of antenatal betamethasone produced a decrease of $\mathrm{S} 100 \mathrm{~B}$ concentrations in both the hippocampus and serum of male rats. The effect on the hippocampus was dose-dependent, as this region was not affected by the administration of betamethasone at half dose regime.

\section{Developmental expression of S100B}

The present study offers reference values for S100B protein in the serum and different brain regions in both genders, showing the developmental expression of $\mathrm{S} 100 \mathrm{~B}$ at key time points. Neural development in the rat at $\mathrm{P} 1$ is equivalent to very preterm human infants, whereas P21 corresponds to full term neonates (Romijn, Hofman et al. 1991; Clancy, Darlington et al. 2001). Our time points therefore cover the whole perinatal period, revealing essential details about brain development. Interestingly, S100B concentration shows a time-dependent and brain region-specific pattern of expression in the rat brain (Pinto, Gottfried et al. 2000; Tramontina, Conte et al. 2002).

Our results confirm that developmental changes occur in S100B expression, i.e., showing the highest concentrations in the cerebellum and sub ventricular zone at $\mathrm{P} 2$ and in the hippocampus at P21, whereas there was no trend over time in the olfactory bulbs. Consistently, a developmental increase in S100B concentration has been reported in the human hippocampus, where S100B is already present at 15 weeks' of gestation and increases as from 25 weeks, as was measured immunocytochemically in aborted fetuses (Tiu, Chan et al. 2000).

With respect to S100B circulating concentrations, which have been shown to be a reliable marker for human brain development (Michetti and Gazzolo 2002), we further report that S100B showed the highest levels at $\mathrm{P} 21$. Moreover, S100B was higher in males compared to females at P1. Of note, gender differences in S100B blood levels have been reported in investigations in both human infants (Gazzolo, Vinesi et al. 2000) and children (Gazzolo, Michetti et al. 2003). These findings in blood might reflect different patterns of brain development in the two sexes (MacLusky and Naftolin 1981), since the protein is mainly concentrated in the CNS. In addition, gender- 
specific differences have been described also in the effect of S100B overexpression on anxiety-related behavior, i.e., transgenic female mice showed hyperactivity in the open field test, whereas behavior is not affected in transgenic males (Gerlai and Roder 1993).

\section{Effects of antenatal betamethasone on S100B concentration}

The neurotrophic factor S100B can be reduced by antenatal insults, e.g., exposure to ethanol (Eriksen, Gillespie et al. 2000) or cocaine (Akbari, Whitaker-Azmitia et al. 1994), thus leading to impaired development of serotonergic neurons (Tajuddin and Druse 1999). Interestingly, the stimulation of astrocyte $5-\mathrm{HT} 1_{A}$ receptors might modulate the release of $\mathrm{S} 100 \mathrm{~B}$ protein (Azmitia, Griffin et al. 1992), that is one of the most potent trophic factors for serotonergic neurons (Azmitia, Dolan et al. 1990; Liu and Lauder 1992). Moreover, acute predator stress has been shown to induce changes in $5100 \mathrm{~B}$ levels in CSF, possibly due to a response to the serotonin effects on astrocytes, although S100B concentration within hippocampus was not affected (Margis, Zanatto et al. 2004).

Steroids are known to reduce neurotrophic factors concentrations, e.g., BDNF in the rat hippocampus (Schaaf, Hoetelmans et al. 1997). In this study, glucocorticoids effects on S100B concentration were investigated in the brain and serum. Two dose regimens of antenatal betamethasone were used: a clinically-equivalent dose $(C D)$ to attempt to replicate the clinical situation of $12 \mathrm{mg}$ twice, 24 hours apart; and half of this dose (HD), equivalent to $6 \mathrm{mg}$ twice, 24 hours apart, according to the idea that it may be an equally effective but less toxic treatment (Jobe and Soll 2004).

We report that $C D$ decreased $S 100 B$ at $P 1$ in males only, whereas HD did not. In contrast to males, females were not affected by betamethasone at any time point. Of note, this gender difference was found in the same animals regarding cell proliferation within the hippocampus (Bruschettini, Steinbusch et al. 2005). In addition, antenatal betamethasone is known to affect hippocampal mineralocorticoid receptors protein expression more in males than in females (Owen and Matthews 2003). However, it can not be excluded that a decrease in S100B content might have occurred earlier or within a 
smaller time window in female compared to males, reflecting gender differences as discussed in the previous paragraph.

Even though at P2 no differences were observed between the different groups, the decreased S100B concentration at P1 might have permanent consequences on brain development. Of note, S100B protein infusion has been recently reported to enhance neurogenesis within the hippocampus in the rat (Kleindienst, McGinn et al. 2005). Thus, a decreased S100B concentration at P1 might imply essential alterations in the cell proliferation within the hippocampus. Moreover, a loss of S100B appears to be detrimental on brain development, as reported in S100B transgenic animal models, where knock-out mice displayed chronic gliosis (Chang, Ariah et al. 2005). In addition, cell damage within the hippocampus due to corticosteroid exposure may induce cognitive deficits (Sousa and Almeida 2002). A lower amount of S100B might be caused by decreased translation or stability of S100B mRNA, or an increased turnover of S100B protein (Eriksen, Gillespie et al. 2000). Interestingly, S100B mRNA levels in hippocampal astrocytes have been reported to be increased 24 hours after corticosteroid exposure and decreased at 96 and 120 hours, whereas S100B protein concentrations were reduced 96 and 120 hours but not increased at 24 hours (Niu, Hinkle et al. 1997). Though the present investigation differs remarkably with the in vitro study by Niu et al, the time interval between corticosteroid treatment and the induced reduction in $\mathrm{S} 100 \mathrm{~B}$ protein concentration was comparable in both studies.

The region-specific effect of betamethasone on the hippocampus in S100B expression might be explained by the high concentration of glucocorticoid receptors in hippocampal pyramidal neurons, particularly in the CA2 and CA3 regions, where the glucocorticoid receptors concentration is higher than in other cerebral regions (McEwen, Wallach et al. 1974). Consistently, the hippocampus appears to be highly vulnerable to exposure to exogenous glucocorticoids, resulting in acute neural degeneration (Uno, Eisele et al. 1994) and loss of synaptic density (Colberg, Antonow-Schlorke et al. 2004). Moreover, this hippocampal susceptibility was found also in our previous investigation using the same brain homogenates, where antenatal betamethasone affected cell proliferation in this region. Of note, hippocampal 
dysfunction has been associated with both cognitive and emotional impairment (see review by Bannerman et al (2004)).

We further report lower S100B levels in the serum of treated male pups at P1. However, the lower circulating levels did not reflect an overall decreased concentration in the CNS, since S100B amount in the whole brain was not affected by betamethasone. This discrepancy might be explained by the specific permeability rates through brain-blood barrier (BBB) in different brain regions (Ilbay, Sahin et al. 2003). In addition, it should be noted that data on experimental models (Stonestreet, Petersson et al. 1999) and in humans (Ment, Oh et al. 1995) support the hypothesis that antenatal glucocorticoids administration decreases BBB permeability. In line with this, the lower circulating S100B levels that we report might be due to an effect of steroids on BBB, independent of any direct brain damage, causing a lower rate of the protein spreading from the brain to the blood. Of note, $\mathrm{S100B}$ is highly expressed by perivascular astrocytes and appears in blood seconds after BBB opening (Marchi, Fazio et al. 2003). In this respect, S100B might constitute a useful tool to detect modifications in BBB permeability (Kapural, Krizanac-Bengez et al. 2002; Marchi, Rasmussen et al. 2003; Watson, Shirreffs et al. 2005), which plays an important role in cerebrovascular function.

\section{Conclusion}

Hippocampal S100B content was reduced by a clinically-equivalent dose equivalent to $12 \mathrm{mg}$ twice, 24 hours apart of antenatal betamethasone in males, but not by half of this dose. Interestingly, the effect of betamethasone on brain cell proliferation also showed a dose-dependent pattern, as investigated in the same hippocampal homogenates (Bruschettini, Steinbusch et al. 2005).

We speculate that lowering the dose of antenatal steroids may be less detrimental for brain maturation and we therefore reiterate the need for clinical trials with a low dose regimen. 


\section{Acknowledgement}

The authors would like to thank Mrs. Rosanna Frulio for her assistance and expert advice with the immunoluminometric assay.

\section{REFERENCES}

(2000). "Antenatal corticosteroids revisited: repeat courses." NIH Consens Statement 17(2): 1-18.

Akbari, H. M., P. M. Whitaker-Azmitia, et al. (1994). "Prenatal cocaine decreases the trophic factor S-100 beta and induced microcephaly: reversal by postnatal 5-HT1A receptor agonist." Neurosci Lett 170(1): 141-4.

Antonow-Schlorke, I., M. Schwab, et al. (2003). "Glucocorticoid exposure at the dose used clinically alters cytoskeletal proteins and presynaptic terminals in the fetal baboon brain." J Physiol 547(Pt 1): 117-23.

Azmitia, E. C., K. Dolan, et al. (1990). "S-100B but not NGF, EGF, insulin or calmodulin is a CNS serotonergic growth factor." Brain Res 516(2): 354-6.

Azmitia, E. C., W. S. Griffin, et al. (1992). "S100 beta and serotonin: a possible astrocyticneuronal link to neuropathology of Alzheimer's disease." Prog Brain Res 94: 459-73.

Bannerman, D. M., J. N. Rawlins, et al. (2004). "Regional dissociations within the hippocampus--memory and anxiety." Neurosci Biobehav Rev 28(3): 273-83.

Brabham, T., A. Phelka, et al. (2000). "Effects of prenatal dexamethasone on spatial learning and response to stress is influenced by maternal factors." Am J Physiol Regul Integr Comp Physiol 279(5): R1899-909.

Bruschettini, M., H. W. M. Steinbusch, et al. (2005). "The effects of single course of prenatal betamethasone on fetal growth, $\mathrm{S100B}$ protein and cell proliferation in the brain and in the lungs." PAS 2005; 57:3219.

Chang, M. S., L. M. Ariah, et al. (2005). "Chronic gliosis induced by loss of S-100B: knockout mice have enhanced GFAP-immunoreactivity but blunted response to a serotonin challenge." Brain Res 1031(1): 1-9.

Chapman, R. H. and J. M. Stern (1978). "Maternal stress and pituitary-adrenal manipulations during pregnancy in rats: effects on morphology and sexual behavior of male offspring." J Comp Physiol Psychol 92(6): 1074-83.

Clancy, B., R. B. Darlington, et al. (2001). "Translating developmental time across mammalian species." Neuroscience 105(1): 7-17.

Colberg, C., I. Antonow-Schlorke, et al. (2004). "Recovery of glucocorticoid-related loss of

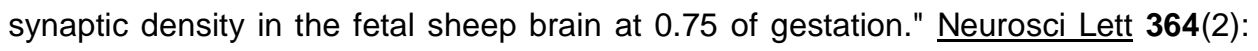
130-4.

Crowley, P. (2003). "Antenatal corticosteroids--current thinking." Bjog 110 Suppl 20: 77-8. 
Donato, R. (2001). "S100: a multigenic family of calcium-modulated proteins of the EF-hand type with intracellular and extracellular functional roles." Int J Biochem Cell Biol 33(7): 637-68.

Dunlop, S. A., M. A. Archer, et al. (1997). "Repeated prenatal corticosteroids delay myelination in the ovine central nervous system." J Matern Fetal Med 6(6): 309-13.

Eriksen, J. L., R. A. Gillespie, et al. (2000). "Effects of in utero ethanol exposure and maternal treatment with a $5-\mathrm{HT}(1 \mathrm{~A})$ agonist on S100B-containing glial cells." Brain Res Dev Brain Res 121(2): 133-43.

Fraser, J., M. Walls, et al. (2004). "Respiratory complications of preterm birth." Bmj 329(7472): 962-5.

Fuentes-Pardo, B., J. Hernandez-Falcon, et al. (1990). "Role of corticosterone on the development of passive electrical properties of cultured chick embryo neurons." $\underline{\mathrm{J} \text { Dev }}$ Physiol 13(2): 67-73.

Gazzolo, D., M. Kornacka, et al. (2003). "Maternal glucocorticoid supplementation and S100B protein concentrations in cord blood and urine of preterm infants." Clin Chem 49(7): 1215-8.

Gazzolo, D., F. Michetti, et al. (2003). "Pediatric concentrations of S100B protein in blood: age- and sex-related changes." Clin Chem 49(6 Pt 1): 967-70.

Gazzolo, D., P. Vinesi, et al. (2000). "S100B protein concentrations in cord blood: correlations with gestational age in term and preterm deliveries." Clin Chem 46(7): 998-1000.

Gerlai, R. and J. Roder (1993). "Female specific hyperactivity in $\mathrm{S} 100$ beta transgenic mice does not habituate in open-field." Behav Brain Res 59(1-2): 119-24.

Huang, W. L., L. D. Beazley, et al. (1999). "Effect of corticosteroids on brain growth in fetal sheep." Obstet Gynecol 94(2): 213-8.

Ilbay, G., D. Sahin, et al. (2003). "Changes in blood-brain barrier permeability during hot water-induced seizures in rats." Neurol Sci 24(4): 232-5.

Jobe, A. H. and R. F. Soll (2004). "Choice and dose of corticosteroid for antenatal treatments." Am J Obstet Gynecol 190(4): 878-81.

Kapural, M., L. Krizanac-Bengez, et al. (2002). "Serum S-100beta as a possible marker of blood-brain barrier disruption." Brain Res 940(1-2): 102-4.

Kleindienst, A., M. J. McGinn, et al. (2005). "Enhanced Hippocampal Neurogenesis by Intraventricular S100B Infusion Is Associated with Improved Cognitive Recovery after Traumatic Brain Injury." J Neurotrauma 22(6): 645-55.

Liu, J. P. and J. M. Lauder (1992). "S-100 beta and insulin-like growth factor-II differentially regulate growth of developing serotonin and dopamine neurons in vitro." $\underline{\mathrm{J} N e u r o s c i}$ Res 33(2): 248-56.

MacLusky, N. J. and F. Naftolin (1981). "Sexual differentiation of the central nervous system." Science 211(4488): 1294-302.

Marchi, N., V. Fazio, et al. (2003). "Serum transthyretin monomer as a possible marker of blood-to-CSF barrier disruption." J Neurosci 23(5): 1949-55. 
Marchi, N., P. Rasmussen, et al. (2003). "Peripheral markers of brain damage and bloodbrain barrier dysfunction." Restor Neurol Neurosci 21(3-4): 109-21.

Margis, R., V. C. Zanatto, et al. (2004). "Changes in S100B cerebrospinal fluid levels of rats subjected to predator stress." Brain Res 1028(2): 213-8.

Martin, C. R., L. J. Van Marter, et al. (2005). "Antenatal Glucocorticoids Increase Early Total Thyroxine Levels in Premature Infants." Biol Neonate 87(4): 273-280.

McEwen, B. S., G. Wallach, et al. (1974). "Corticosterone binding to hippocampus: immediate and delayed influences of the absence of adrenal secretion." Brain Res 70(2): 32134.

Ment, L. R., W. Oh, et al. (1995). "Antenatal steroids, delivery mode, and intraventricular hemorrhage in preterm infants." Am J Obstet Gynecol 172(3): 795-800.

Michetti, F. and D. Gazzolo (2002). "S100B protein in biological fluids: a tool for perinatal medicine." Clin Chem 48(12): 2097-104.

Niu, H., D. A. Hinkle, et al. (1997). "Dexamethasone regulates basic fibroblast growth factor, nerve growth factor and S100beta expression in cultured hippocampal astrocytes." Brain Res Mol Brain Res 51(1-2): 97-105.

Owen, D. and S. G. Matthews (2003). "Glucocorticoids and sex-dependent development of brain glucocorticoid and mineralocorticoid receptors." Endocrinology 144(7): 2775-84.

Pine, D. and D. Charney (2002). "Children, stress, and sensitization: an integration of basic and clinical research on emotion?" Biol Psychiatry 52(8): 773.

Pinto, S. S., C. Gottfried, et al. (2000). "Immunocontent and secretion of S100B in astrocyte cultures from different brain regions in relation to morphology." FEBS Lett 486(3): 203-7.

Romijn, H. J., M. A. Hofman, et al. (1991). "At what age is the developing cerebral cortex of the rat comparable to that of the full-term newborn human baby?" Early Hum Dev 26(1): 61-7.

Schaaf, M. J., R. W. Hoetelmans, et al. (1997). "Corticosterone regulates expression of BDNF and trkB but not NT-3 and trkC mRNA in the rat hippocampus." $\underline{\mathrm{J} \text { Neurosci Res }}$ 48(4): 334-41.

Scheepens, A., D. van den Hove, et al. (2003). "A single course of prenatal betamethasone in the rat alters postnatal brain cell proliferation but not apoptosis." $\underline{J}$ Physiol 552(Pt 1): 163-75.

Sousa, N. and O. F. Almeida (2002). "Corticosteroids: sculptors of the hippocampal formation." Rev Neurosci 13(1): 59-84.

Spinillo, A., F. Viazzo, et al. (2004). "Two-year infant neurodevelopmental outcome after single or multiple antenatal courses of corticosteroids to prevent complications of prematurity." Am J Obstet Gynecol 191(1): 217-24.

Stonestreet, B. S., K. H. Petersson, et al. (1999). "Antenatal steroids decrease blood-brain barrier permeability in the ovine fetus." Am J Physiol 276(2 Pt 2): R283-9. 
Tajuddin, N. F. and M. J. Druse (1999). "In utero ethanol exposure decreased the density of serotonin neurons. Maternal ipsapirone treatment exerted a protective effect." Brain Res Dev Brain Res 117(1): 91-7.

Tamvakopoulos, C. S., J. M. Neugebauer, et al. (2002). "Analysis of betamethasone in rat plasma using automated solid-phase extraction coupled with liquid chromatographytandem mass spectrometry. Determination of plasma concentrations in rat following oral and intravenous administration." $\underline{\mathrm{J} \text { Chromatogr B Analyt Technol Biomed Life Sci }}$ 776(2): 161-8.

Tiu, S. C., W. Y. Chan, et al. (2000). "Differential expression of S100B and S100A6(1) in the human fetal and aged cerebral cortex." Brain Res Dev Brain Res 119(2): 159-68.

Tramontina, F., S. Conte, et al. (2002). "Developmental changes in S100B content in brain tissue, cerebrospinal fluid, and astrocyte cultures of rats." Cell Mol Neurobiol 22(3): 373-8.

Uno, H., S. Eisele, et al. (1994). "Neurotoxicity of glucocorticoids in the primate brain." Horm Behav 28(4): 336-48.

Velazquez, P. N. and M. C. Romano (1987). "Corticosterone therapy during gestation: effects on the development of rat cerebellum." Int J Dev Neurosci 5(3): 189-94.

Wagner, J. P., I. B. Black, et al. (1999). "Stimulation of neonatal and adult brain neurogenesis by subcutaneous injection of basic fibroblast growth factor." J Neurosci 19(14): 600616.

Watson, P., S. M. Shirreffs, et al. (2005). "Blood-brain barrier integrity may be threatened by exercise in a warm environment." Am J Physiol Regul Integr Comp Physiol. 




\title{
Chapter 4
}

\section{Lowering the dose of antenatal steroids: the effects of a single course of betamethasone on somatic growth and brain cell proliferation in the rat}

\author{
Bruschettini $\mathbf{M}^{1 / 2 / 3}$, Van den Hove DLA ${ }^{1 / 2}$, \\ Gazzolo $D^{3 / 4}$, Steinbusch HWM ${ }^{1}$, Blanco $\mathrm{CE}^{2}$
}

1 Department of Psychiatry and Neuropsychology, Division of Neuroscience, European Graduate School of Neuroscience (EURON) \&

2 Department of Pediatrics, Research Institute Growth and Development (GROW), Faculty of Medicine, University of Maastricht, 6200 MD Maastricht, The Netherlands 3 G. Gaslini Children's Hospital, University of Genoa, Genoa, Italy 4 Maternal Fetal and Neonatal Health, G Garibaldi Hospital, 95100 Catania, Italy

American Journal of Obstetrics and Gynecology 194(5):1341-6 (2006) 


\section{Abstract}

We investigated the effects of a single course of antenatal betamethasone on neonatal somatic and brain development. On day 20 of gestation pregnant rats were injected with either with $170 \mu \mathrm{g} \mathrm{kg}^{-1}$ body weight of betamethasone ("clinically-equivalent dose", equivalent to $12 \mathrm{mg}$ twice, 24 hours apart) or half this dose or vehicle. Pups (8-11 animals per experimental group per timepoint per gender) were analyzed at 1 (P1), 2 and 21 days after birth. We report that betamethasone induced a significant dose-dependent decrease of somatic measurements in both genders. At P1 cell proliferation was affected by the "clinically-equivalent dose" only in the subventricular zone in both genders and in the hippocampus in males. In summary, we show for the first time that a lower dose (equivalent to $6 \mathrm{mg}$ ) induces fewer and less severe effects on somatic growth, whereas it does not affect cell proliferation within the brain.

\section{INTRODUCTION}

Betamethasone is used in the prevention of respiratory distress syndrome (RDS) in premature babies born between 24 and 34 weeks of gestation. It is known to accelerate maturation of the fetal lungs (Ballard and Ballard 1995) and reduce neonatal morbidity and mortality (2000). However, a single course of antenatal corticosteroids has been shown to decrease birth weight and head circumference at birth (Thorp, Jones et al. 2002) and to affect cortisol response to stressors (Davis, Townsend et al. 2004). Others, however, found no growth restriction following antenatal glucocorticoids (Vermillion, Soper et al. 1999).

In animal models, antenatal glucocorticoids have been shown to cause a wide range of side effects, e.g., reduction of cerebellar DNA content (Velazquez and Romano 1987) and loss of synaptic density in the frontal neocortex, caudate putamen and hippocampus (Colberg, Antonow-Schlorke et al. 2004). In many of these animal studies the doses used had been higher than in the human situation. Recently, our group showed that a single course of antenatal betamethasone (equivalent to 2 injections, 12 hours apart, in the clinic) impaired growth and cell proliferation within the brain of the rat 
(Scheepens, van de Waarenburg et al. 2003). In the present study, our primary aim was to investigate the effects of both a standard, clinicallyequivalent dose (CD) of antenatal betamethasone (equivalent to 2 injections 24 hours apart) and of half this dose (HD), focusing on somatic growth and neonatal brain development.

\section{METHODS}

The animal studies described here were all approved by the Animal Ethics Board of the University of Maastricht, The Netherlands.

Pregnant Fisher 344 dams (Charles River, The Netherlands; pregnancy confirmed by vaginal plug) were delivered to our animal facility on day 14 of gestation (G14). The animals were kept under standard laboratory conditions with 12 hours light/12 hours dark and standard rat chow and water ad libitum. The rats were randomly assigned to an experimental group treated either with a clinically-equivalent dose (CD) of antenatal betamethasone, half this dose (HD), or vehicle (as specified in the next paragraph). Pups were examined at P(ostnatal day)1, P2 and P21. For the age between P2 and P21 the pups were all cross-fostered to dams that had given birth on the same day and had received vehicle-only treatment (to prevent a possible betamethasone effect on maternal behavior influencing the results). All the litters were kept at 8 pups per dam and the pups were kept with the mother until P21, i.e., they were not weaned.

\section{Betamethasone treatment}

As mentioned previously, women threatening to deliver preterm are administered $12 \mathrm{mg}$ betamethasone (Celestone Chronodose, ScheringPlough, The Netherlands) twice 24 hours, apart. With an average weight of around $80 \mathrm{~kg}$, this corresponds to $170 \mu \mathrm{g} \mathrm{kg}^{-1}$ betamethasone with a plasma half-life of $6 \mathrm{~h}$ in the human. The second injection therefore occurs at an interval of four half-lives. Within the rat, betamethasone has a plasma half-life of $2 \mathrm{~h}$ (Tamvakopoulos, Neugebauer et al. 2002). An equivalent dose for a rat would then be two doses of $170 \mu \mathrm{g} \mathrm{kg}^{-1}, 8 \mathrm{~h}$ apart. 
Betamethasone was diluted in its own buffer to a concentration of 230 $\mu \mathrm{g} \mathrm{ml}^{-1}$. The animals were injected in the nape of the neck with a clinicallyequivalent dose (CD) of antenatal betamethasone $\left(170 \mathrm{\mu g} \mathrm{kg}^{-1}\right.$, corresponding to $12 \mathrm{mg}$ in the clinic), half this dose (HD; $85 \mu_{\mathrm{g} \mathrm{kg}}{ }^{-1}$, corresponding to $6 \mathrm{mg}$ in the clinic) or vehicle-only at 9 AM and 5 PM on G20. All the animals delivered on G22 which was designated as pup age P0. For birth measurements (within 90 mins after delivery) the pups were sexed, weighed and had their crown-tail (C-T) length and head diameter measured by using a digital vernier caliper. All measurements were taken by the same investigator (M.B., blind to the experimental group) to preserve consistency. During this time the dam was never left without any pups and the pups were not separated from their dam for more than $3 \mathrm{~min}$ to minimize the stress levels experienced.

\section{Tracer method}

We used the ${ }^{3} \mathrm{H}$-thymidine $\left({ }^{3} \mathrm{H}\right.$-Thy) incorporation method to calculate mitotic activity in specific brain regions at 1,2 and 21 days after birth by measuring the DNA synthetic rate, which is proportional to the rate of cell proliferation.

On their assigned day (P1, P2, or P21) the pups were injected with 5 $\mu \mathrm{Ci}$ (g body weight) ${ }^{-1}{ }^{3} \mathrm{H}$-Thy $\left(25 \mathrm{Ci} \mathrm{mmol}^{-1}, 1 \mathrm{~m} \mathrm{Ci} \mathrm{ml}^{-1}\right.$ in $0.9 \% \mathrm{NaCl}$, Amersham Pharmacia Biotech, The Netherlands) by subcutaneous injection into the nape of the neck. Following ${ }^{3} \mathrm{H}$-Thy infusion the pups were kept at $34{ }^{\circ} \mathrm{C}$ and $75 \%$ humidity in a pediatric incubator. Exactly $1 \mathrm{~h}$ later the pups were killed by decapitation and the brains were quickly removed and dissected. We isolated 4 brain regions: the olfactory bulbs (OB); the cerebellum; the entire hippocampal formation; and the sub ventricular zone (SVZ) contained within the rostral forebrain. The microdissected regions were then weighed, quickly snap frozen in liquid nitrogen and stored at $-70^{\circ} \mathrm{C}$. Subsequently the heart, lungs, liver and kidneys were taken and weighed. All dissections were performed by the same investigator (M.B.) to preserve consistency.

The dissected brain regions were then placed in $350 \mu$ lolfactory bulbs and hippocampus) or $1 \mathrm{ml}$ (cerebellum and SVZ) pre-cooled lysis buffer containing: $137 \mathrm{mM} \mathrm{NaCl}, 20 \mathrm{mM}$ Tris- $\mathrm{HCl}(\mathrm{pH} 8.0), 1 \%$ NP-40, $10 \%$ glycerol and a complete protease inhibitor tablet (Roche, The Netherlands). 
The samples were then homogenized using a Bead Beater (Biospec products, OK, USA) for $3 \times 30 \mathrm{sec}$, each time with cooling of the samples on ice between runs.

An aliquot of the homogenate was used to extract all cellular DNA using a standard tri-chloracetic acid precipitation protocol in order to determine the amount of ${ }^{3} \mathrm{H}$-Thy which was taken up by proliferating cells and incorporated into newly synthesized DNA during the $1 \mathrm{~h}$ exposure. Essentially, this measure represents the product of the number of $S$ phase cells within the sample times the DNA synthetic rate of these $S$ phase cells. However, the incorporation of ${ }^{3} \mathrm{H}$-Thy into DNA depends on the amount of precursor taken up by the tissue. As a consequence, differences in e.g. blood flow between experimental groups might result in differences in ${ }^{3} \mathrm{H}$-Thy incorporation which does not reflect differences in mitotic activity. For this purpose, another aliquot of the homogenate was used to measure total amount of radioactivity in the tissue fraction.

Homogenized tissue and DNA samples were solubilised in $1 \mathrm{ml}$ Soluene-350 (Packard Instruments, The Netherlands) at $50^{\circ} \mathrm{C}$ for 3-24 hours or until the samples were completely dissolved. Afterward $5 \mathrm{ml}$ of Hionic-Flour scintillation cocktail (Packard Instruments, The Netherlands) was added and the samples were read for $20 \mathrm{~min}$ on a Wallac WinSpectral 1414 liquid scintillation counter. The appropriate quench curves were produced using tritium standards added to homogenized brain tissue and subsequently used to convert the sample counts per min to disintegrations per min (d.p.m.). The d.p.m. measures were corrected for the wet weight of tissue $(\mathrm{mg})$ and the percentage of ${ }^{3} \mathrm{H}$-Thy incorporated into DNA relative to the total amount of radioactivity counted in the appropriate tissue of each brain region was calculated.

\section{Statistics}

We used a standardized and randomized block design for these studies whereby each dam had one pup of each sex used at each time point to remove any litter effects. Differences in litter size were tested using a one-way analysis of Variance (ANOVA). Mortality was tested using the Fisher exact test. In all other cases, the data were evaluated with a three-way ANOVA 
(experimental group $\mathrm{x}$ gender $\mathrm{x}$ age). Effects were analyzed in more detail with least significant difference (LSD) post hoc tests $(P<0.05)$. All statistics were carried out using SPSS software version 11.5 (SPSS Inc, USA). Data are presented as means \pm standard error of the mean (S.E.M.).

\section{RESULTS}

\section{Litter size and pre-weaning mortality}

No significant differences between groups were observed in litter size (7.6, 7.3 and 9.3 pups/litter for vehicle, HD, and CD, respectively), and pre-weaning mortality (6 pups died: 2 vehicle and 4 CD).

\section{Body weight, head diameter and C-T length at birth}

Somatic measurements at birth (P0) are shown in Fig. 1.

Birth measures as compared to Vehicle (100\%) group

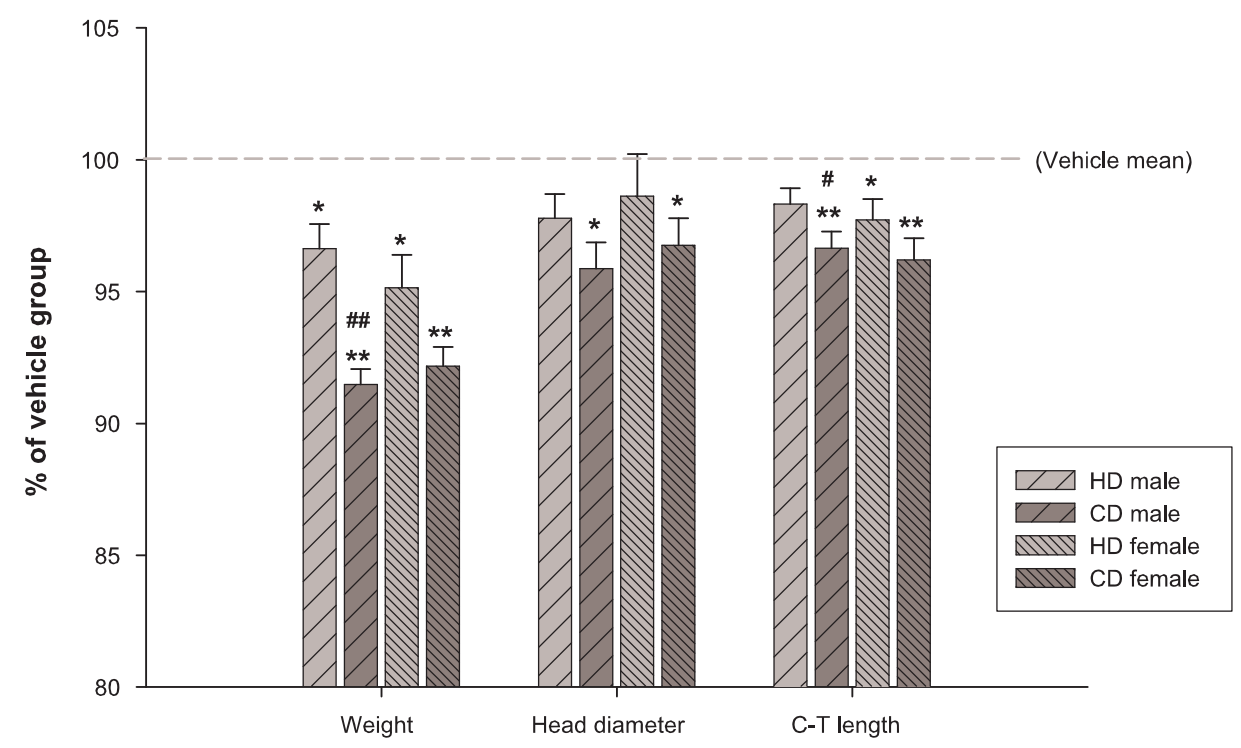

Figure 1. Overview of birth measures - Values are expressed as percentage of the vehicle group and represent Mean $+\mathrm{SEM}, \mathrm{n}=20$ to 34 /experimental group/gender, ${ }^{*}=\mathrm{P}<0.05$ compared to Vehicle group, ${ }^{*}=\mathrm{P}<0.001$ compared to Vehicle group, ${ }^{\#}=\mathrm{P}<0.05$ compared to $\mathrm{HD},{ }^{\# \#}=\mathrm{P}<0.001$ compared to HD; LSD test. 
Antenatal betamethasone caused a significant dose-dependent body weight reduction in the CD (-8.0\%) and HD (-3.1\%) groups. The same effect was found for C-T length (CD: $-3.6 \%$, HD: $-1.6 \%$ ).

CD decreased head diameter at birth compared to both vehicle $(-3.7 \%)$ and HD, whereas head diameter was not significantly reduced by HD. There was a tendency towards a significant effect of HD on head diameter in males $(P=0.098)$.

Female pups were smaller compared to males on all parameters (body weight and $\mathrm{C}-\mathrm{T}$ length: $\mathrm{P}<0.01$; head diameter $\mathrm{P}<0.05)$.

\section{Postnatal somatic growth and relative organ weights}

Somatic measures were affected in the treated pups only on P1 (see Table I), with a gender-independent reduction in body weight $(\mathrm{P}<0.01)$ and in C-T length $(P=0.041)$, and a tendency for head diameter $(P=0.083)$. Post hoc analysis showed that HD did not cause growth retardation, but CD did (body weight: $P=0.028$; $C-T$ length: $P=0.011$; head diameter: $P=0.032$ ). $C-T$ length measures were not taken at P21 and gender by experimental group interactions were not found for any somatic measure at any time point.

Overall, relative weights of both the liver and lungs (\% of body weight) were reduced by the betamethasone treatment, whereas heart and kidneys were not affected (data not shown).

\section{Brain and brain region weights}

CD betamethasone treatment decreased brain weight in both male $(-8.7 \%$, $\mathrm{P}=0.039)$ and female $(-6.2 \%, \mathrm{P}=0.026)$ offspring at $\mathrm{P} 1$, but not relative weight (brain/body weight ratio).

CD caused an overall decrease in both cerebellum $(-11.2 \%, P<0.01)$ and hippocampus $(-5.4 \%, P=0.041)$ weight compared to the HD. At P1, SVZ weight was decreased by both doses compared to vehicle in the males (CD: $21.7 \%, P<0.01$; HD: $-15.1 \%, P=0.016)$. At $P 2$, cerebellar weight was reduced only by $\mathrm{HD}(-17.4 \%, \mathrm{P}=0.037)$, whereas hippocampal weight by CD $(-22.3 \%$, $\mathrm{P}=0.021)$ in the female. 
Table 1. Effect of antenatal betamethasone on somatic growth parameters, (mean \pm SEM, $\mathrm{n}=8$ to $11 /$ gender/experimental group/timepoint). Data were evaluated with a three-way ANOVA (experimental group $\mathrm{x}$ gender $\mathrm{x}$ age). Symbols used for post hoc differences: ${ }^{*}=$ $\mathrm{P}<0.05$ compared to Vehicle, ${ }^{* *}=\mathrm{P}<0.01$ compared to vehicle. $\mathrm{CD}$ : clinically-equivalent dose (corresponding to $12 \mathrm{mg}$ twice 24 hours apart in the woman), HD: half CD (corresponding to 6 $\mathrm{mg})$.

\begin{tabular}{|c|c|c|c|c|c|}
\hline \multicolumn{2}{|c|}{ Gender and Dose } & Parameter & $\underline{\mathbf{P 1}}$ & $\mathbf{P 2}$ & P21 \\
\hline Male & Vehicle & \multirow{8}{*}{$\begin{array}{c}\text { Body weight } \\
\text { (g) }\end{array}$} & $5.2 \pm 0.1$ & $5.8 \pm 0.2$ & $26.1 \pm 0.6$ \\
\hline & $\mathrm{HD}$ & & $4.8 \pm 0.1$ & $5.3 \pm 0.1$ & $25.8 \pm 0.4$ \\
\hline & $\mathrm{CD}$ & & $4.6 \pm 0.1 * *$ & $5.5 \pm 0.2$ & $24.6 \pm 0.6$ \\
\hline \multirow[t]{3}{*}{ Female } & Vehicle & & $4.9 \pm 0.1$ & $5.4 \pm 0.1$ & $24.6 \pm 1.1$ \\
\hline & $\mathrm{HD}$ & & $4.7 \pm 0.2$ & $5.2 \pm 0.2$ & $24.3 \pm 0.4$ \\
\hline & $\mathrm{CD}$ & & $4.5 \pm 0.1 *$ & $5.0 \pm 0.2$ & $25.0 \pm 0.9$ \\
\hline \multicolumn{2}{|c|}{ Dose effect } & & $\mathrm{P}=0.004$ & $\mathrm{NS}$ & \\
\hline \multicolumn{2}{|c|}{ Gender effect } & & $\mathrm{P}=0.059$ & $\mathrm{P}=0.04$ & \\
\hline \multirow[t]{3}{*}{ Male } & Vehicle & \multirow{8}{*}{$\begin{array}{l}\text { Head diameter } \\
(\mathrm{mm})\end{array}$} & $10.4 \pm 0.2$ & $11.1 \pm 0.3$ & $15.6 \pm 0.3$ \\
\hline & $\mathrm{HD}$ & & $10.2 \pm 0.2$ & $10.4 \pm 0.2$ & $15.6 \pm 0.2$ \\
\hline & $\mathrm{CD}$ & & $10.1 \pm 0.2$ & $10.6 \pm 0.3$ & $15.3 \pm 0.2$ \\
\hline \multirow[t]{3}{*}{ Female } & Vehicle & & $10.3 \pm 0.1$ & $10.6 \pm 0.3$ & $15.4 \pm 0.3$ \\
\hline & $\mathrm{HD}$ & & $10.1 \pm 0.3$ & $10.3 \pm 0.2$ & $15.2 \pm 0.2$ \\
\hline & $\mathrm{CD}$ & & $10.3 \pm 0.2$ & $10.2 \pm 0.3$ & $15.3 \pm 0.3$ \\
\hline \multirow{2}{*}{\multicolumn{2}{|c|}{$\begin{array}{l}\text { Dose effect } \\
\text { Gender effect }\end{array}$}} & & $\mathrm{P}=0.04$ & $\mathrm{NS}$ & \\
\hline & & & $\mathrm{NS}$ & NS & \\
\hline \multirow[t]{3}{*}{ Male } & Vehicle & \multirow{8}{*}{$\begin{array}{l}\text { C-T length } \\
(\mathrm{mm})\end{array}$} & $44.7 \pm 0.6$ & $47.6 \pm 0.7$ & \\
\hline & $\mathrm{HD}$ & & $43.9 \pm 0.5$ & $46.0 \pm 0.5$ & \\
\hline & $\mathrm{CD}$ & & $42.3 \pm 0.5 *$ & $46.9 \pm 1.0$ & \\
\hline Female & Vehicle & & $43.9 \pm 0.5$ & $46.5 \pm 0.6$ & \\
\hline & $\mathrm{HD}$ & & $43.0 \pm 0.6$ & $46.3 \pm 0.6$ & \\
\hline & $\mathrm{CD}$ & & $42.9 \pm 1.0$ & $44.8 \pm 1.0$ & \\
\hline \multicolumn{2}{|c|}{ Dose effect } & & NS & NS & \\
\hline \multicolumn{2}{|c|}{ Gender effect } & & NS & NS & \\
\hline
\end{tabular}

\section{Cell proliferation within the brain}

At $\mathrm{P} 1$, cell proliferation within the hippocampus was higher in $C D$ than in HD in the males (+64.2\%, P=0.028) (see Fig. 2). In the SVZ, the CD group showed a higher degree of cell proliferation compared to vehicle $(+55.4 \%$, $\mathrm{P}=0.007)$ and in males compared to both $\mathrm{HD}(+82.8 \%, \mathrm{P}=0.011)$ and vehicle $(+71.2 \%, P=0.019)$. In the rest of the brain, cell proliferation was higher in CD compared to both $\mathrm{HD}(+38.2 \%, \mathrm{P}=0.002)$ and vehicle $(+34.3 \%, \mathrm{P}=0.002)$. 
At P2, cell proliferation was not significantly changed by betamethasone. At P21, CD increased cell proliferation within the hippocampus compared to vehicle in the females $(+4.3 \%, P=0.050)$ (data not shown). In the cerebellum, CD increased cell proliferation compared to vehicle $(+12.5 \%, P=0.012)$ and $\mathrm{HD}$ (males only; $+11.0 \%, \mathrm{P}=0.014)$.

Cell proliferation was lower in males in $\mathrm{OB}(-6.2 \%, \mathrm{P}=0.039)$, hippocampus (-16.1\%, $\mathrm{P}<0.01)$ and SVZ $(-12.9 \%, \mathrm{P}<0.01)$.

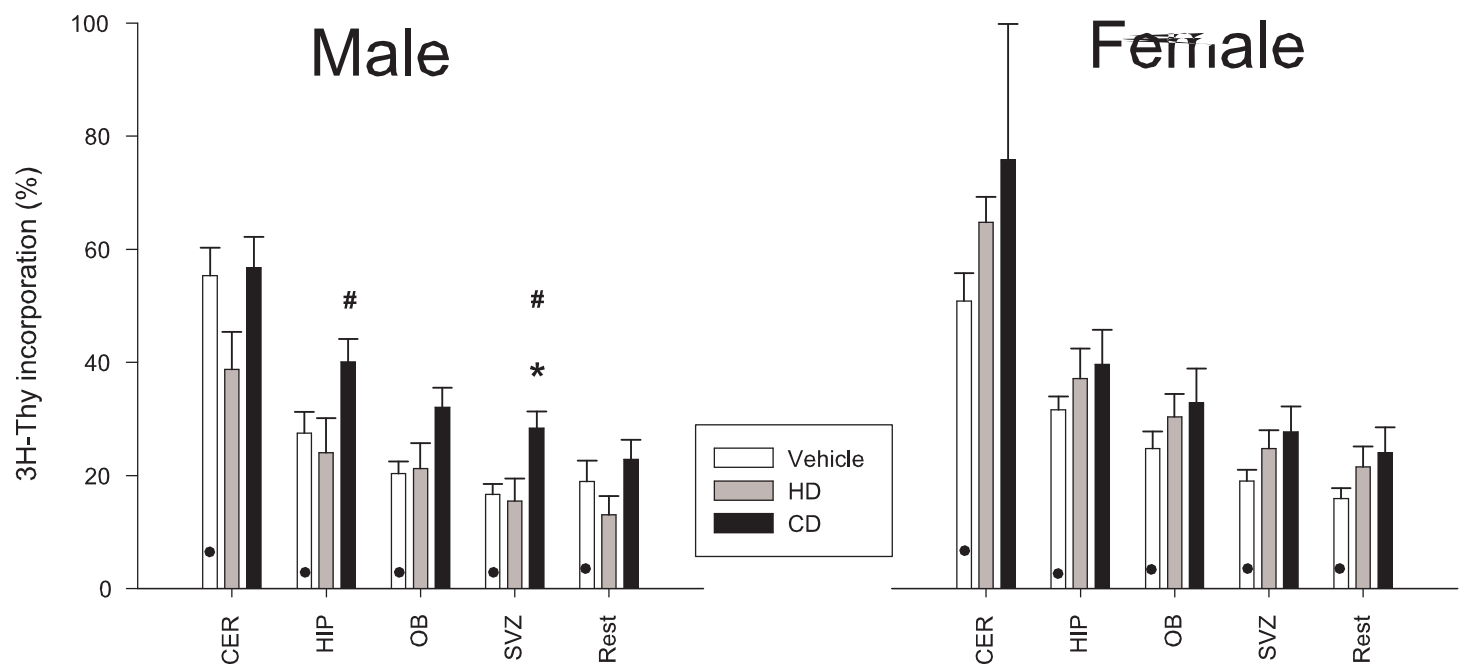

Figure 2. Brain cell proliferation at P1- Graph showing the effect of antenatal betamethasone on postnatal brain cell proliferation (expressed as $\%{ }^{3} \mathrm{H}$-Thy incorporation; see text) in males and females. CD betamethasone treatment caused significant increases in proliferation in HIP and SVZ at P1, whereas HD did not affect cell proliferation in any of the brain regions. For comparison, brain cell proliferation levels at P21 in the vehicle group are depicted by dots.

Values represent Mean $+\mathrm{SEM}, \mathrm{n}=11$ to 17 /experimental group/time; ${ }^{*}=\mathrm{P}<0.05$ compared to Vehicle, ${ }^{\#}=\mathrm{P}<0.05$ compared to HD.

CER: Cerebellum; HIP: Hippocampus; OB: Olfactory bulbs; SVZ: Subventricular zone; Rest: rest of the brain. 


\section{COMMENT}

The present study shows that a lower dose of antenatal betamethasone results in less severe effects on somatic growth while it does not seem to impair cell proliferation within the neonatal brain.

Recently, our group showed that a single course of betamethasone consisting of two injections $4 \mathrm{~h}$ apart in the rat, corresponding to two injections 12 hours apart in the human, induced somatic growth retardation and a reduction of brain cell proliferation (Scheepens, van de Waarenburg et al. 2003). In the present study we chose a $8 \mathrm{~h}$ interval, since the Consensus Statement (2000) recommends a 24 hours interval between the two injections. In addition, we used lower doses: a clinically-equivalent dose (CD) to attempt to replicate the clinical situation of $12 \mathrm{mg}$ twice, 24 hours apart; and half this dose (HD). This latter dose regimen (6 mg twice, 24 hours apart) has been recently suggested, since it may be an equally effective but less toxic treatment (Jobe and Soll 2004).

A major concern with regard to the interpretation of animal studies examining the effects of glucocorticoids on neural measures is the comparison of the stage of brain development. Estimates of the rat equivalent age of a term human in respect of neural development have ranged from 7 to 24 days of postnatal age with a general consensus that a 10- to 14-day-old rat is equivalent to a term human (Clancy, Darlington et al. 2001). Term rats are therefore equivalent to very preterm human infants, i.e., those who would receive antenatal glucocorticoids in utero. A further concern is the comparison of neural cell cycle times. Ideally, we would expose the rat brain cells to betamethasone for the same number of cell cycles as occurs in the human. Fortuitously, the cell cycle time of the developing primate (and presumably human) brain is three to five times longer than that of a rodent fetus in the third trimester of pregnancy, which is similar to the difference in betamethasone half-life (Kornack and Rakic 1998).

\section{Somatic growth}

The effects of glucocorticoids in pregnancy on growth restriction are not clear in human studies (Vermillion, Soper et al. 1999; Thorp, Jones et al. 2002). We show that a single course of antenatal betamethasone retards somatic 
growth. This might be the result of a reduction of circulating levels of growth factors such as growth hormone $(\mathrm{GH})$ and therefore insulin-like growth factor 1 (IGF-1), which are known to stimulate growth (Price, Stiles et al. 1992). Interestingly, at birth HD affected body weight and C-T length less than CD. Moreover, head diameter was not decreased by HD at birth. Of note, the fast growth catch-up observed after betamethasone treatment does not necessarily imply a better outcome. On the contrary, a reduced birth size followed by a fast weight gain has been associated with an additional risk of disease in later life.(Gluckman and Hanson 2004)

In our previous investigation there was no difference in the degree of growth retardation caused by the two doses (except for C-T length in males) (Scheepens, van de Waarenburg et al. 2003). This discrepancy may be due to the lower dose now been used, revealing the presence of a ceiling effect in terms of growth retardation. The longer interval between the two injections may be an alternative explanation, resulting in a lower peak concentration of betamethasone in both the dam and fetus. Obviously, a combination of these two factors, i.e., lower dose and longer injection interval, is also a possible explanation. In line with this finding, HD does not produce a reduction in head diameter, as observed in human neonates following a single course of betamethasone (Thorp, Jones et al. 2002). Of note, a reduced head diameter at birth has been associated with learning problems in school-age children (Stathis, O'Callaghan et al. 1999).

The milder effects found in the present study were also visible in the postnatal growth of the pups, characterized by a prompt catch-up, with a reduction in weight and $\mathrm{C}-\mathrm{T}$ length only by $\mathrm{CD}$ at $\mathrm{P} 1$, and no differences after P1. However, a rapid postnatal weight gain may increase the incidence of coronary heart disease in adult life (Gluckman and Hanson 2004).

Taken together, these findings suggest that lowering the dose of antenatal betamethasone may result in fewer and less severe effects on somatic growth.

\section{Cell proliferation within the neonatal brain}

It is known that glucocorticoids are essential for maturation in the developing CNS, where they play a pivotal role in the remodeling of axons and dendrites, 
and in cell survival (Meyer 1983). Antenatal glucocorticoids administration, however, has been shown to be able to suppress the proliferation of cells derived from the hippocampus of rat embryos (Yu, Lee et al. 2004), possibly permanently altering brain structure (Matthews 2000).

In the present study, the effects of antenatal betamethasone on cell proliferation within the brain are less clear compared to those on somatic growth. Whereas HD did not affect cell proliferation, CD increased cell proliferation in the hippocampus (males only) and SVZ (both genders) at P1. This enhanced cell proliferation might be the rebound of a inhibition of cell proliferation prior to this time point, as observed in our previous investigation, which showed a catch-up in cell proliferation at P2 in all the brain regions studied after an initial decrease observed at P1 (Scheepens, van de Waarenburg et al. 2003). The timing of events, i.e., the inhibition of cell proliferation followed by a catch-up, might have shifted, with the inhibition now occurring before $\mathrm{P} 1$ due to the longer injection interval -i.e., lower concentration of betamethasone (see above)- used in the present study.

The altered proliferation rate that we report might involve a downregulation in the expression of neurotrophic factors, such as brainderived neurotrophic factor (BDNF) and S100B protein. BDNF is implicated in neuronal proliferation, migration and differentiation, whereas S100B protein promotes proliferation in both neuronal and glial cells (Michetti and Gazzolo 2002; Arcuri, Bianchi et al. 2004). Interestingly, these growth factors have been shown to be reduced by antenatal glucocorticoids in the rat hippocampus (Schaaf, Hoetelmans et al. 1997) and in the urine of human infants (Gazzolo, Kornacka et al. 2003). In particular, S100B protein is reduced in the hippocampus in males only (Bruschettini, Van den Hove et al. 2005), possibly reflecting different patterns of brain development in the two sexes (MacLusky and Naftolin 1981).

As described above regarding somatic growth, the present data suggest that also cell proliferation within the brain is spared by halving the dose of antenatal betamethasone. 


\section{Conclusion}

We show that a single course of antenatal betamethasone (equivalent to two injections, 24 hours apart) induces somatic growth retardation and affects cell proliferation within the hippocampus and SVZ. Moreover, we show for the first time that a lower dose (equivalent to $6 \mathrm{mg}$ twice, 24 hours apart) induces fewer and less severe effects on somatic growth, whereas it does not affect cell proliferation within the brain. This suggests that lowering the dose of antenatal betamethasone might indeed be effective in minimizing related sideeffects, once that clinical trials show its effectiveness for inducing lung maturation. We therefore reiterate the need for randomized clinical trials with a low dose regimen.

\section{REFERENCES}

(2000). "Antenatal corticosteroids revisited: repeat courses." NIH Consens Statement 17(2): 1-18.

Arcuri, C., R. Bianchi, et al. (2004). "S100B increases proliferation in PC12 neuronal cells and reduces their responsiveness to NGF via Akt activation." $\underline{\mathrm{J} \text { Biol }}$ Chem.

Ballard, P. L. and R. A. Ballard (1995). "Scientific basis and therapeutic regimens for use of antenatal glucocorticoids." Am J Obstet Gynecol 173(1): 254-62.

Bruschettini, M., D. L. A. Van den Hove, et al. (2005). "A single course of antenatal betamethasone reduces neurotrophic factor S100B concentration in the hippocampus and serum in the neonatal rat." Dev Brain Res in press.

Clancy, B., R. B. Darlington, et al. (2001). "Translating developmental time across mammalian species." Neuroscience 105(1): 7-17.

Colberg, C., I. Antonow-Schlorke, et al. (2004). "Recovery of glucocorticoid-related loss of synaptic density in the fetal sheep brain at 0.75 of gestation." Neurosci Lett 364(2): 130-4.

Davis, E. P., E. L. Townsend, et al. (2004). "Effects of prenatal betamethasone exposure on regulation of stress physiology in healthy premature infants." Psychoneuroendocrinology 29(8): 1028-36.

Gazzolo, D., M. Kornacka, et al. (2003). "Maternal glucocorticoid supplementation and S100B protein concentrations in cord blood and urine of preterm infants." Clin Chem 49(7): 1215-8.

Gluckman, P. D. and M. A. Hanson (2004). "Living with the past: evolution, development, and patterns of disease." Science 305(5691): 1733-6.

Jobe, A. H. and R. F. Soll (2004). "Choice and dose of corticosteroid for antenatal treatments." Am J Obstet Gynecol 190(4): 878-81.

Kornack, D. R. and P. Rakic (1998). "Changes in cell-cycle kinetics during the development and evolution of primate neocortex." Proc Natl Acad Sci U S A 95(3): 1242-6. 
MacLusky, N. J. and F. Naftolin (1981). "Sexual differentiation of the central nervous system." Science 211(4488): 1294-302.

Matthews, S. G. (2000). "Antenatal glucocorticoids and programming of the developing CNS." Pediatr Res 47(3): 291-300.

Meyer, J. S. (1983). "Early adrenalectomy stimulates subsequent growth and development of the rat brain." Exp Neurol 82(2): 432-46.

Michetti, F. and D. Gazzolo (2002). "S100B protein in biological fluids: a tool for perinatal medicine." Clin Chem 48(12): 2097-104.

Price, W. A., A. D. Stiles, et al. (1992). "Gene expression of insulin-like growth factors (IGFs), the type 1 IGF receptor, and IGF-binding proteins in dexamethasoneinduced fetal growth retardation." Endocrinology 130(3): 1424-32.

Schaaf, M. J., R. W. Hoetelmans, et al. (1997). "Corticosterone regulates expression of BDNF and trkB but not NT-3 and trkC mRNA in the rat hippocampus." $\underline{\mathrm{J}}$ Neurosci Res 48(4): 334-41.

Scheepens, A., D. van den Hove, et al. (2003). "A single course of prenatal betamethasone in the rat alters postnatal brain cell proliferation but not apoptosis." J Physiol 552(Pt 1): 163-75.

Stathis, S. L., M. O'Callaghan, et al. (1999). "Head circumference in ELBW babies is associated with learning difficulties and cognition but not ADHD in the schoolaged child." Dev Med Child Neurol 41(6): 375-80.

Tamvakopoulos, C. S., J. M. Neugebauer, et al. (2002). "Analysis of betamethasone in rat plasma using automated solid-phase extraction coupled with liquid chromatography-tandem mass spectrometry. Determination of plasma concentrations in rat following oral and intravenous administration." $\underline{J}$ Chromatogr B Analyt Technol Biomed Life Sci 776(2): 161-8.

Thorp, J. A., P. G. Jones, et al. (2002). "Does antenatal corticosteroid therapy affect birth weight and head circumference?" Obstet Gynecol 99(1): 101-8.

Velazquez, P. N. and M. C. Romano (1987). "Corticosterone therapy during gestation: effects on the development of rat cerebellum." Int J Dev Neurosci 5(3): 189-94.

Vermillion, S. T., D. E. Soper, et al. (1999). "Neonatal sepsis after betamethasone administration to patients with preterm premature rupture of membranes." $\underline{\mathrm{Am}}$ J Obstet Gynecol 181(2): 320-7.

Yu, I. T., S. H. Lee, et al. (2004). "Differential effects of corticosterone and dexamethasone on hippocampal neurogenesis in vitro." Biochem Biophys Res Commun 317(2): 484-90. 




\title{
Chapter 5
}

\section{Cognition- and anxiety-related behavior, synaptophysin- and MAP2- immunoreactivity in the adult rat treated with a single course of antenatal betamethasone}

\author{
Bruschettini $\mathbf{M}^{1 / 2 / 3 / 5}$, Van den Hove DLA ${ }^{1 / 2 / 5}$, Timmers $\mathbf{S}^{1}$, \\ Welling $\mathrm{M}^{1}$, Steinbusch $\mathrm{HP}^{1 / 2}$, Prickaerts $\mathrm{J}^{1 / 5}$, \\ Gazzolo $D^{3 / 4}$, Blanco $\mathrm{CE}^{2}$, Steinbusch $\mathrm{HWM}^{1 / 5}$
}

1 Department of Psychiatry and Neuropsychology, Division of Neuroscience, University of Maastricht, 6200 MD Maastricht, The Netherlands

2 Department of Pediatrics, Research Institute Growth and Development (GROW), Faculty of Medicine, University of Maastricht, 6200 MD Maastricht, The Netherlands

3 G. Gaslini Children's Hospital, University of Genoa, 16167 Genoa, Italy 4 Maternal Fetal and Neonatal Health, G Garibaldi Hospital, 95100 Catania, Italy 5 European Graduate School of Neuroscience (EURON), University of Maastricht, 6200 MD Maastricht, The Netherlands

Pediatr Res 60(1):50-4 (2006) 


\section{ABSTRACT}

We investigated the effects of a single course of antenatal betamethasone on cognition- and anxiety-related behavior and synaptophysin- and microtubuleassociated protein 2 (MAP2)- immunoreactivity in the adult rat hippocampus. On day 20 of gestation pregnant rats were injected with either 1) $170 \mathrm{\mu g} \mathrm{kg}^{-1}$ body weight of betamethasone ("clinically-equivalent dose", equivalent to 12 mg twice, 24 hours apart), 2) half this dose or 3) vehicle. Cognition- and anxiety- related behavior of the offspring was analyzed at an age of 5 months using the Morris water maze, object recognition task and open field test. Subsequently, synaptophysin- and MAP2- immunoreactivity were measured in the hippocampus. We report no detrimental effects of antenatal betamethasone on cognition- and anxiety-related behavior and synaptophysin-immunoreactivity in the adult rat. On the other hand, MAP2immunoreactivity was decreased by betamethasone in males, suggesting a permanent impairment in the hippocampus. Interestingly, the lower dose appears to have less influence in terms of growth restriction - known to be associated with an increased risk of disease in adulthood. Further research might elucidate whether the betamethasone effect on hippocampal neurons persists later in life and could affect the aging process increasing the risk for neuropathology of the adult.

\section{INTRODUCTION}

Antenatal glucocorticoids are widely used to prevent respiratory distress syndrome in case of threat of preterm delivery (2000). Though beneficial for lung maturation, this treatment causes a wide range of side effects in humans, including a reduction in weight and head circumference at birth (Thorp, Jones et al. 2002), and in impairment in both circulating glucocorticoid bioactivity (Kajantie, Raivio et al. 2004) and cortisol response to stressors (Davis, Townsend et al. 2004). Animal studies showed that antenatal glucocorticoids affect the hypothalamic-pituitary-adrenal (HPA) axis (Burlet, Fernette et al. 2005), an impairment of which has been linked to the development of anxiety and mood disorders (Pine and Charney 2002). Further, this treatment has been reported to reduce DNA content (Velazquez and Romano 1987), cell 
proliferation rate (Scheepens, van den Hove et al. 2003), synaptic density (Colberg, Antonow-Schlorke et al. 2004) and neurotrophic factor concentrations within the neonatal brain (Bruschettini, van den Hove et al. 2005) and induces neural degeneration within the developing hippocampus (Uno, Lohmiller et al. 1990). However, little is known about the consequences for later life, in particular the effects on cognition- and anxiety- related behavior are unclear (Rayburn, Christensen et al. 1998; Burlet, Fernette et al. 2005).

The presynaptic marker protein synaptophysin is a calcium binding protein that plays an important role in the generation and maintenance of small vesicle membranes and their interaction with cytoskeletal elements. Decrease in the synaptophysin-immunoreactivity $(\mathrm{IR})$ is associated with brain injury and aging, possibly reflecting functional disturbances of synaptic transmission (Martinez, Di Giacomo et al. 1997). The neuronal microtubuleassociated protein 2 (MAP2) determines stability and arrangement of neuronal microtubules. Loss of MAP2-IR after brain injury correlates with neuronal degeneration (Matesic and Lin 1994) and is associated with agerelated impairment of synaptic plasticity, cognition and memory functions. Interestingly, both synaptophysin-IR and MAP2-IR have been reported to be decreased in the hippocampus shortly after betamethasone injection (Antonow-Schlorke, Kuhn et al. 2001; Schwab, Antonow-Schlorke et al. 2001; Colberg, Antonow-Schlorke et al. 2004), whereas the long term consequences on these parameters are not known. As the hippocampus is involved in learning and memory processes, we aimed to evaluate the effects of a single course of antenatal betamethasone as used in clinical practice on (i) cognition- and anxiety- related behavior and (ii) synaptophysin-IR and MAP2-IR in the adult rat hippocampus.

\section{METHODS}

\subsection{Animals}

The animal study was approved by the Animal Ethics Board of the University of Maastricht, The Netherlands. 
Pregnant Fisher 344 dams (Charles River, The Netherlands; pregnancy confirmed by vaginal plug) were delivered to our animal facility on day 14 of gestation (Embryonic day 14, E14). The animals were kept under standard laboratory conditions with 12 hours light/12 hours dark and standard rat chow and water ad libitum.

Dams were injected subcutaneously twice 8 hours apart with either 170 or $85 \mu \mathrm{g} \mathrm{kg}^{-1}$ betamethasone, representing a clinically-equivalent dose $(C D$, corresponding to a single course of $12 \mathrm{mg}$ betamethasone twice, 24 hours apart in the woman) and half of this dose (HD), respectively, as described in a previous study(Bruschettini, van den Hove et al. 2005). Betamethasone injection occurred at E20 when brain development in the rat is comparable to very preterm human infants (Clancy, Darlington et al. 2001).

All the dams delivered on E22, corresponding to Postnatal day 0 (P0). Pups were labeled with paw cut and cross-fostered to dams that had given birth on the same day and had received vehicle-only treatment (to prevent a possible betamethasone effect on maternal behavior). All the litters were culled at 4 males and 4 females per dam, and the cages cleaned once a week. At P21 the pups were weaned and housed together (2 rats of the same gender and experimental group per cage) up to 5 months of age.

\subsection{Behavioral tests}

At an age of 5 months, rat performance was assessed in the Morris water maze (MWM; spatial memory), object recognition task (ORT; object memory) and open field test (OF; anxiety).

\subsection{Morris water maze (MWM).}

This test was conducted in a tank (diameter $1.53 \mathrm{~m}$ ) in which an escape platform (diameter $11 \mathrm{~cm}$ ) was submerged $(1.5 \mathrm{~cm}$ ) below the surface of the water. The rats started facing the wall of the tank from one of out four different, randomly chosen, starting positions, and were trained to find the invisible platform at a fixed invisible position in the water tank. Abundant spatial cues were provided by the furniture in the room and the presence of the experimenter. A video camera installed above the pool and attached to a PC which registered automatically (EthoVision Color Pro, Noldus, The 
Netherlands) the movements of a rat. A trial lasted until a rat had found the platform or until $60 \mathrm{~s}$ had elapsed. If a rat did not find the platform within $60 \mathrm{~s}$, it was placed on the platform for $3 \mathrm{~s}$ and then removed from the water tank. The rats were given two trials a day for four days and the time between subsequent trials was $10 \mathrm{~min}$. Escape latency was averaged per rat per session of two trials. A probe trial lasting $60 \mathrm{~s}$, during which the platform was removed from the water tank, was given after the last trial to reveal whether the animals had learned the position of the platform. In the probe trial all rats started, facing the wall of the tank, from the position opposite to the position of the removed platform.

\subsubsection{Objects Recognition Task (ORT).}

The rats were placed in the arena (diameter $83 \mathrm{~cm}$, height $40 \mathrm{~cm}$ ) facing the transparent segment of the wall, made of polyvinyl chloride. A testing session comprised two trials of 3 minutes each. During the first trial (T1) the apparatus contained two identical objects. After the first exploration period the rat was put back in its home cage for 1 hour and then was put back in the arena for the second trial (T2), but now with two dissimilar objects, a familiar one (the sample) and a new one. The duration of exploring each object in T1 and T2 was recorded manually with a personal computer. Exploration was defined as follows: directing the nose to the object at a distance of no more than $2 \mathrm{~cm}$ and/or touching the object with the nose. Sitting on the object was not considered as exploratory behavior. In order to avoid the presence of olfactory trails, the objects were always thoroughly cleaned. Moreover, each object was available in triplicate so that none of the two objects from the first trial had to be used as the familiar object in the second trial. In addition, all combinations and locations of objects were used in a balanced manner to reduce potential biases due to preferences for particular locations or objects. The light intensity (20 IX) was equal in the different parts of the apparatus. We used four different sets of objects that could not be displaced by a rat. Testing sessions were given on three consecutive days. The basic measures were the total exploration time of both objects during $T 1$ and $T 2, E 1$ and $E 2$, respectively. $A$ discrimination index, D2, was calculated as following: D2 = (exploration new object - exploration familiar object) / total exploration time. In addition, each 
experimental group was compared to the level expected by chance, i.e. equal amount of time spent on the new and the old object $(D 2=0)$. In the last day of test trial, a longer interval (4 hour) between T1 and T2 was used to discriminate cognition differences between experimental groups.

\section{Open Field (OF).}

This test was conducted in a square clear Plexiglas box $(100 \times 100 \times 30 \mathrm{~cm})$ with an open top and a dark floor, in a dimly illuminated room. The arena was subdivided into a central zone $(64 \times 64 \mathrm{~cm})$, corners $(16 \times 16 \mathrm{~cm})$ and walls $(16 \times 64 \mathrm{~cm})$. As a rat was placed in the centre of the OF, the position of the animals were registered automatically via a PC (EthoVision Color Pro, Noldus, The Netherlands) through a video camera installed $250 \mathrm{~cm}$ above the field for 5 minutes. Testing was carried out for 4 days, consisting of a single 5 min session per day.

\subsection{MAP2-IR and synaptophysin-IR}

At an age of 6 months rats were anaesthetized by a sodium pentobarbital injection (60 mg/kg, i.p.). Subsequently the brains of the rat were fixated by means of a transcardial perfusion with a flush of tyrode solution $\left(\mathrm{pH} 7.4,4^{\circ} \mathrm{C}\right)$ followed by a Somogyi fixation. After dissection of the brain, it was post fixed in the same fixating for two hours. Thereafter the brain segments were cryoprotected in 20\% sucrose in Tris - buffered saline (TBS, pH 7.4) for $48 \mathrm{~h}$ and afterwards they were frozen by means of $\mathrm{CO}_{2}$ and stored at $-75^{\circ} \mathrm{C}$ for further analysis. Sections of $30 \mu \mathrm{m}$ were cut with the cryostat at levels of the hippocampus (between $1.60 \mathrm{~mm}$ and $-5.80 \mathrm{~mm}$ from bregma) for synaptophysin and MAP2 staining. The serial brain slices of $30 \mu \mathrm{m}$ were stained with monoclonal antibodies against synaptophysin (mouse anti synaptophysin, 1: 2000, Chemicon International, Temecula) and MAP2 (monoclonal anti-MAP2 $(2 a+2 b)$, Clone AP -20, $1: 1000$, Sigma Chemical Company, St. Louis) by means of the $A B C$-technique. Before all antibody incubations, washing steps were carried out using subsequently TBS-T (10 $\mathrm{min})$, TBS (10 $\mathrm{min})$ and TBS-T (10 min). Next, the tissue slides were incubated with $5 \%$ Normal Donkey serum (NDS), to minimize the background reactivity. After administration of the primary antibody as mentioned above, 
the brain slices were kept overnight at $4^{\circ} \mathrm{C}$. Before the secondary biotinylated antibodies were added for an one hour incubation, the slices were repeatedly washed with TBS-T and TBS. Subsequently the brain slices were incubated with a preformed avidin- horseradish peroxidase complex for one hour. Immunostaining was developed by adding DAB solution to the tissue slides which resulted in a brown precipitate. To optimize the color development, the brain slices were washed with Tris- $\mathrm{HCl}$ before the administration of the DAB solution. The staining procedure was finished by washing the slices three times with TBS (10 min) and placing the brain slices on glass slides which are allowed to dry for 24 hours. Thereafter the slides are dehydrated in a $70 \%$ ethanol line followed by enclosing them with Pertex.

Quantification of the tissue staining was performed morphometrically by the same investigator who was blinded to the experimental protocol. Immunoreactivity (IR) of synaptophysin-IR and MAP2-IR was estimated within different layers of the hippocampus. The synaptophysin staining was examined in the hippocampal subfields CA1 and CA3 of the stratum radiatum and the dentate gyrus (DG), whereas MAP2 -IR was examined in the stratum radiatum $(R)$ and the stratum moleculare $(M)$. For MAP2-IR, slices between 3.14 and $-5.80 \mathrm{~mm}$ from the bregma were examined and averaged.

For each animal and histochemical staining, multiple areas were measured and the results were averaged. Namely, for the synaptophysin staining, three areas were measured in the CA1 subfield, whereas for the CA3 and the DG two. On the other hand, the MAP2-IR measurements were made in one area, both for the stratum radiatum and the stratum moleculare. The number of animals in each treatment group ranged from 6 to 8 for both the synaptophysin and the MAP2 staining. An Olympus Ax70 microscope equipped with a cooled CCD Olympus Digital video camera F-view was used to detect IR by an image analysis system, slightly modified for detection of grayscale punctae (AnalySIS, Soft Imaging System, Münster, Germany). All measurements were performed on a single focal plane. Shading error correction was performed before measurements to correct for irregularities in illumination of the microscopic fields. Background levels were equalized and the detection threshold was tested and kept at the same level for all samples. 


\subsection{Statistics}

A one-way analysis of variance (ANOVA) was used for somatic measures.

For the acquisition of the MWM, treatment effects were evaluated with a two-factorial (treatment and session) ANOVA with repeated measures over session. For the probe trial, preferences for quadrants were evaluated per group by analyzing with t-statistics whether the time spent in a training quadrant, were the platform was located during training, differed from the chance level (15 s).

The data of the testing sessions of the ORT and OF were aggregated per treatment condition to enhance the reliability of the data. A one-factorial ANOVA was used to analyze the effects between groups.

For MAP2-IR and synaptophysin-IR, treatment effects were analyzed with a one-way ANOVA $(P<0.05)$.

All statistics were carried out using SPSS software version 12.0.1 (SPSS Inc, USA). Data are presented as means \pm standard error of the mean (S.E.M.).

\section{RESULTS}

\subsection{Somatic growth}

Betamethasone reduced both body weight, head diameter and C-T length at birth $(P<0.001)$. This difference in size was not observed anymore at 3 weeks of age. Female pups were always more affected than males on all parameters $(\mathrm{P}<0.001)$. Post-hoc analyses per gender are shown in Figure 1.

\subsubsection{Morris water maze (MWM)}

Figure $2 \mathrm{~A}$ depicts the time to find the platform during the acquisition. There was no betamethasone effect except on day $2(P=0.044)$. All experimental groups showed a reduced escape latency over the different days (time effect; $\mathrm{P}<0.001)$. In the probe trial, no significant differences were found between groups (Figure 2B). A training quadrant preference was shown in all the males, whereas in the females only for $H D(P<0.05)$. 

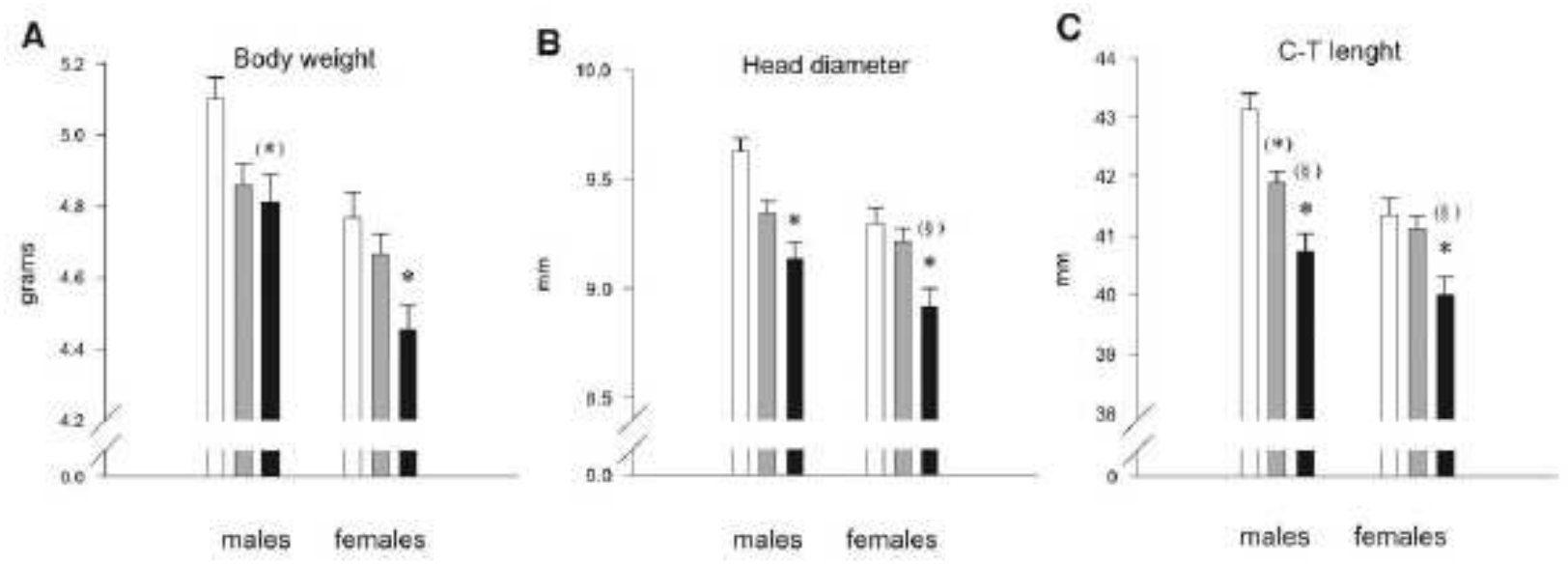

Figure 1. Somatic growth parameters at birth (mean $\pm S E M)$. Vehicle=white bars, $H D=g r e y$, $C D=$ black; $n=22-30$. Symbols used for Bonferroni post hoc differences: $\left({ }^{\S}\right)=0.05<P<0.10$ compared to $\mathrm{HD},\left(^{*}\right)=0.05<\mathrm{P}<0.10$ compared to Vehicle group, ${ }^{*}=\mathrm{P}<0.05$ compared to Vehicle group.
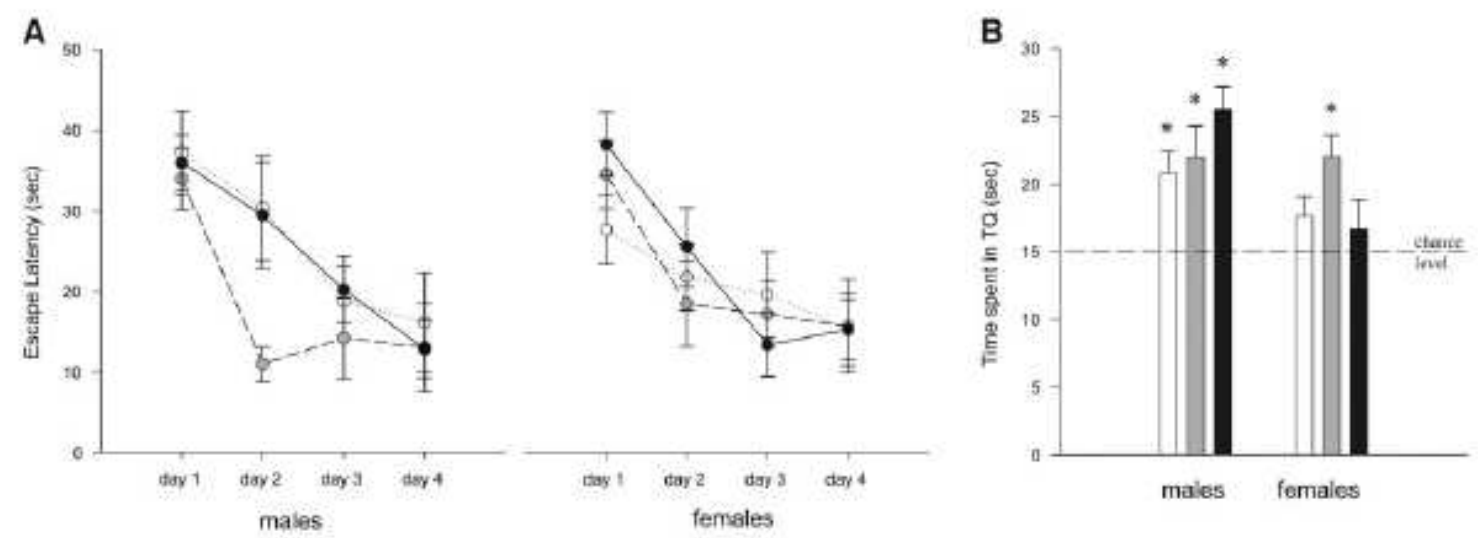

Figure 2. A. Time spent in the Morris Maze during four successive days of training (mean $\pm S E M)$; Vehicle=dotted lines, $H D=$ dashed, $C D=$ solid; $n=10$. A treatment effect was found on day 2 combining males and females. B. Time spent in the training quadrant in the probe trial; $n=10$. A dashed line is drawn at $15 \mathrm{~s}$. which indicates the time that animals would have spent in this training quadrant (TQ) at chance level. ${ }^{*}=P<0.05$ compared to chance level. 


\subsubsection{Object recognition task (ORT)}

There were no significant differences in E1, E2 and D2 between experimental groups (Figure 3). However, by comparing each group with the level expected by chance, only $C D$ resulted in higher $D 2$ in the 4-hours interval $(P<0.05$, males and females combined), whereas there was no treatment effect with the 1-hour interval.

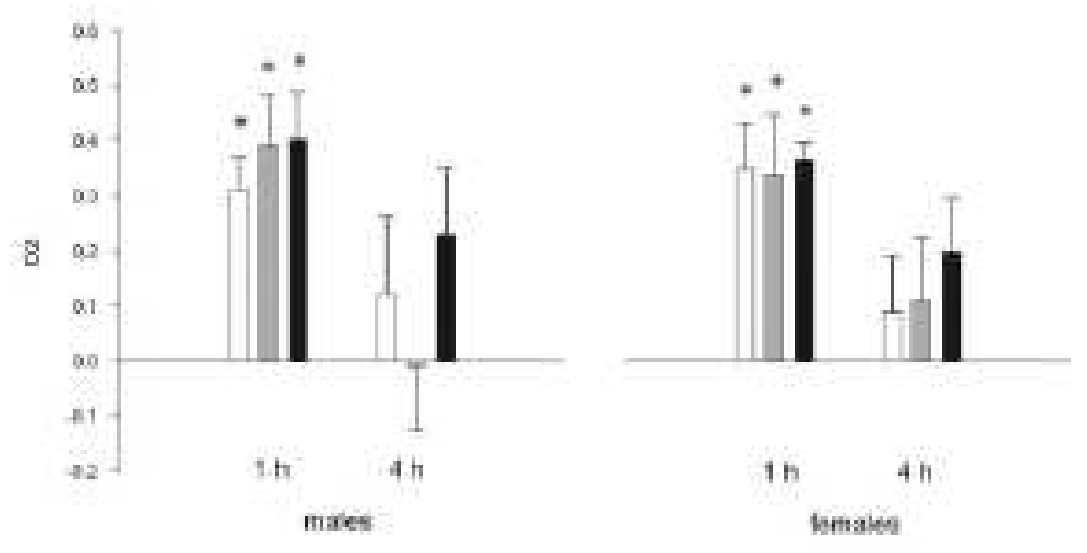

Figure 3. In the object recognition task animals were tested at 1 or 4 hours between the first and the second trial. Values are expressed as mean $\pm S E M$; Vehicle=white bars, HD=grey, $C D=$ black; $n=10 .{ }^{*}=P<0.05$ compared to chance level, i.e. discrimination index (D2) $=0$.

\subsubsection{Open Field (OF)}

The amount of time spent in the different zones of the open filed did not differ between groups (data not shown).

\subsection{Synaptophysin-IR and MAP2-IR}

Immunohistochemical distribution of synaptophysin-IR revealed an extensive and dense granular pattern in the hippocampus, with big clusters of synaptic vesicles in CA3 region. Antenatal betamethasone caused no significant synaptophysin-IR changes in the three regions examined (data not shown). Males showed higher values than females in both $C A 3$ and DG $(P<0.001)$.

Exposure to antenatal betamethasone resulted in a tendency towards a significant decrease of MAP2-IR in both the stratum moleculare $(P=0.097)$ and the stratum radiatum $(P=0.099)$ in males (Figure 4). By comparing treated 
(CD and HD) versus untreated animals, the loss of MAP2-IR by betamethasone was significant in the stratum moleculare $(-18.1 \% ; P=0.031)$ and border-line significant in the radiatum $(-15.4 \%$; $P=0.057)$. Females were not affected by betamethasone treatment. No differences were observed in hippocampus volume.

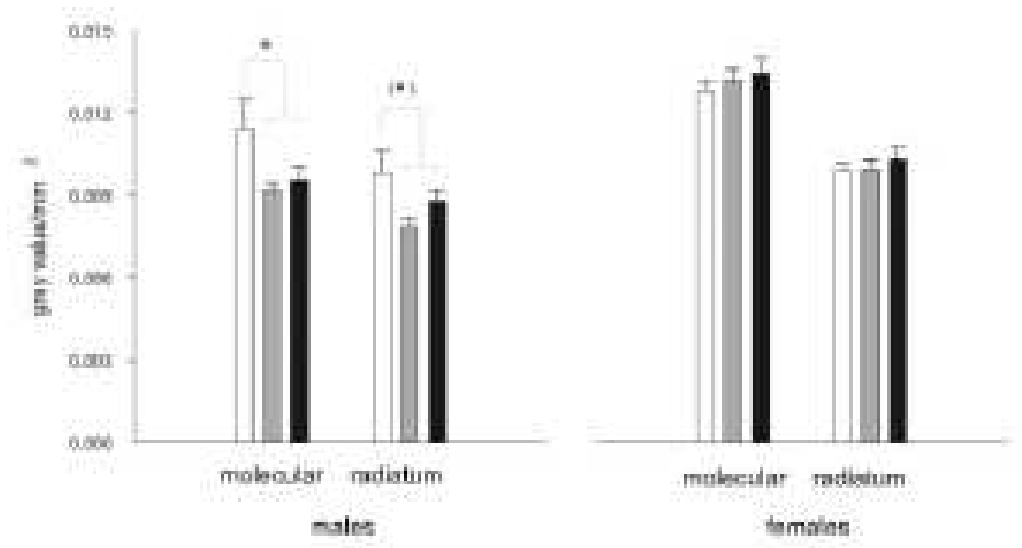

Figure 4. MAP2-IR is expressed as grey value/ $\mu \mathrm{m}^{2}$ (mean+SEM); Vehicle=white bars, $\mathrm{HD}=$ grey, $C D=$ black; $n=10 . \quad\left({ }^{*}\right)=0.05<P<0.10$ betamethasone-treated compared to vehicle; ${ }^{*}=\mathrm{P}<0.05$ betamethasone-treated compared to vehicle.

\section{DISCUSSION}

The present study shows that a single course of antenatal betamethasone impaired fetal growth and MAP2-IR in adult male rats. No significant effect on cognition- and anxiety- related behavior and synaptophysin-IR was observed.

Both body weight, head diameter and crown-tail length were reduced at birth by a single course of betamethasone equivalent to $12 \mathrm{mg}$ twice 24 hours apart (CD) but not by half of this dose (HD). Corticosteroids have been shown to affect fetal growth, probably reducing the circulating levels of growth hormone $(\mathrm{GH})$ and therefore insulin-like growth factor 1 (IGF-1), which are known to stimulate growth (Price, Stiles et al. 1992). In addition, the transplacental transfer of maternal stress hormones, i.e., corticotrophinreleasing factor (CRF) and corticosterone, may affect fetal growth. Moreover, a single course of antenatal betamethasone reduces brain weight in the adult sheep (Moss, Doherty et al. 2005) and head diameter in human neonates 
(Thorp, Jones et al. 2002), a finding that has been associated with learning problems in school-age children (Stathis, O'Callaghan et al. 1999). It is well known that reduced birth size is associated with an increased risk of disease in adulthood (Barker 1995). Interestingly, this relationship has been suggested to reflect the sensitivity of fetal growth to adverse antenatal events without implying a causal role of being born small, i.e. birth weight may represent a rough integrated measure of intrauterine processes (Gluckman and Hanson 2004). Even the temporary effect on somatic growth reported in this study might therefore have a significant impact on health, as discussed before in more detail (Gluckman and Hanson 2004; Bruschettini 2006). Of note, in the present study HD appears to have less influence in terms of growth restriction and the implications mentioned above when compared to $C D$, and a clear dose-dependency in the effect of antenatal betamethasone on fetal growth was previously described by our group using the same animal model and dose regimen (Bruschettini 2006).

To our knowledge, this is the first report of long-term effects of antenatal betamethasone on MAP2-IR and synaptophysin-IR, shown immunohistochemically in the rat hippocampus at 6 months of age, which is comparable to an adult human being.

A glucocorticoid effect on MAP2-IR - an acute effect of which has been previously described in the fetal sheep (Schwab, Antonow-Schlorke et al. 2001) - seems to be permanent, suggesting that antenatal betamethasone induces structural alterations in the hippocampus. In rodents it has been shown that loss of MAP2-IR is associated with neuronal degeneration, which might affect cognition (Matesic and Lin 1994). Of note, Di Stefano and colleagues (Di Stefano, Casoli et al. 2001) have shown a decrease of MAP2IR during aging in the rat hippocampus. Thus, loss of MAP2-IR in the hippocampus may be associated with age-related impairment of learning and memory.

Glucocorticoids contribute to brain aging by prolonged exposure to excess glucocorticoid, possibly as a result of decreased glucocorticoid receptors and also altered regulation of neuronal turnover in the DG (Nichols, Zieba et al. 2001). Cumulative hippocampal changes by corticosteroids lead to abnormal neuroendocrine functioning, cognitive impairment, and increased 
vulnerability to serious life events in people with mood disorders (Brown, Rush et al. 1999). An increase in synaptophysin-IR described with aging suggests a role for synaptophysin in the maintenance of the structural components in the hippocampus (Himeda, Mizuno et al. 2005). The decrease in MAP2-IR was not associated with impairment in learning and memory. However, we cannot exclude that a MAP2-IR decline might result in a cognitive deficit in later life due to aging.

Interestingly, the decrease in MAP2-IR was present in males only. Hippocampal corticosteroid receptor levels are known to be affected in the neonate rat following maternal deprivation (Sutanto, Rosenfeld et al. 1996). Recent evidences suggest that the effects of maternal stress and exogenous glucocorticoids are super imposable (Hougaard, Andersen et al. 2005). Gender-specific stress responses vary depending on developmental age at the time of stress exposure, i.e. male stress responses appear fixed across the lifespan whereas females show a more variable pattern (Bowman 2005). Moreover, recent evidence show that antenatal glucocorticoids induce gender-specific alterations regarding both cognition and hippocampal cholinergic function in adult rats (Kreider, Levin et al. 2005). Steroids affect mineralocorticoid receptor (MR; type I) protein expression within the hippocampus more in males than in females, whereas betamethasone has no effect on glucocorticoid receptor (GR; type II) protein expression (Owen and Matthews 2003). This gender differences in the pattern of MR and GR expression during development may result in different periods of vulnerability to glucocorticoid exposure in fetal life. In the present study female rats might be spared at the age of 6 months by the neuroprotective role exerted by estrogen (Norbury, Cutter et al. 2003). However, a decline in MAP2-IR might occur when estrogens decrease with aging. This awaits further research.

No differences were observed in synaptophysin-IR. Fetal in vivo studies concerning the effect of antenatal betamethasone treatment on synaptophysin showed a reduction in IR after administration of betamethasone (Colberg, Antonow-Schlorke et al. 2004). However, in those investigations the animals were analyzed immediately after glucocorticoid exposure. Taken together, antenatal betamethasone appears to induce an 
acute synaptophysin-IR decrease (Colberg, Antonow-Schlorke et al. 2004) which does not seem to last as seen in the present work.

Further, betamethasone treatment did not show any negative effects on adult cognition. Interestingly, discrimination in the ORT was increased by $C D$, whereas HD somewhat improved spatial learning in the MWM, but only in males. In line with this, antenatal betamethasone has been shown to enhance selective memory in the juvenile mouse, continuing into adulthood in males (Rayburn, Christensen et al. 1997) and improves school behavior in 6 years old girls (MacArthur, Howie et al. 1982). On the other hand, perinatal steroid administration in the rat has been associated with impaired spatial memory in a dose-dependent manner, though in this study dexamethasone was injected at P4 (Vicedomini, Nonneman et al. 1986).

In the present study anxiety-related behavior was not affected by betamethasone in the OF. The same finding was found in the mouse (Rayburn, Christensen et al. 1998), whereas postnatal glucocorticoids resulted in a more anxious behavior in the adult rat (Neal, Weidemann et al. 2004). This might be due to the permanent changes induced by perinatal glucocorticoid exposure on the anterior pituitary gland (Burlet, Fernette et al. 2005). In addition, betamethasone effects on anxiety might have been masked by the previous intensive behavioral analysis, i.e. MWM and ORT, with the same strain of rats as been recently suggested (Van den Hove, Blanco et al. 2005).

In summary, we report no detrimental effects of a single course of antenatal betamethasone on cognition- and anxiety- related behavior and synaptophysin-IR in the adult rat. On the other hand, MAP2-IR was decreased in males, suggesting that hippocampus-related cognition may be affected in this gender eventually. Further research might elucidate whether this effect increases with aging and whether both genders are affected in the long run. Finally, HD appears to have less influence in terms of growth restriction when compared to $C D$, supporting the idea that reducing the dose of antenatal betamethasone might be less harmful (Barker 1995; Gluckman and Hanson 2004), once that clinical trials show its effectiveness for inducing lung maturation. 


\section{Acknowledgements}

DVDV and JP are supported by the EU Framework 6 Integrated Project NEWMOOD (LSHM-CT-2004-503474)

\section{REFERENCES}

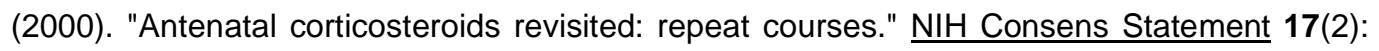
1-18.

Antonow-Schlorke, I., B. Kuhn, et al. (2001). "Antenatal betamethasone treatment reduces synaptophysin immunoreactivity in presynaptic terminals in the fetal sheep brain." Neurosci Lett 297(3): 147-50.

Barker, D. J. (1995). "Fetal origins of coronary heart disease." Bmj 311(6998): 171-4.

Bowman, R. E. (2005). "Stress-induced changes in spatial memory are sexually differentiated and vary across the lifespan." J Neuroendocrinol 17(8): 526-35.

Brown, E. S., A. J. Rush, et al. (1999). "Hippocampal remodeling and damage by corticosteroids: implications for mood disorders." Neuropsychopharmacology 21(4): 474-84.

Bruschettini, M. (2006). "Lowering the dose of antenatal steroids: the effects of a single course of betamethasone on somatic growth and brain cell proliferation in the rat." AJOG, in press.

Bruschettini, M., D. L. van den Hove, et al. (2005). "A single course of antenatal betamethasone reduces neurotrophic factor $\mathrm{S} 100 \mathrm{~B}$ concentration in the hippocampus and serum in the neonatal rat." Brain Res Dev Brain Res 159(2): 113-8.

Burlet, G., B. Fernette, et al. (2005). "Antenatal glucocorticoids blunt the functioning of the hypothalamic-pituitary-adrenal axis of neonates and disturb some behaviors in juveniles." Neuroscience 133(1): 221-30.

Clancy, B., R. B. Darlington, et al. (2001). "Translating developmental time across mammalian species." Neuroscience 105(1): 7-17.

Colberg, C., I. Antonow-Schlorke, et al. (2004). "Recovery of glucocorticoid-related loss of synaptic density in the fetal sheep brain at 0.75 of gestation." Neurosci Lett $364(2)$ : 130-4.

Davis, E. P., E. L. Townsend, et al. (2004). "Effects of prenatal betamethasone exposure on regulation of stress physiology in healthy premature infants." Psychoneuroendocrinology 29(8): 1028-36.

Di Stefano, G., T. Casoli, et al. (2001). "Distribution of map2 in hippocampus and cerebellum of young and old rats by quantitative immunohistochemistry." $\underline{\mathrm{J} \text { Histochem Cytochem }}$ 49(8): 1065-6. 
Gluckman, P. D. and M. A. Hanson (2004). "Developmental origins of disease paradigm: a mechanistic and evolutionary perspective." Pediatr Res 56(3): 311-7.

Himeda, T., K. Mizuno, et al. (2005). "Effects of age on immunohistochemical changes in the mouse hippocampus." Mech Ageing Dev 126(6-7): 673-7.

Hougaard, K. S., M. B. Andersen, et al. (2005). "Prenatal stress may increase vulnerability to life events: Comparison with the effects of prenatal dexamethasone." Brain Res Dev Brain Res 159(1): 55-63.

Kajantie, E., T. Raivio, et al. (2004). "Circulating glucocorticoid bioactivity in the preterm newborn after antenatal betamethasone treatment." J Clin Endocrinol Metab 89(8): 3999-4003.

Kreider, M. L., E. D. Levin, et al. (2005). "Gestational dexamethasone treatment elicits sexdependent alterations in locomotor activity, reward-based memory and hippocampal cholinergic function in adolescent and adult rats." Neuropsychopharmacology 30(9): 1617-23.

MacArthur, B. A., R. N. Howie, et al. (1982). "School progress and cognitive development of 6-year-old children whose mothers were treated antenatally with betamethasone." Pediatrics 70(1): 99-105.

Martinez, G., C. Di Giacomo, et al. (1997). "MAP2, synaptophysin immunostaining in rat brain and behavioral modifications after cerebral postischemic reperfusion." Dev Neurosci 19(6): 457-64.

Matesic, D. F. and R. C. Lin (1994). "Microtubule-associated protein 2 as an early indicator of ischemia-induced neurodegeneration in the gerbil forebrain." $\mathrm{J}$ Neurochem 63(3): 1012-20.

Moss, T. J., D. A. Doherty, et al. (2005). "Effects into adulthood of single or repeated antenatal corticosteroids in sheep." Am J Obstet Gynecol 192(1): 146-52.

Neal, C. R., Jr., G. Weidemann, et al. (2004). "Effect of neonatal dexamethasone exposure on growth and neurological development in the adult rat." Am J Physiol Regul Integr Comp Physiol 287(2): R375-85.

Nichols, N. R., M. Zieba, et al. (2001). "Do glucocorticoids contribute to brain aging?" Brain Res Brain Res Rev 37(1-3): 273-86.

Norbury, R., W. J. Cutter, et al. (2003). "The neuroprotective effects of estrogen on the aging brain." Exp Gerontol 38(1-2): 109-17.

Owen, D. and S. G. Matthews (2003). "Glucocorticoids and sex-dependent development of brain glucocorticoid and mineralocorticoid receptors." Endocrinology 144(7): 2775-84.

Pine, D. and D. Charney (2002). "Children, stress, and sensitization: an integration of basic and clinical research on emotion?" Biol Psychiatry 52(8): 773.

Price, W. A., A. D. Stiles, et al. (1992). "Gene expression of insulin-like growth factors (IGFs), the type 1 IGF receptor, and IGF-binding proteins in dexamethasone-induced fetal growth retardation." Endocrinology 130(3): 1424-32. 
Rayburn, W. F., H. D. Christensen, et al. (1997). "A placebo-controlled comparison between betamethasone and dexamethasone for fetal maturation: differences in neurobehavioral development of mice offspring." Am J Obstet Gynecol 176(4): 84250; discussion 850-1.

Rayburn, W. F., H. D. Christensen, et al. (1998). "Effect of in utero exposure to betamethasone on motivation/anxiety testing in mice offspring." Neurotoxicol Teratol 20(4): 475-81.

Scheepens, A., D. van den Hove, et al. (2003). "A single course of prenatal betamethasone in the rat alters postnatal brain cell proliferation but not apoptosis." J Physiol 552(Pt 1): 163-75.

Schwab, M., I. Antonow-Schlorke, et al. (2001). "Effect of antenatal betamethasone treatment on microtubule-associated proteins MAP1B and MAP2 in fetal sheep." $\underline{J}$ Physiol 530(Pt 3): 497-506.

Stathis, S. L., M. O'Callaghan, et al. (1999). "Head circumference in ELBW babies is associated with learning difficulties and cognition but not ADHD in the school-aged child." Dev Med Child Neurol 41(6): 375-80.

Sutanto, W., P. Rosenfeld, et al. (1996). "Long-term effects of neonatal maternal deprivation and ACTH on hippocampal mineralocorticoid and glucocorticoid receptors." Brain Res Dev Brain Res 92(2): 156-63.

Thorp, J. A., P. G. Jones, et al. (2002). "Does antenatal corticosteroid therapy affect birth weight and head circumference?" Obstet Gynecol 99(1): 101-8.

Uno, H., L. Lohmiller, et al. (1990). "Brain damage induced by prenatal exposure to dexamethasone in fetal rhesus macaques. I. Hippocampus." Brain Res Dev Brain Res 53(2): 157-67.

Van den Hove, D. L., C. E. Blanco, et al. (2005). "Prenatal restraint stress and long-term affective consequences." Dev Neurosci 27(5): 313-20.

Velazquez, P. N. and M. C. Romano (1987). "Corticosterone therapy during gestation: effects on the development of rat cerebellum." Int J Dev Neurosci 5(3): 189-94.

Vicedomini, J. P., A. J. Nonneman, et al. (1986). "Perinatal glucocorticoids disrupt learning: a sexually dimorphic response." Physiol Behav 36(1): 145-9. 



\title{
Chapter 6
}

\author{
General Discussion
}

\section{Antenatal betamethasone and brain development: future perspectives}

Bruschettini Matteo 


\section{Summary of the main findings}

The work described in this thesis shows that antenatal betamethasone (AB) may have significant, both short- and long-term, consequences on offspring development.

In the rat model, two dose regimens of a single course of $A B$ were used, i.e., a dose equivalent to that used in clinical practice (12 mg, twice, 24 hours apart) and half of this dose $(6 \mathrm{mg})$.

The major findings reported in this thesis are:

- In the clinic, AB induced a reduction of neurotrophic S100B protein in the urine of human newborns (Chapter 2). Of note, in this clinical study, only the standard dose regimen (12 mg twice 24 hours apart) was used.

- In the rat, $A B$ resulted in significant dose-dependent growth restriction in both genders. Moreover, AB altered neonatal hippocampal S100B concentrations and cell proliferation within the neonatal brain in male offspring (Chapters 3 and 4). Further, in the blood, also the lower dose $(6 \mathrm{mg})$ of $A B$ reduced $S 100 B$ levels in male pups.

- In adult offspring $A B$ did not affect cognition- and anxiety-related behavior and synaptophysin immunoreactivity (IR) within the hippocampus. However, MAP2-IR was reduced in male rats treated with AB (Chapter 5).

- Overall, males were more affected when compared to females, the latter of which showed no impairment in neonatal hippocampal S100B levels, neonatal brain cell proliferation or MAP2-IR within the adult hippocampus.

- Halving the dose of $A B$ resulted in less growth restriction. Further, no impairment of neonatal hippocampal S100B concentration and cell proliferation within the brain was observed by using the lower dose. 


\section{Extrapolation to the human situation}

A crucial difference between humans and rats lies within the timing of brain development. Roughly, a term human infant is equivalent to a 2-week-old rat (Romijn, Hofman et al. 1991; Clancy, Darlington et al. 2001), thus betamethasone injection at E20 in the rat occurs when neural development is comparable to very preterm human infants. Subsequently, the pups were analyzed at 1,2 and 21 days after birth in order to assess the effects a short interval after GC exposure (i.e., 1 and 2 days after birth) and as well at a stage when cell proliferation rate in the brain is as low as in the adult (i.e., 21 days after birth).

A major disadvantage of this animal model is that it does not represent a situation of preterm delivery, since all dams delivered at term. Therefore, it can not be ruled out that this difference with the clinical situation had influenced the neurodevelopmental parameters that we investigated. However, as stated in the Introduction, the principle of injecting rats antenatally with GCs is widely used and accepted and has yielded a lot of valuable information so far (Matthews 2000). Moreover, no animal model mimics the human situation by inducing preterm delivery.

Of note, this study did not aim to evaluate the effects of $A B$ on lung maturation. In this regard, clinical trials are needed to assess the efficacy and safety of new dose regimens of GC.

\section{The effects of $A B$ on somatic growth}

As mentioned in the Introduction, the $\mathrm{DOHaD}$ (Developmental origins of adult health and disease) concept states that the risk of disease in adulthood partly depends upon variations in the prenatal environment, which are often reflected in body weight at birth (Gillman 2005). We report that the administration of $A B$ resulted in dose-dependent fetal growth restriction (Chapter 4). Consequently, halving the dose of $A B$, which resulted in a milder effect on birth weight, may have important consequences for adult health and disease. 


\section{The effects of $A B$ on S100B protein in the human and in the rat}

To our knowledge, we show for the first time that $A B$ reduces $S 100 B$ concentrations in both humans (in the urine) and rats (in the brain and in the blood).

In our clinical study, S100B levels were measured in the blood and urine of infants exposed twice to $12 \mathrm{mg}$ of betamethasone and a control group that did not received $A B$. The results showed that $A B$ reduced $S 100 B$ levels in the urine but not in the blood, the latter of which is probably due to the short half-life of the protein (Michetti and Gazzolo 2002). Urinary S100B was significantly lower in the $A B$ group as compared to controls at each timepoint, i.e., at first urination, at $24,48,72$ and 120 hours after birth. Since renal function did not differ between the groups and S100B is absent from kidney tissue (Michetti and Gazzolo 2002), it is reasonable to suppose that its source in the urine is the CNS.

In the rat, $A B$ decreased $S 100 B$ concentrations in the blood and in the hippocampus of males but not in female offspring (see following chapter concerning gender differences). Of note, urine was not analyzed. In support of this finding, it has been reported that dexamethasone is able to reduce $\mathrm{S100B}$ protein concentrations in rat hippocampal astrocytes in vitro (Niu, Hinkle et al. 1997).

Interestingly, S100B protein has been shown to enhance neurogenesis within the hippocampus in the rat (Kleindienst, McGinn et al. 2005). Although two days after birth no differences were observed between the different groups, the short-term decrease in S100B concentration might have permanent consequences on brain development, possibly involving essential alterations in cell proliferation rate within the hippocampus. Of note, S100B concentration in the whole brain was not affected by betamethasone. We report that hippocampal S100B was reduced by GC but not by the half dose, suggesting that lowering the dose of $A B$ might induce less severe effects on brain maturation.

In the serum, both doses (12 and $6 \mathrm{mg}$ ) of $A B$ reduced S100B levels in male pups. The discrepancy between serum and brain concentrations of S100B might be explained by the specific permeability rates through the brain-blood barrier in different brain regions. 


\section{The effects of $A B$ on cell proliferation in the brain}

We show that $A B$ alters cell proliferation within the hippocampus and SVZ, whereas a lower dose does not affect cell proliferation within the brain. This increase in cell proliferation might be the rebound of a inhibition of cell proliferation prior to this time point, i.e., a catch-up in cell proliferation after an initial decrease (Scheepens, van de Waarenburg et al. 2003). Moreover, this measure of proliferation is a 'snapshot' of 30-40 minutes worth of proliferation, i.e., the approximate time ${ }^{3} \mathrm{H}$-thymidine is incorporated into DNA (Boswald, Harasim et al. 1990). Thus, possibly, a decrease in cell proliferation has started within hours of the first betamethasone injection at E20, i.e., 4 days earlier.

Of note, hippocampal neurogenesis in the rat has been shown to be increased by intraventricular S100B infusion (Kleindienst, McGinn et al. 2005). It might be that the initial decrease of cell proliferation within the hippocampus following $A B$ might be related to the lower perinatal levels of $S 100 B$.

These data suggest that lowering the dose of antenatal betamethasone might indeed be effective in minimizing related side-effects.

\section{The effects of $A B$ on cognition- and anxiety-related behavior, synaptophysin- and MAP2- immunoreactivity in adulthood}

We report that $A B$ reduced MAP2-IR in adult male rats, whereas no significant effect on cognition- and anxiety- related behavior and synaptophysin-IR was observed. It has previously been reported that $A B$ may reduce MAP2-IR measured immediately after $A B$ injection (Schwab, Antonow-Schlorke et al. 2001). However, our study shows for the first time that this effect seems to be permanent, suggesting that $A B$ induces structural alterations in the hippocampus. This effect on MAP2-IR might be associated with the decreased S100B protein concentrations observed in the male pups.

Some of the underlying processes resemble those observed with prenatal stress. For example, a significant decrease in MAP2-IR and synaptophysin-IR has been observed in prenatally stressed adult rats, possibly implying a long-lasting astroglial reaction and reduced dendritic arborization (Barros, Duhalde-Vega et al. 2006). Further, prenatal restraint stress has been reported to reduce S100B protein concentration within the 
hippocampus (Van den Hove, Steinbusch et al. 2006). It has been shown that loss of MAP2-IR is associated with neuronal degeneration, which might affect cognition (Matesic and Lin 1994).

In the present study, AB did not impair cognition- and anxiety-related behavior, in contrast with previous studies (Burlet, Fernette et al. 2005; Sloboda, Challis et al. 2005; Velisek 2006). This discrepancy might be due to the different dose of $A B$ used, as few studies have used a clinically relevant dose and only a single course of $\mathrm{AB}$. Further, the choice of different strains might be involved, since Fischer 344 rats are known to be hyperresponsive to stress (Sternberg, Glowa et al. 1992; Izumi, Washizuka et al. 1997). It has been suggested that Fischer 344 rats exposed to GC exposure, when challenged show less reactivity than control rats, as they have already been exposed to stress prenatally (Van den Hove, Blanco et al. 2005). Moreover, the difference between experimental groups might have been masked by the intensive behavioral testing which lasted for 5 weeks.

\section{Gender differences}

We report a clear gender-specific effect of $A B$ on $S 100 B$ levels within the brain and the blood, brain cell proliferation and hippocampal MAP2-IR. Of note, this gender difference appeared to be persistent, since it was observed both in neonatal and adult offspring. The diverse impact on male and female offspring might be related to the different timing of relevant developmental processes over gestation in relation to the timing of the GC exposure (MacLusky and Naftolin 1981).

Elevated plasma adrenocorticotropic hormone concentrations were observed in adult males but not in females (O'Regan, Kenyon et al. 2004). Similarly, maternal GC exposure induced a reduction of plasma corticosterone response to acute stress and hypothalamic noradrenalin in male adult offspring only (Reznikov, Nosenko et al. 1999). In the guinea pig, antenatal GCs increased plasma cortisol in female fetuses, but decreased cortisol levels in male fetuses (Dean and Matthews 1999). Further, they altered the regulation of the pituitary and the adrenal cortex more in male offspring, 
resulting in a reduction of anxiety-like behaviour, whilst increasing locomotor activity in females (Owen and Matthews 2007). In addition, antenatal GCs have been shown to impair learning in males, whereas females showed improved cognitive performance (Kreider, Levin et al. 2005). Within the hippocampus, there is a more profound effect of GC on mineralocorticoid receptor expression in males than in females (Owen and Matthews 2003).

Interestingly, $A B$ is known to promote lung maturation to a greater extent in females than in males (Van Marter, Leviton et al. 1990). Thus, others have suggested that a better oxygenation in female offspring might, to some degree, explain the better neurological outcome observed in this gender in clinical practice (Hindmarsh, O'Callaghan et al. 2000). However, our data suggest a limited role for oxygenation in this respect, since all pups were born at term, concomitant with a normal lung development. Nevertheless, this awaits further research.

In our studies, rats were investigated up to the age of 6 months, roughly corresponding to young adulthood, when estrogens still play an important neuroprotective role in females (Norbury, Cutter et al. 2003). More animal research is required to investigate the effects of $A B$ on brain structure and functioning with further ageing. 


\section{Conclusion}

The present work reports both short- and long-term consequences of $A B$ for neurotrophic factors expression, cell proliferation in the brain and MAP-IR within the hippocampus of male offspring. Of note, a lower dose of $A B$ (equivalent to $6 \mathrm{mg}$ twice 24 hours apart) induced milder effects, supporting the idea that reducing the dose might be less harmful. First however, clinical trials need to show its effectiveness for inducing lung maturation.

Moreover, female rats showed only a reduction of somatic growth, with an extent super imposable to males.

Clinical trials might elucidate whether different, milder, dose regimens could promote proper lung maturation without impairing brain development. 


\section{References}

(1995). "Effect of corticosteroids for fetal maturation on perinatal outcomes. NIH Consensus Development Panel on the Effect of Corticosteroids for Fetal Maturation on Perinatal Outcomes." Jama 273(5): 413-8.

(2000). "Antenatal corticosteroids revisited: repeat courses." NIH Consens Statement 17(2): 1-18.

Akbari, H. M., P. M. Whitaker-Azmitia, et al. (1994). "Prenatal cocaine decreases the trophic factor S-100 beta and induced microcephaly: reversal by postnatal $5-\mathrm{HT} 1 \mathrm{~A}$ receptor agonist." Neurosci Lett 170(1): 141-4.

Antonow-Schlorke, I., B. Kuhn, et al. (2001). "Antenatal betamethasone treatment reduces synaptophysin immunoreactivity in presynaptic terminals in the fetal sheep brain." Neurosci Lett 297(3): 147-50.

Antonow-Schlorke, I., M. Schwab, et al. (2003). "Glucocorticoid exposure at the dose used clinically alters cytoskeletal proteins and presynaptic terminals in the fetal baboon brain." J Physiol 547(Pt 1): 117-23.

Arcuri, C., R. Bianchi, et al. (2004). "S100B increases proliferation in PC12 neuronal cells and reduces their responsiveness to NGF via Akt activation." $\underline{\mathrm{J} \text { Biol Chem. }}$

Azmitia, E. C., K. Dolan, et al. (1990). "S-100B but not NGF, EGF, insulin or calmodulin is a CNS serotonergic growth factor." Brain Res 516(2): 354-6.

Azmitia, E. C., W. S. Griffin, et al. (1992). "S100 beta and serotonin: a possible astrocyticneuronal link to neuropathology of Alzheimer's disease." Prog Brain Res 94: 459-73.

Ballard, P. L. and R. A. Ballard (1995). "Scientific basis and therapeutic regimens for use of antenatal glucocorticoids." Am J Obstet Gynecol 173(1): 254-62.

Bannerman, D. M., J. N. Rawlins, et al. (2004). "Regional dissociations within the hippocampus--memory and anxiety." Neurosci Biobehav Rev 28(3): 273-83.

Barker, D. J. (1995). "The fetal origins of adult disease." Proc R Soc Lond B Biol Sci 262: 3743.

Barros, V. G., M. Duhalde-Vega, et al. (2006). "Astrocyte-neuron vulnerability to prenatal stress in the adult rat brain." J Neurosci Res 83(5): 787-800.

Baudier, J., N. Glasser, et al. (1984). "Purification, characterization and ion binding properties of human brain S100b protein." Biochim Biophys Acta 790(2): 164-73.

Benzon, H. T., T. L. Chew, et al. (2007). "Comparison of the Particle Sizes of Different Steroids and the Effect of Dilution: A Review of the Relative Neurotoxicities of the Steroids." Anesthesiology 106(2): 331-338.

Bohn, M. C., M. K. O'Banion, et al. (1994). "In vitro studies of glucocorticoid effects on neurons and astrocytes." Ann N Y Acad Sci 746: 243-58; discussion 258-9, 289-93.

Boswald, M., S. Harasim, et al. (1990). "Tracer dose and availability time of thymidine and bromodeoxyuridine: application of bromodeoxyuridine in cell kinetic studies." Cell Tissue Kinet 23(3): 169-81. 
Brabham, T., A. Phelka, et al. (2000). "Effects of prenatal dexamethasone on spatial learning and response to stress is influenced by maternal factors." Am J Physiol Regul Integr Comp Physiol 279(5): R1899-909.

Bruschettini, M., H. W. M. Steinbusch, et al. (2005). "The effects of single course of prenatal betamethasone on fetal growth, $\mathrm{S} 100 \mathrm{~B}$ protein and cell proliferation in the brain and in the lungs." PAS 2005; 57:3219.

Bruschettini, M., D. L. A. Van den Hove, et al. (2005). "A single course of antenatal betamethasone reduces neurotrophic factor $\mathrm{S} 100 \mathrm{~B}$ concentration in the hippocampus and serum in the neonatal rat." Dev Brain Res in press.

Burlet, G., B. Fernette, et al. (2005). "Antenatal glucocorticoids blunt the functioning of the hypothalamic-pituitary-adrenal axis of neonates and disturb some behaviors in juveniles." Neuroscience 133(1): 221-30.

Chang, M. S., L. M. Ariah, et al. (2005). "Chronic gliosis induced by loss of S-100B: knockout mice have enhanced GFAP-immunoreactivity but blunted response to a serotonin challenge." Brain Res 1031(1): 1-9.

Chapman, R. H. and J. M. Stern (1978). "Maternal stress and pituitary-adrenal manipulations during pregnancy in rats: effects on morphology and sexual behavior of male offspring." J Comp Physiol Psychol 92(6): 1074-83.

Clancy, B., R. B. Darlington, et al. (2001). "Translating developmental time across mammalian species." Neuroscience 105(1): 7-17.

Colberg, C., I. Antonow-Schlorke, et al. (2004). "Recovery of glucocorticoid-related loss of

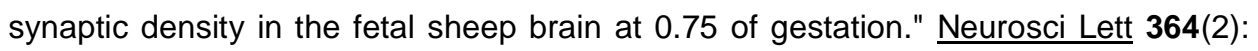
130-4.

Crowley, P. (2003). "Antenatal corticosteroids--current thinking." Bjog 110 Suppl 20: 77-8.

Crowley, P. A. (1995). "Antenatal corticosteroid therapy: a meta-analysis of the randomized trials, 1972 to 1994." Am J Obstet Gynecol 173(1): 322-35.

Crowther, C. A., R. R. Haslam, et al. (2006). "Neonatal respiratory distress syndrome after repeat exposure to antenatal corticosteroids: a randomised controlled trial." Lancet 367(9526): 1913-9.

Davis, E. P., E. L. Townsend, et al. (2004). "Effects of prenatal betamethasone exposure on regulation of stress physiology in healthy premature infants." Psychoneuroendocrinology 29(8): 1028-36.

De Kloet, E. R., E. Vreugdenhil, et al. (1998). "Brain corticosteroid receptor balance in health and disease." Endocr Rev 19(3): 269-301.

Dean, F. and S. G. Matthews (1999). "Maternal dexamethasone treatment in late gestation alters glucocorticoid and mineralocorticoid receptor mRNA in the fetal guinea pig brain." Brain Res 846(2): 253-9.

Dhabhar, F. S., B. S. McEwen, et al. (1997). "Adaptation to prolonged or repeated stress-comparison between rat strains showing intrinsic differences in reactivity to acute stress." Neuroendocrinology 65(5): 360-8. 
Donato, R. (2001). "S100: a multigenic family of calcium-modulated proteins of the EF-hand type with intracellular and extracellular functional roles." Int J Biochem Cell Biol 33(7): 637-68.

Dunlop, S. A., M. A. Archer, et al. (1997). "Repeated prenatal corticosteroids delay myelination in the ovine central nervous system." J Matern Fetal Med 6(6): 309-13.

Elenkov, I. J. and G. P. Chrousos (2002). "Stress hormones, proinflammatory and antiinflammatory cytokines, and autoimmunity." Ann N Y Acad Sci 966: 290-303.

Emgard, M., M. Paradisi, et al. (2007). "Prenatal glucocorticoid exposure affects learning and vulnerability of cholinergic neurons." Neurobiol Aging 28(1): 112-21.

Eriksen, J. L., R. A. Gillespie, et al. (2000). "Effects of in utero ethanol exposure and maternal treatment with a 5-HT(1A) agonist on S100B-containing glial cells." Brain Res Dev Brain Res 121(2): 133-43.

Fraser, J., M. Walls, et al. (2004). "Respiratory complications of preterm birth." Bmj 329(7472): 962-5.

Fuentes-Pardo, B., J. Hernandez-Falcon, et al. (1990). "Role of corticosterone on the development of passive electrical properties of cultured chick embryo neurons." $\underline{\mathrm{J} \text { Dev }}$ Physiol 13(2): 67-73.

Gale, C. R. and C. N. Martyn (2004). "Birth weight and later risk of depression in a national birth cohort." Br J Psychiatry 184: 28-33.

Gazzolo, D., M. Bruschettini, et al. (2002). "Maternal nitric oxide supplementation decreases cord blood S100B in intrauterine growth-retarded fetuses." Clin Chem 48(4): 647-50.

Gazzolo, D., M. Bruschettini, et al. (2001). "Increased urinary S100B protein as an early indicator of intraventricular hemorrhage in preterm infants: correlation with the grade of hemorrhage." Clin Chem 47(10): 1836-8.

Gazzolo, D., M. Bruschettini, et al. (2001). "S100b protein concentrations in urine are correlated with gestational age in healthy preterm and term newborns." $\underline{\text { Clin Chem }}$ 47(6): 1132-3.

Gazzolo, D., M. Kornacka, et al. (2003). "Maternal glucocorticoid supplementation and S100B protein concentrations in cord blood and urine of preterm infants." Clin Chem 49(7): 1215-8.

Gazzolo, D., E. Marinoni, et al. (2002). "Circulating S100beta protein is increased in intrauterine growth-retarded fetuses." Pediatr Res 51(2): 215-9.

Gazzolo, D., F. Michetti, et al. (2003). "Pediatric concentrations of S100B protein in blood: age- and sex-related changes." Clin Chem 49(6 Pt 1): 967-70.

Gazzolo, D., P. Vinesi, et al. (1999). "Elevated S100 blood level as an early indicator of intraventricular hemorrhage in preterm infants. Correlation with cerebral Doppler velocimetry." J Neurol Sci 170(1): 32-5.

Gazzolo, D., P. Vinesi, et al. (1998). "S100 blood concentrations in children subjected to cardiopulmonary by-pass." Clin Chem 44(5): 1058-60. 
Gazzolo, D., P. Vinesi, et al. (2000). "S100B protein concentrations in cord blood: correlations with gestational age in term and preterm deliveries." Clin Chem 46(7): 998-1000.

Gerlai, R. and J. Roder (1993). "Female specific hyperactivity in S100 beta transgenic mice does not habituate in open-field." Behav Brain Res 59(1-2): 119-24.

Gillman, M. W. (2005). "Developmental origins of health and disease." N Engl J Med 353(17): 1848-50.

Gluckman, P. D. and M. A. Hanson (2004). "Living with the past: evolution, development, and patterns of disease." Science 305(5691): 1733-6.

Haas, D. M., W. McCullough, et al. (2006). "The first 48 hours: Comparing 12-hour and 24hour betamethasone dosing when preterm deliveries occur rapidly." $\mathrm{J}$ Matern Fetal Neonatal Med 19(6): 365-9.

Haas, D. M., W. McCullough, et al. (2005). "Neonatal outcomes with different betamethasone

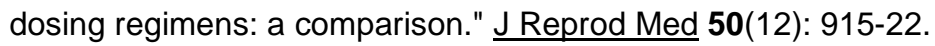

Haglid, K. G., Q. Yang, et al. (1997). "S-100beta stimulates neurite outgrowth in the rat sciatic nerve grafted with acellular muscle transplants." Brain Res 753(2): 196-201.

Heizmann, C. W. (1999). "Ca2+-binding S100 proteins in the central nervous system." Neurochem Res 24(9): 1097-100.

Hindmarsh, G. J., M. J. O'Callaghan, et al. (2000). "Gender differences in cognitive abilities at 2 years in ELBW infants. Extremely low birth weight." Early Hum Dev 60(2): 115-22.

Huang, W. L., L. D. Beazley, et al. (1999). "Effect of corticosteroids on brain growth in fetal sheep." Obstet Gynecol 94(2): 213-8.

Ilbay, G., D. Sahin, et al. (2003). "Changes in blood-brain barrier permeability during hot water-induced seizures in rats." Neurol Sci 24(4): 232-5.

Izumi, J., M. Washizuka, et al. (1997). "Evidence for a depressive-like state induced by repeated saline injections in Fischer 344 rats." Pharmacol Biochem Behav 57(4): 883-

8.

Jacobson, L. and R. Sapolsky (1991). "The role of the hippocampus in feedback regulation of the hypothalamic-pituitary-adrenocortical axis." Endocr Rev 12(2): 118-34.

Jellyman, J. K., D. S. Gardner, et al. (2004). "Pituitary-adrenal responses to acute hypoxemia during and after maternal dexamethasone treatment in sheep." Pediatr Res 56(6): 864-72.

Jobe, A. H. and R. F. Soll (2004). "Choice and dose of corticosteroid for antenatal treatments." Am J Obstet Gynecol 190(4): 878-81.

Jonsson, H., P. Johnsson, et al. (2000). "Elimination of S100B and renal function after cardiac surgery." J Cardiothorac Vasc Anesth 14(6): 698-701.

Jung-Testas, I. and E. E. Baulieu (1998). "Steroid hormone receptors and steroid action in rat glial cells of the central and peripheral nervous system." J Steroid Biochem Mol Biol 65(1-6): 243-51. 
Kajantie, E., T. Raivio, et al. (2004). "Circulating glucocorticoid bioactivity in the preterm

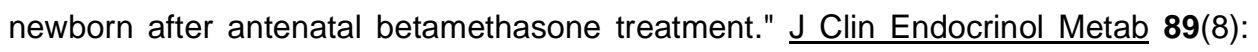
3999-4003.

Kapural, M., L. Krizanac-Bengez, et al. (2002). "Serum S-100beta as a possible marker of blood-brain barrier disruption." Brain Res 940(1-2): 102-4.

Kleindienst, A., M. J. McGinn, et al. (2005). "Enhanced Hippocampal Neurogenesis by Intraventricular S100B Infusion Is Associated with Improved Cognitive Recovery after Traumatic Brain Injury." J Neurotrauma 22(6): 645-55.

Kornack, D. R. and P. Rakic (1998). "Changes in cell-cycle kinetics during the development and evolution of primate neocortex." Proc Natl Acad Sci U S A 95(3): 1242-6.

Kreider, M. L., E. D. Levin, et al. (2005). "Gestational dexamethasone treatment elicits sexdependent alterations in locomotor activity, reward-based memory and hippocampal cholinergic function in adolescent and adult rats." Neuropsychopharmacology 30(9): 1617-23.

Lee, B. H., B. J. Stoll, et al. (2006). "Adverse neonatal outcomes associated with antenatal dexamethasone versus antenatal betamethasone." Pediatrics 117(5): 1503-10.

Liggins, G. C. (1968). "Premature parturition after infusion of corticotrophin or cortisol into foetal lambs." J Endocrinol 42(2): 323-9.

Liggins, G. C. and R. N. Howie (1972). "A controlled trial of antepartum glucocorticoid treatment for prevention of the respiratory distress syndrome in premature infants." Pediatrics 50(4): 515-25.

Liu, J. P. and J. M. Lauder (1992). "S-100 beta and insulin-like growth factor-II differentially regulate growth of developing serotonin and dopamine neurons in vitro." $\underline{\mathrm{J} \text { Neurosci }}$ Res 33(2): 248-56.

MacLusky, N. J. and F. Naftolin (1981). "Sexual differentiation of the central nervous system." Science 211(4488): 1294-302.

Marchi, N., V. Fazio, et al. (2003). "Serum transthyretin monomer as a possible marker of blood-to-CSF barrier disruption." J Neurosci 23(5): 1949-55.

Marchi, N., P. Rasmussen, et al. (2003). "Peripheral markers of brain damage and bloodbrain barrier dysfunction." Restor Neurol Neurosci 21(3-4): 109-21.

Margis, R., V. C. Zanatto, et al. (2004). "Changes in S100B cerebrospinal fluid levels of rats subjected to predator stress." Brain Res 1028(2): 213-8.

Marinoni, E., R. Di lorio, et al. (2002). "Ontogenetic localization and distribution of S-100beta protein in human placental tissues." Obstet Gynecol 99(6): 1093-9.

Martin, C. R., L. J. Van Marter, et al. (2005). "Antenatal Glucocorticoids Increase Early Total Thyroxine Levels in Premature Infants." Biol Neonate 87(4): 273-280.

Martin, S. J. and R. E. Clark (2007). "The rodent hippocampus and spatial memory: from synapses to systems." Cell Mol Life Sci 64(4): 401-31. 
Martinez, G., C. Di Giacomo, et al. (1997). "MAP2, synaptophysin immunostaining in rat brain and behavioral modifications after cerebral postischemic reperfusion." Dev Neurosci 19(6): 457-64.

Matesic, D. F. and R. C. Lin (1994). "Microtubule-associated protein 2 as an early indicator of ischemia-induced neurodegeneration in the gerbil forebrain." $\underline{J}$ Neurochem $63(3)$ : 1012-20.

Matthews, S. G. (2000). "Antenatal glucocorticoids and programming of the developing CNS." Pediatr Res 47(3): 291-300.

Matthews, S. G., D. Owen, et al. (2002). "Glucocorticoids, hypothalamo-pituitary-adrenal (HPA) development, and life after birth." Endocr Res 28(4): 709-18.

McEwen, B. S., G. Wallach, et al. (1974). "Corticosterone binding to hippocampus: immediate and delayed influences of the absence of adrenal secretion." Brain Res 70(2): 32134.

Ment, L. R., W. Oh, et al. (1995). "Antenatal steroids, delivery mode, and intraventricular hemorrhage in preterm infants." Am J Obstet Gynecol 172(3): 795-800.

Meyer, J. S. (1983). "Early adrenalectomy stimulates subsequent growth and development of the rat brain." Exp Neurol 82(2): 432-46.

Michetti, F., E. Dell'Anna, et al. (1983). "Immunochemical and immunocytochemical study of S-100 protein in rat adipocytes." Brain Res 262(2): 352-6.

Michetti, F. and D. Gazzolo (2002). "S100B protein in biological fluids: a tool for perinatal medicine." Clin Chem 48(12): 2097-104.

Michetti, F., A. Massaro, et al. (1979). "The nervous system-specific S-100 antigen in cerebrospinal fluid of multiple sclerosis patients." Neurosci Lett 11(2): 171-5.

Michetti, F., A. Massaro, et al. (1980). "The S-100 antigen in cerebrospinal fluid as a possible index of cell injury in the nervous system." J Neurol Sci 44(2-3): 259-63.

Miller, S. L., M. Chai, et al. (2006). "The effects of maternal betamethasone administration on the intrauterine growth restricted fetus." Endocrinology.

Mulder, E. J., J. B. Derks, et al. (1997). "Antenatal corticosteroid therapy and fetal behaviour: a randomised study of the effects of betamethasone and dexamethasone." $\mathrm{Br} \mathrm{J}$ Obstet Gynaecol 104(11): 1239-47.

Nilsson, P. M., P. Nyberg, et al. (2001). "Increased susceptibility to stress at a psychological assessment of stress tolerance is associated with impaired fetal growth." Int J Epidemiol 30(1): 75-80.

Niu, H., D. A. Hinkle, et al. (1997). "Dexamethasone regulates basic fibroblast growth factor, nerve growth factor and S100beta expression in cultured hippocampal astrocytes." Brain Res Mol Brain Res 51(1-2): 97-105.

Norbury, R., W. J. Cutter, et al. (2003). "The neuroprotective effects of estrogen on the aging brain." Exp Gerontol 38(1-2): 109-17. 
O'Regan, D., C. J. Kenyon, et al. (2004). "Glucocorticoid exposure in late gestation in the rat permanently programs gender-specific differences in adult cardiovascular and metabolic physiology." Am J Physiol Endocrinol Metab 287(5): E863-70.

O'Shea, T. M., J. M. Kothadia, et al. (1999). "Randomized placebo-controlled trial of a 42-day tapering course of dexamethasone to reduce the duration of ventilator dependency in very low birth weight infants: outcome of study participants at 1-year adjusted age." Pediatrics 104(1 Pt 1): 15-21.

Ogunyemi, D. (2005). "A comparison of the effectiveness of single-dose vs multi-dose antenatal corticosteroids in pre-term neonates." J Obstet Gynaecol 25(8): 756-60.

Owen, D. and S. G. Matthews (2003). "Glucocorticoids and sex-dependent development of brain glucocorticoid and mineralocorticoid receptors." Endocrinology 144(7): 2775-84.

Owen, D. and S. G. Matthews (2007). "Repeated maternal glucocorticoid treatment affects activity and hippocampal NMDA receptor expression in juvenile guinea pigs." $\underline{\mathrm{J}}$ Physiol 578(Pt 1): 249-57.

Papile, L. A., J. Burstein, et al. (1978). "Incidence and evolution of subependymal and intraventricular hemorrhage: a study of infants with birth weights less than 1,500 gm." J Pediatr 92(4): 529-34.

Parer, J. (2004). "Repeat courses of antenatal corticosteroids: what does the evidence show?" J Matern Fetal Neonatal Med 15(6): 349-50.

Peltoniemi, O. M., M. A. Kari, et al. (2007). "Randomized trial of a single repeat dose of prenatal betamethasone treatment in imminent preterm birth." Pediatrics 119(2): 2908.

Pine, D. and D. Charney (2002). "Children, stress, and sensitization: an integration of basic and clinical research on emotion?" Biol Psychiatry 52(8): 773.

Pinto, S. S., C. Gottfried, et al. (2000). "Immunocontent and secretion of S100B in astrocyte cultures from different brain regions in relation to morphology." FEBS Lett 486(3): 203-7.

Prechtl, H. F. (1974). "The behavioural states of the newborn infant (a review)." Brain Res 76(2): 185-212.

Price, W. A., A. D. Stiles, et al. (1992). "Gene expression of insulin-like growth factors (IGFs), the type 1 IGF receptor, and IGF-binding proteins in dexamethasone-induced fetal growth retardation." Endocrinology 130(3): 1424-32.

Rayburn, W. F., H. D. Christensen, et al. (1998). "Effect of in utero exposure to betamethasone on motivation/anxiety testing in mice offspring." Neurotoxicol Teratol 20(4): 475-81.

Reznikov, A. G., N. D. Nosenko, et al. (1999). "Prenatal stress and glucocorticoid effects on the developing gender-related brain." J Steroid Biochem Mol Biol 69(1-6): 109-15.

Roberts, D. and S. Dalziel (2006). "Antenatal corticosteroids for accelerating fetal lung maturation for women at risk of preterm birth." Cochrane Database Syst Rev 3: CD004454. 
Rodriguez-Pinilla, E., D. Prieto-Merino, et al. (2006). "[Antenatal exposure to corticosteroids for fetal lung maturation and its repercussion on weight, length and head circumference in the newborn infant]." Med Clin (Barc) 127(10): 361-7.

Romijn, H. J., M. A. Hofman, et al. (1991). "At what age is the developing cerebral cortex of the rat comparable to that of the full-term newborn human baby?" Early Hum Dev 26(1): 61-7.

Schaaf, M. J., R. W. Hoetelmans, et al. (1997). "Corticosterone regulates expression of BDNF and trkB but not NT-3 and trkC mRNA in the rat hippocampus." $\underline{\mathrm{J} \text { Neurosci Res }}$ 48(4): 334-41.

Scheepens, A., M. van de Waarenburg, et al. (2003). "A single course of prenatal betamethasone in the rat alters postnatal brain cell proliferation but not apoptosis." $\underline{\mathrm{J}}$ Physiol 552(Pt 1): 163-75.

Scheepens, A., G. Wassink, et al. (2003). "A delayed increase in hippocampal proliferation following global asphyxia in the neonatal rat." Brain Res Dev Brain Res 142(1): 67-76.

Schwab, M., I. Antonow-Schlorke, et al. (2001). "Effect of antenatal betamethasone treatment on microtubule-associated proteins MAP1B and MAP2 in fetal sheep." $\underline{J}$ Physiol 530(Pt 3): 497-506.

Schwab, M., T. Coksaygan, et al. (2006). "Kinetics of betamethasone and fetal cardiovascular adverse effects in pregnant sheep after different doses." Obstet Gynecol 108(3 Pt 1): 617-25.

Sloboda, D. M., J. R. Challis, et al. (2005). "Synthetic glucocorticoids: antenatal administration and long-term implications." Curr Pharm Des 11(11): 1459-72.

Sloboda, D. M., T. J. Moss, et al. (2007). "Prenatal betamethasone exposure results in pituitary-adrenal hyporesponsiveness in adult sheep." Am J Physiol Endocrinol Metab 292(1): E61-70.

Sousa, N. and O. F. Almeida (2002). "Corticosteroids: sculptors of the hippocampal formation." Rev Neurosci 13(1): 59-84.

Sousa, N., M. D. Madeira, et al. (1998). "Effects of corticosterone treatment and rehabilitation on the hippocampal formation of neonatal and adult rats. An unbiased stereological study." Brain Res 794(2): 199-210.

Spinillo, A., F. Viazzo, et al. (2004). "Two-year infant neurodevelopmental outcome after single or multiple antenatal courses of corticosteroids to prevent complications of prematurity." Am J Obstet Gynecol 191(1): 217-24.

Stathis, S. L., M. O'Callaghan, et al. (1999). "Head circumference in ELBW babies is associated with learning difficulties and cognition but not ADHD in the school-aged child." Dev Med Child Neurol 41(6): 375-80.

Sternberg, E. M., J. R. Glowa, et al. (1992). "Corticotropin releasing hormone related behavioral and neuroendocrine responses to stress in Lewis and Fischer rats." Brain Res 570(1-2): 54-60. 
Stonestreet, B. S., K. H. Petersson, et al. (1999). "Antenatal steroids decrease blood-brain barrier permeability in the ovine fetus." Am J Physiol 276(2 Pt 2): R283-9.

Tajuddin, N. F. and M. J. Druse (1999). "In utero ethanol exposure decreased the density of serotonin neurons. Maternal ipsapirone treatment exerted a protective effect." Brain Res Dev Brain Res 117(1): 91-7.

Tamvakopoulos, C. S., J. M. Neugebauer, et al. (2002). "Analysis of betamethasone in rat plasma using automated solid-phase extraction coupled with liquid chromatographytandem mass spectrometry. Determination of plasma concentrations in rat following oral and intravenous administration." J Chromatogr B Analyt Technol Biomed Life Sci 776(2): 161-8.

Theogaraj, E., C. D. John, et al. (2005). "Perinatal Glucocorticoid Treatment Produces Molecular, Functional and Morphological Changes in the Anterior Pituitary Gland of the Adult Male Rat." Endocrinology.

Thompson, C., H. Syddall, et al. (2001). "Birth weight and the risk of depressive disorder in late life." Br J Psychiatry 179: 450-5.

Thorp, J. A., P. G. Jones, et al. (2002). "Does antenatal corticosteroid therapy affect birth weight and head circumference?" Obstet Gynecol 99(1): 101-8.

Tiu, S. C., W. Y. Chan, et al. (2000). "Differential expression of S100B and S100A6(1) in the human fetal and aged cerebral cortex." Brain Res Dev Brain Res 119(2): 159-68.

Tramontina, F., S. Conte, et al. (2002). "Developmental changes in S100B content in brain

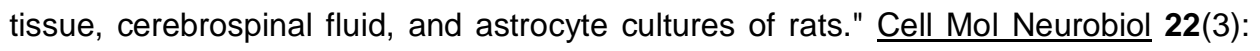
373-8.

Uno, H., S. Eisele, et al. (1994). "Neurotoxicity of glucocorticoids in the primate brain." Horm Behav 28(4): 336-48.

Uno, H., L. Lohmiller, et al. (1990). "Brain damage induced by prenatal exposure to dexamethasone in fetal rhesus macaques. I. Hippocampus." Brain Res Dev Brain Res 53(2): 157-67.

Van den Hove, D. L., C. E. Blanco, et al. (2005). "Prenatal restraint stress and long-term affective consequences." Dev Neurosci 27(5): 313-20.

Van den Hove, D. L., H. W. Steinbusch, et al. (2006). "Prenatal stress reduces S100B in the neonatal rat hippocampus." Neuroreport 17(10): 1077-80.

Van Marter, L. J., A. Leviton, et al. (1990). "Maternal glucocorticoid therapy and reduced risk of bronchopulmonary dysplasia." Pediatrics 86(3): 331-6.

Velazquez, P. N. and M. C. Romano (1987). "Corticosterone therapy during gestation: effects on the development of rat cerebellum." Int J Dev Neurosci 5(3): 189-94.

Velisek, L. (2006). "Prenatal exposure to betamethasone decreases anxiety in developing rats: hippocampal neuropeptide y as a target molecule." Neuropsychopharmacology 31(10): 2140-9. 
Chapter 6

Vermillion, S. T., D. E. Soper, et al. (1999). "Neonatal sepsis after betamethasone administration to patients with preterm premature rupture of membranes." $\underline{\mathrm{Am} \mathrm{J}}$ Obstet Gynecol 181(2): 320-7.

Vidaeff, A. C. and J. M. Mastrobattista (2001). "Controversies in the use of antenatal steroids for fetal maturation." Semin Perinatol 25(6): 385-96.

Wagner, J. P., I. B. Black, et al. (1999). "Stimulation of neonatal and adult brain neurogenesis by subcutaneous injection of basic fibroblast growth factor." J Neurosci 19(14): 600616.

Wapner, R. J., Y. Sorokin, et al. (2006). "Single versus weekly courses of antenatal corticosteroids: evaluation of safety and efficacy." Am J Obstet Gynecol 195(3): 63342.

Watson, P., S. M. Shirreffs, et al. (2005). "Blood-brain barrier integrity may be threatened by exercise in a warm environment." Am J Physiol Regul Integr Comp Physiol.

Whitelaw, A. and M. Thoresen (2000). "Antenatal steroids and the developing brain." Arch Dis Child Fetal Neonatal Ed 83(2): F154-7.

Wijnberger, L. D., P. G. Nikkels, et al. (2002). "Expression in the placenta of neuronal markers for perinatal brain damage." Pediatr Res 51(4): 492-6.

Yu, I. T., S. H. Lee, et al. (2004). "Differential effects of corticosterone and dexamethasone on hippocampal neurogenesis in vitro." Biochem Biophys Res Commun 317(2): 484-90. 




\section{Summary}

Infant respiratory distress syndrome (RDS) is a life-threatening disorder caused by developmental insufficiency of surfactant production and structural immaturity in the lungs of preterm infants. The use of antenatal betamethasone $(A B)$ has resulted in a significant decrease in neonatal mortality and morbidity. However, this treatment strategy may also cause a wide range of side effects in humans, like impairments in somatic growth, brain development and hypothalamic-pituitary-adrenal function. In the present work, the short- and long-term consequences of $A B$ on offspring development were analyzed in human infants and in the rat. Within the rat model, a lower dose regimen of $A B$ was used in order to assess whether lowering the dose might induce milder side effects. The main findings of this thesis are:

In the clinic, AB induced a reduction of neurotrophic $5100 \mathrm{~B}$ protein in the urine of the human newborns (Chapter 2). Of note, in this clinical study, only the standard dose regimen (12 $\mathrm{mg}$ twice 24 hours apart) was used.

In the rat, $A B$ resulted in a significant dose-dependent growth restriction in both genders. Moreover, AB reduced hippocampal S100B concentrations and cell proliferation within the brain of neonatal male offspring (Chapters 3 and 4). S100B levels were also reduced in the male blood by the the lower dose $(6 \mathrm{mg})$ of $A B$.

In adult offspring $A B$ did not affect cognition- and anxiety-related behavior and synaptophysin immunoreactivity (IR) within the hippocampus. However, MAP2-IR was reduced in male adult rats treated with AB (Chapter 5).

Overall, males were more affected as compared to females, the latter of which showed no impairment in neonatal hippocampal S100B levels, brain cell proliferation and MAP2-IR within the adult hippocampus.

Halving the dose of $A B$ resulted in less growth restriction. Further, no impairment of neonatal hippocampal S100B concentration and cell proliferation within the brain was observed by using the lower dose. 
In conclusion, the present work confirms that a single course of $A B$ might induce permanent consequences on offspring development. A lower dose of $A B$ (equivalent to $6 \mathrm{mg}$ twice 24 hours apart) induced milder effects, supporting the idea that reducing the dose might be less harmful. First however, clinical trials need to show whether different dose regimens could promote proper lung maturation without impairing brain development. 




\section{Curriculum Vitae}

Matteo Bruschettini was born on May 7th 1975 in Genoa, located in the Italian Riviera. He graduated at the Liceo Scientifico M.L. King in 1994, and in the same year he started to study Medicine at the University of Genoa. He received his MD degree on July 2000, and in the autumn of that same year he entered the residency in pediatrics at the University of Genoa. Besides his training in the clinics of G. Gaslini Children's Hospital, he actively joined the Perinatal Research Team on S100B protein led by Dr. Diego Gazzolo. In June 2003 he left for Maastricht as a Marie Curie Fellow and then Ph.D. student under the supervision of Professor Harry W.M. Steinbusch, Professor Carlos E. Blanco and Dr. Daniël van den Hove. In August 2005 he moved to Stockholm, where he worked as Guest Researcher in the Neonatal Research Unit at Karolinska University. He is currently working in the Department of Pediatric in Dolo Hospital, nearby Venice (Italy). 



\section{Acknowledgements}

I am happy to have here the possibility to express my gratitude to many people who significantly contributed to this thesis, in different ways.

Firstly, my thankfulness is for my promoters Prof. Dr. H.W.M. Steinbusch and Prof. Dr. C.E. Blanco. Dear Harry thanks for your assistance and for sharing your experience. I enjoyed very much also your hospitality and your availability to come to visit me at my place and then in Sweden. Dear Carlos, I remember my sense of excitement when I came to Maastricht to work with you, after having listened to your intriguing talks in international congresses. Thanks for your patient assistance and for sharing your knowledge.

Thanks to my co-promoters, Dr. D.L.A. van den Hove and Dr. D. Gazzolo. Dear Daniel, you have supervised me with clear teachings in an efficient and gratifying way, I have really appreciated it! And, even more important, you are an inestimable precious friend! Dear Diego, you have been a kind of older brother since I was a child; you triggered me in the world of science step by step, challenging me to improve and to go further. I would like to thank also to the Professors in Gaslini Children's Hospital in Genoa, particularly my father for his delicate and warm support and Prof. A. Martini.

De paranimfen: Ronald, we have shared a lot in the last years, you are a very dear friend; Mustafa, you are the first person I met in Maastricht... I had an excellent start! Thanks for all the fun and the jokes.

I have a very pleasant memory of all the people in NP department, thanks for your patience all the times I was messing up the lab and for your enthusiasm in joining different events... during and after work: Eva, Imke, Bart, Roselie, Brenda, Evi, Marjo, Dirk, Hatice, Ivona, Angela, Jos, Gunter, Nicolien, Hellen, Mandy, Arjan, Evita, Silvie, Maaike, Eveline, Marijke, Nicole, Akke, Mirèse, Govert, Christoph, Yasin. I have been impressed by the widespread openmindedness in accepting to pray together and to discuss about Life: Mu, Monica, Bernhard, Pilar, Mario, Susanne, Chunyan, Marjanne, Anne, Callylou, Stefan, Stefano, Abraham, Luca, Giuseppe. To this regard, thank you very much Father Paul Horsch for helping me in aiming the desired direction. 
Sabino, Sacha, Andrea, Sofia: grazie mille for the Italian-speaking gatherings that we spent together.

The Irish: Peter, Siobhain, Lieve, Lillian and Gloria. I do not know how many pints we had... but I do remember the nights out!

The running team: Guido, Pawel and Bert: it has been a pleasure to train with you, let's keep going!

Finally, a big hug to my... big Italian-Estonian family! Kallis Olja, you are a special gift in my life; I pray to offer always my best to you. 




\section{Publications and Presentations}

\section{Journal articles}

Florio P, Marinoni E, Di lorio R, Bashir M, Ciotti S, Sacchi R, Bruschettini M, Lituania M, Serra G, Michetti F, Petraglia F, Gazzolo D. Urinary S100B protein concentrations are increased in intrauterine growth-retarded newborns. Pediatrics. 2006 Sep;118(3):e747-54.

Van den Hove DL, Steinbusch HW, Bruschettini M, Gazzolo D, Frulio R, Scheepens A, Prickaerts J, Blanco CE. Prenatal stress reduces S100B in the neonatal rat hippocampus. Neuroreport. 2006 Jul 17;17(10):1077-80.

Bruschettini M, Van den Hove DLA, Timmers S, Welling M, Steinbusch HP, Prickaerts J, Gazzolo D, Blanco CE, Steinbusch HWM. Cognition- and anxiety-related behavior, synaptophysin- and MAP2-immunoreactivity in the adult rat treated with a single course of antenatal betamethasone. Pediatr Res.2006 Jul;60(1):50-4. Epub 2006 May 11.

Bruschettini M, Van den Hove DLA, Gazzolo D, Steinbusch HWM, Blanco CE. Lowering the dose of antenatal steroids: the effects of a single course of betamethasone on somatic growth and brain cell proliferation in the rat. AJOG 2006 May;194(5):1341-6.

Gazzolo D, Marinoni E, Di lorio R, Lituania M, Marras M, Bruschettini M, Bruschettini PL, Frulio R, Michetti F, Petraglia F, Florio P. High maternal blood S100B levels in pregnancies complicated by intrauterine growth restriction and Intraventricular Hemorrhage. Clin Chem 2006 May;52(5):819-826 
Garnier $Y$, Berger R, Alm S, von Duering MU, Coumans AB, Michetti F, Bruschettini M, Lituania M, Hasaart TH, Gazzolo D. Systemic endotoxin administration results in increased $\mathrm{S100B}$ protein blood levels and periventricular brain white matter injury in the preterm fetal sheep. Eur $J$ Obstet Gynecol Reprod Biol. 2006 Jan 1;124(1):15-22.

Gazzolo D, Florio P, Ciotti S, Marinoni E, DI lorio R, Bruschettini M, Sacchi R, Serra G, Lituania M, Michetti F. S100B Protein in Urine of Preterm Newborns with Ominous Outcome. Pediatr Res. 2005 Dec;58(6):1170-4.

Bruschettini M, Van den Hove DLA, Gazzolo D, Bruschettini P, Blanco CE, Steinbusch HWM (2005) A single course of antenatal betamethasone reduces neurotrophic factor $\mathrm{S} 100 \mathrm{~B}$ concentration in the hippocampus and serum in the neonatal rat. Dev Brain Res 2005; 159 (2): 113-118.

Van den Hove DLA, Blanco CE, Aendekerk B, Desbonnet L, Bruschettini M, Steinbusch HP, Prickaerts J, Steinbusch HWM (2005) Prenatal restraint stress and long-term affective consequences. Dev Neurosci 27(5):313-20.

Gazzolo D, Perrone S, Paffetti P, Longini M, Vezzosi P, Bruschettini M, Lituania M, Buonocore G. Non protein bound iron concentrations in amniotic fluid. Clin Biochem. 2005 Jul;38(7):674-7.

Gazzolo D, Lituania M, Bruschettini M, Ciotti S, Sacchi R, Serra G, Calevo MG, Corvino V, Buonocore G, Michetti F. S100B protein levels in saliva: correlation with gestational age in normal term and preterm newborns. Clin Biochem. 2005 Mar;38(3):229-33.

Florio P, Luisi S, Bruschettini M, Grutzfeld D, Dobrzanska A, Bruschettini P, Petraglia F, Gazzolo D. Cerebrospinal fluid activin a measurement in asphyxiated full-term newborns predicts hypoxic ischemic encephalopathy. Clin Chem. 2004 Dec;50(12):2386-9. 
Florio P, Michetti F, Bruschettini M, Lituania M, Bruschettini P, Severi FM, Petraglia F, Gazzolo D. Amniotic fluid S100B protein in mid-gestation and intrauterine fetal death. Lancet. 2004 Jul 17;364(9430):270-2

Gazzolo D, Grutzfeld D, Michetti F, Toesca A, Lituania M, Bruschettini M, Dobrzanska A, Bruschettini P. Increased S100B in cerebrospinal fluid of infants with bacterial meningitis: relationship to brain damage and routine cerebrospinal fluid findings. Clin Chem. 2004 May;50(5):941-4

Gazzolo D, Bruschettini M, Lituania M, Serra G, Santini P, Michetti F. Levels of $\mathrm{S100B}$ protein are higher in mature human milk than in colostrum and milk-formulae milks. Clin Nutr. 2004 Feb;23(1):23-6.

Gazzolo D, Marinoni E, Di lorio R, Bruschettini M, Kornacka M, Lituania M, Majewska U, Serra G, Michetti F. Urinary S100B protein measurements: A tool for the early identification of hypoxic-ischemic encephalopathy in asphyxiated full-term infants. Crit Care Med. 2004 Jan;32(1):131-6.

Gazzolo D, Marinoni E, Di lorio R, Bruschettini M, Kornacka M, Lituania M, Majewska U, Serra G, Michetti F. Measurement of Urinary S100B Protein Concentrations for the Early Identification of Brain Damage in Asphyxiated Full-term Infants. Arch Pediatr Adolesc Med. 2003 Dec;157(12):1163-8

Gazzolo D, Kornacka M, Bruschettini M, Lituania M, Giovannini L, Serra G, Majewska U, Michetti F. Maternal glucocorticoid supplementation and S100B protein concentrations in cord blood and urine of preterm infants. Clin Chem. 2003 Jul;49(7):1215-8

Gazzolo D, Lituania M, Bruschettini M, Bruschettini P, Michetti F. S100B protein concentrations in amniotic fluid are higher in monoamniotic than in 
diamniotic twins and singleton pregnancies. Clin Chem. 2003 Jun;49(6 Pt 1):997-9

Gazzolo D, Michetti F, Bruschettini M, Marchese N, Lituania M, Mangraviti S, Pedrazzi E, Bruschettini P. Pediatric concentrations of S100B protein in blood: age- and sex-related changes. Clin Chem. 2003 Jun;49(6 Pt 1):967-70

Gazzolo D, Bruschettini M, Corvino V, Lituania M, Sarli R, Bruschettini P, Michetti F. Amniotic fluid levels of S100B protein in normal and trisomy-21 foetuses. Clin Chim Acta. 2003 Apr;330(1-2):131-3

Gazzolo D, Monego G, Corvino V, Bruschettini M, Bruschettini P, Zelano G, Michetti F. Human milk contains S100B protein. Biochim Biophys Acta. 2003 Jan 20;1619(2):209-12

Gazzolo D, Visser GH, Lituania M, Sarli R, Bruschettini M, Michetti F, Bruschettini PL. S100B protein cord blood levels and development of fetal behavioral states: a study in normal and small-for-dates fetuses. J Matern Fetal Neonatal Med. 2002 Jun;11(6):378-84

Gazzolo D, Bruschettini M, Di lorio R, Marinoni E, Lituania M, Marras M, Sarli R, Bruschettini PL, Michetti F. Maternal nitric oxide supplementation decreases cord blood S100B in intrauterine growth-retarded fetuses. Clin Chem. 2002;48(4):647-50

De Toni T, Bruschettini M. Adolescents and religion. The risk of religiosity without transcendence. Minerva Pediatr. 2001 Dec;53(6):567-5.

De Toni E, Bruschettini M. Today's adolescents. The Media. Minerva Pediatr. 2001 Oct;53(5):431-41.

Gazzolo D, Bruschettini M, Lituania M, Serra G, Bonacci W, Michetti F. Increased urinary S100B protein as an early indicator of intraventricular 
hemorrhage in preterm infants: correlation with the grade of hemorrhage. Clin Chem. 2001 Oct;47(10):1836-8

Gazzolo D, Bruschettini M, Lituania M, Serra G, Gandullia E, Michetti F. S100b protein concentrations in urine are correlated with gestational age in healthy preterm and term newborns. Clin Chem. 2001 Jun;47(6):1132-3

Gazzolo D, Bruschettini M, Corvino V, Oliva R, Sarli R, Lituania M, Bruschettini P, Michetti F. S100b protein concentrations in amniotic fluid correlate with gestational age and with cerebral ultrasound scanning results in healthy fetuses. Clin Chem. 2001 May;47(5):954-6

\section{Presentations (most relevant)}

Bruschettini M (2007) Antenatal glucocorticoids and CNS development: effects on S100B protein. Invited lecture at G. Garibaldi's Hospital (Catania, Italy)

Bruschettini M (2007) Perinatal glucocorticoids and brain development. Invited lecture at Policlinico Casilino (Rome, Italy)

Bruschettini M (2006) Antenatal glucocorticoids and CNS development. Invited lecture at the International Course in "Recent advances in perinatal medicine" (Erice, Italy)

Bruschettini M, van den Hove DLA, Gazzolo D, Blanco CE, Steinbusch HWM (2006) Cognition- and Anxiety-related behavior, Synaptophysin- and MAP2- IR in the adult rat treated with a single course of antenatal betamethasone. Congress of the European Academy of Pediatrics (Barcelona, Spain). Oral presentation 
Bruschettini M (2005) Antenatal glucocorticoid and brain development. Invited lecture at Karolinska Institute (Stockholm, Sweden)

Bruschettini M, van den Hove DLA, Gazzolo D, Steinbusch HWM, Blanco CE (2004) Effects of Antenatal Betamethasone on Somatic Growth and Brain Development. Congress of the Fetal and Neonatal Physiological Society (Castelvecchio Pascoli, Italy). Oral presentation

\section{Posters (most relevant)}

Bruschettini M, van den Hove DLA, Gazzolo D, Zimmermann LJI, Steinbusch HWM, Blanco CE (2005) A single course of Antenatal Betamethasone, Growth Retardation, S100B protein, and Cell Proliferation within the Brain and the Lungs. Congress of the American Academy of Pediatrics (Washington DC, USA)

Gazzolo D, Florio P, Marinoni E, Di lorio R, Serra G, Bruschettini M, Sacchi R, Ciotti S, Michetti F, Lituania M (2004) Increased S100B urinary measurements at birth may predict neonatal death in preterm newborns. Congress of the European Academy of Pediatrics (Stockholm, Sweden)

Bruschettini M, van den Hove DLA, Zimmermann LJI, van Iwaarden JF, Steinbusch HWM, Blanco CE (2004) Prenatal Betamethasone, Growth Retardation, and Cell Proliferation within the Brain and the Lungs. Congress of the American. Academy of Pediatrics (San Francisco, California, USA) 

